\title{
Essays on the economic and strategic implications of science
}

Citation for published version (APA):

Della Malva, A. (2012). Essays on the economic and strategic implications of science. [Doctoral Thesis, Maastricht University]. Datawyse / Universitaire Pers Maastricht. https://doi.org/10.26481/dis.20120413ad

Document status and date:

Published: 01/01/2012

DOI:

10.26481/dis.20120413ad

Document Version:

Publisher's PDF, also known as Version of record

\section{Please check the document version of this publication:}

- A submitted manuscript is the version of the article upon submission and before peer-review. There can be important differences between the submitted version and the official published version of record.

People interested in the research are advised to contact the author for the final version of the publication, or visit the DOI to the publisher's website.

- The final author version and the galley proof are versions of the publication after peer review.

- The final published version features the final layout of the paper including the volume, issue and page numbers.

Link to publication

\footnotetext{
General rights rights.

- You may freely distribute the URL identifying the publication in the public portal. please follow below link for the End User Agreement:

www.umlib.nl/taverne-license

Take down policy

If you believe that this document breaches copyright please contact us at:

repository@maastrichtuniversity.nl

providing details and we will investigate your claim.
}

Copyright and moral rights for the publications made accessible in the public portal are retained by the authors and/or other copyright owners and it is a condition of accessing publications that users recognise and abide by the legal requirements associated with these

- Users may download and print one copy of any publication from the public portal for the purpose of private study or research.

- You may not further distribute the material or use it for any profit-making activity or commercial gain

If the publication is distributed under the terms of Article $25 \mathrm{fa}$ of the Dutch Copyright Act, indicated by the "Taverne" license above, 


\section{Essays on the Economic and Strategic Implications of Science}


(C) Copyright Antonio Della Malva, Maastricht 2012 ISBN 978-94-6159-139-5 


\title{
Essays on the Economic and Strategic Implications of Science
}

\author{
PROEFSCHRIFT \\ ter verkrijging van de graad van doctor aan de Universiteit Maastricht, \\ op gezag van de Rector Magnificus, Prof. Mr. G.P.M.F. Mols \\ volgens het besluit van het College van Decanen in het openbaar te verdedigen \\ op vrijdag 13 april 2012 om 16:00 uur
}

door

Antonio Della Malva

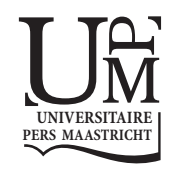


Promoter

Prof. Dr. M.A. Carree

\section{Reading Committee}

Prof. Dr. Roger Meuwissen (Chair)

Prof. Dr. Pierre Mohnen

Prof. Dr. Enrico Santarelli (Universita' di Bologna) 


\section{Table of Contents}

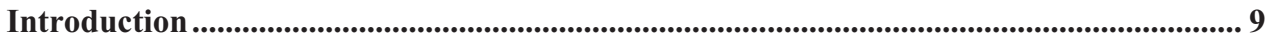

1.1 Science, Innovation and Economic Performance …............................................................... 9

1.1.1 On the mechanisms relating technological progress and growth .................................. 9

1.1.2 A brief history of the interaction between Science and Technology ............................. 10

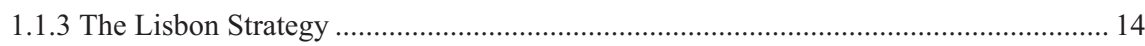

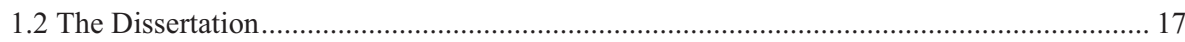

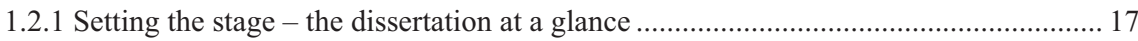

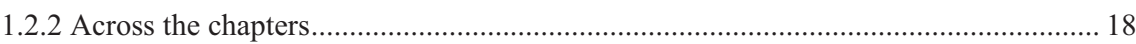

Academic Knowledge and Regional Innovative Performance:

Which Role for Scientific Eminence? ............................................................................ 21

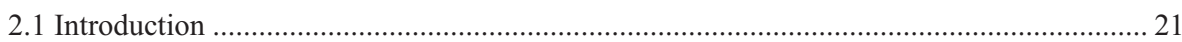

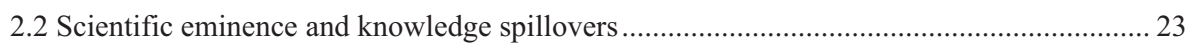

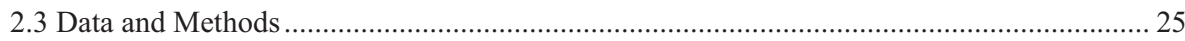

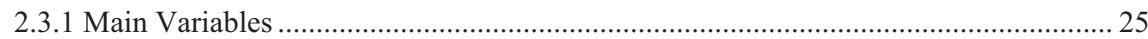

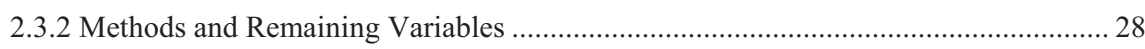

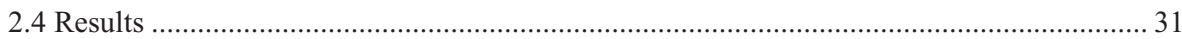

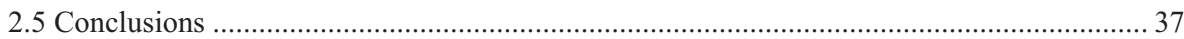

\section{The Contribution of Universities to Growth:}

Empirical Evidence for Italy.............................................................................................. 39

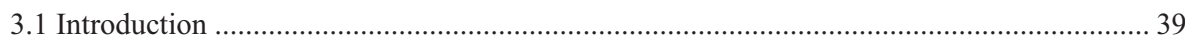

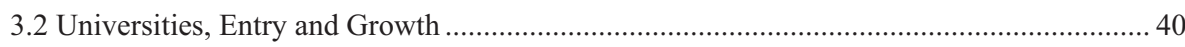

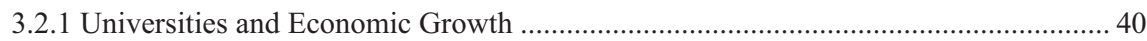

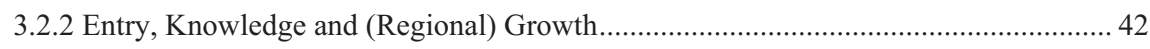

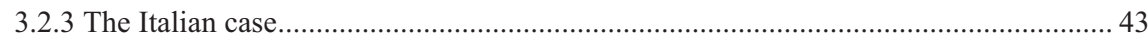

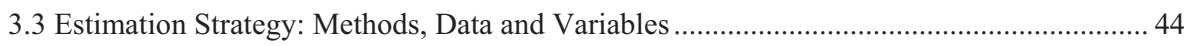

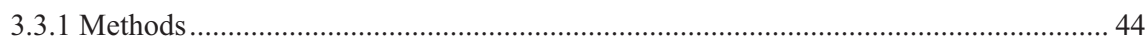

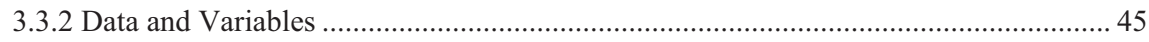

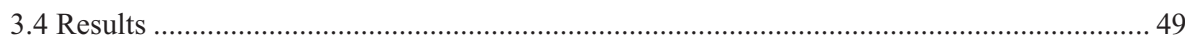

3.4.1 Economic Growth in the Restricted Industry Sector ................................................. 51

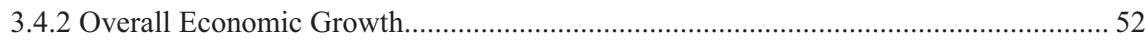

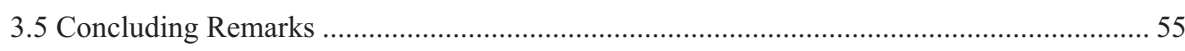

Institutional Change and Academic Patenting:

French Universities and the Innovation Act of 1999 ............................................5 57

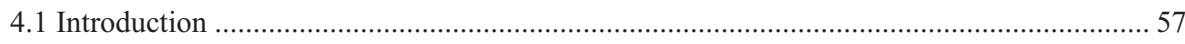

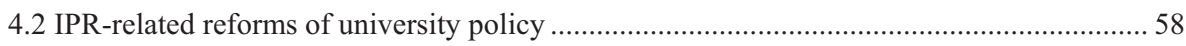

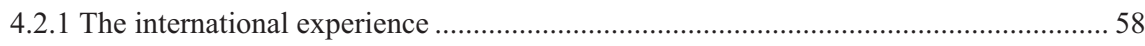




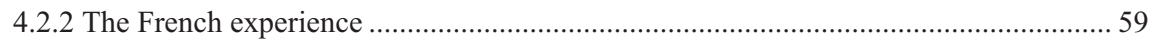

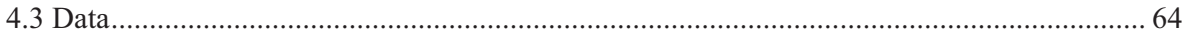

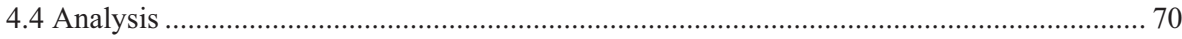

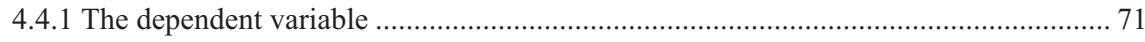

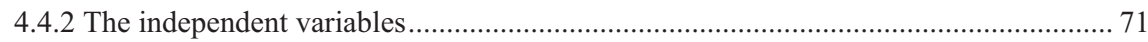

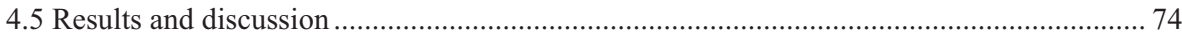

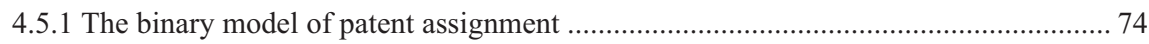

4.5.2 The multinomial model of patent assignment .......................................................... 76

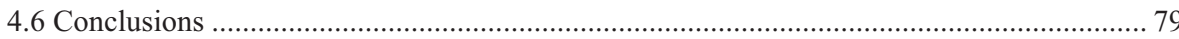

\section{Corporate Science in the Patent System:}

An Analysis of the Semiconductor Technology ............................................................... 83

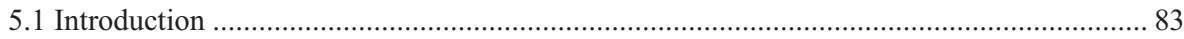

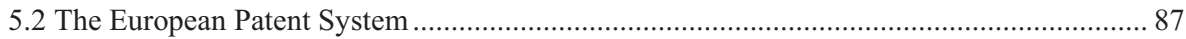

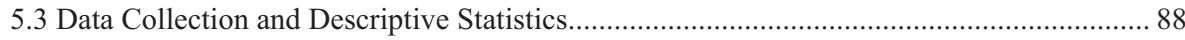

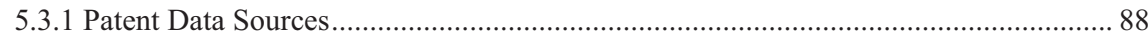

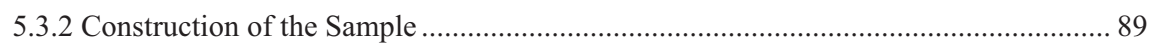

5.3.3 Some Descriptive Statistics on the Cited Scientific Publications.................................. 91

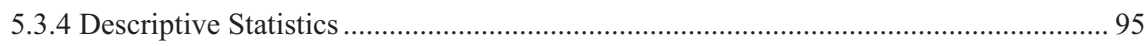

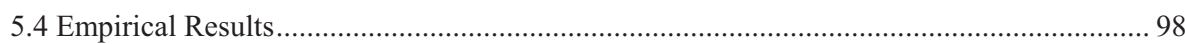

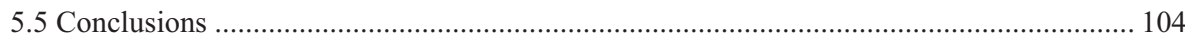

Concluding remarks and directions for future research............................................... 109

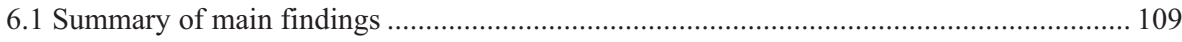

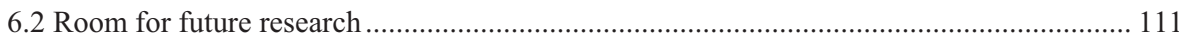

6.2.1 The Scientific Backbone of Radical Innovations ..................................................... 112

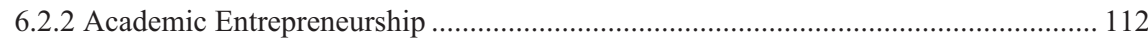

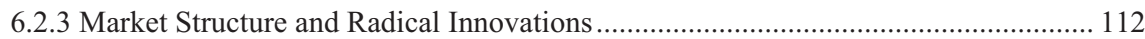

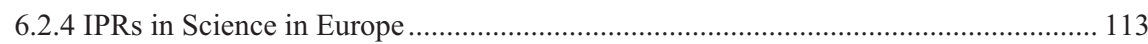

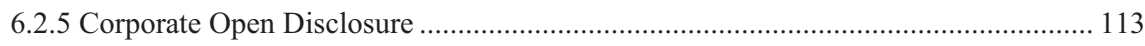

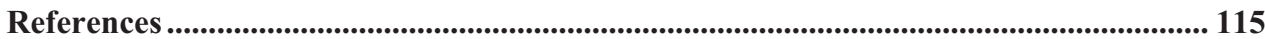

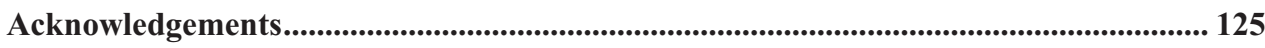

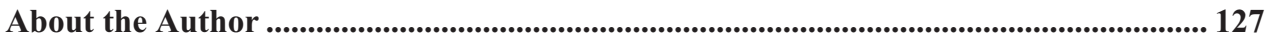




\section{List of Tables}

Table 2.1: Regions with the highest number of "excellent" departments ................................................. 27

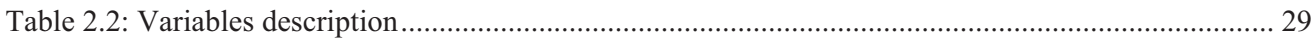

Table 2.3: Summary Statistics and Correlation Matrix ……................................................................. 32

Table 2.4: Pooled OLS Regressions (UNI_QUAL_1) ..................................................................... 33

Table 2.5: Pooled OLS Regressions (UNI_QUAL_2) ........................................................................... 34

Table 2.6: Random-Effect GLS and Fixed Effect OLS Regressions (UNI_QUAL_1).............................. 35

Table 2.7: Random-Effect GLS and Fixed Effect OLS Regressions (UNI_QUAL_2)............................ 36

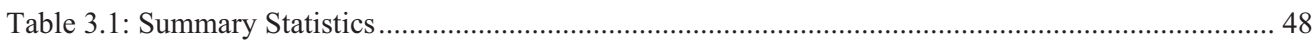

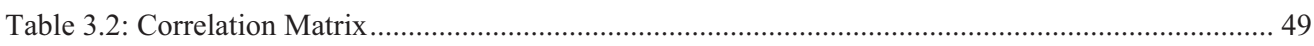

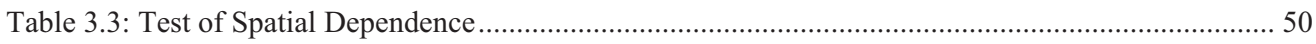

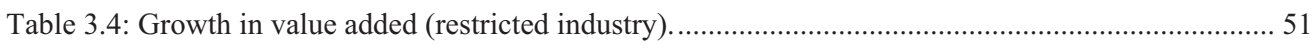

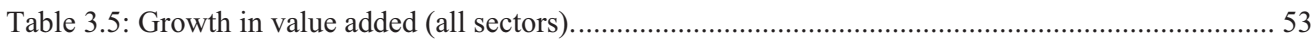

Table 4.1: French academic patenting activity between 1994 and 2002 ................................................. 66

Table 4.2: French patents and academic patents, by technology class ................................................... 66

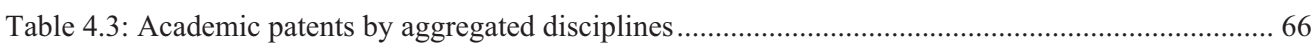

Table 4.4: Academic patents by Applicants and DT-7/OST technology domains ..................................... 68

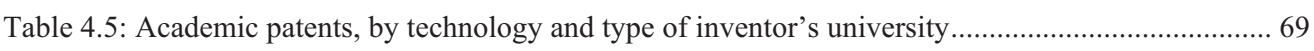

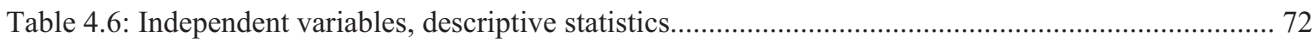

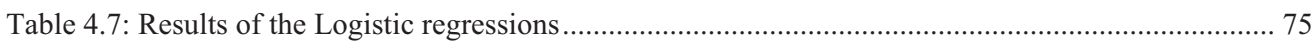

Table 4.8: Results of the Multinomial Logistic regressions ................................................................ 78

Table 5.1: Tests for different distributions of reference categories ....................................................... 92

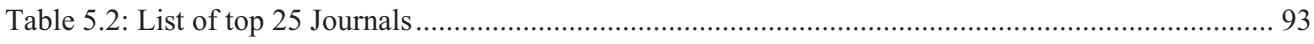

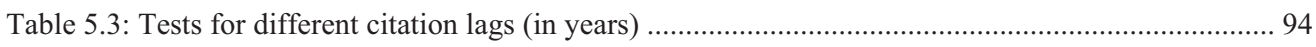

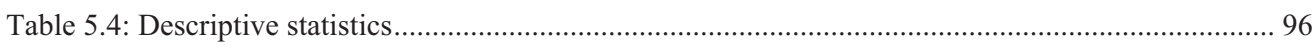

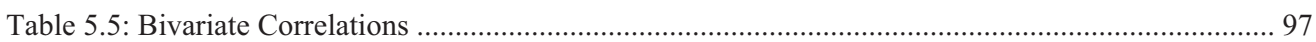

Table 5.6: Heteroscedastic Probit model for the patent grant decision .................................................. 100

Table 5.7: Heteroscedastic Probit model for the patent grant decision for the subsample of firms with less

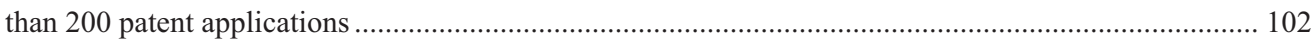




\section{List of Figures}

Figure 1.1: EU 27 Innovation Performance 2010: Enabling Infrastructure ......................................... 16

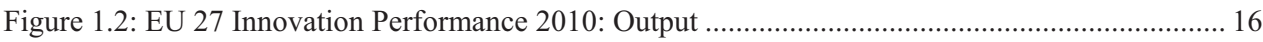

Figure 4.1: Number of academic patents by technological class, 1994-2001/02 ….............................. 68

Figure 4.2: Share of academic patents over all patents, by techn. class, 1994-2001/02 ....................... 68

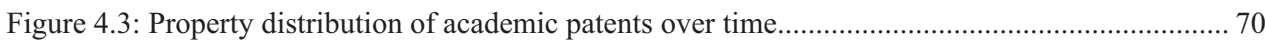




\section{Introduction}

\subsection{Science, Innovation and Economic Performance}

\subsubsection{On the mechanisms relating technological progress and growth}

Considering the history of mankind in the Western world, the last century distinguishes itself for an unprecedented improvement in the standards of living of the population at large. Material comfort is no longer the privilege of a small minority, but it has permeated social boundaries in various respects. Hence the question: What has made this last century so special from an economic standpoint?

There is little doubt that Innovation, "...the new commodity, the new technology, the new source of supply, the new type of organization..." in the words of Schumpeter $(1942,84)$, has accounted for most of the productivity growth in the last decades. Schumpeter related the process of technical change to economic performance. According to Schumpeter (2005), economic cycles can be traced back to the nature of the changes occurring in the economies. Incremental changes are conducive of what he defines "economic growth", being a continuation of the current steady state in the economy. Radical changes are instead the source of "development", the process of creative destruction that, moving away from the static equilibrium, opens up indeterminate future paths. Whether incremental or radical, the concept of novelty is central in the analysis of economic cycles. Schumpeter proposed two mechanisms to explain the mechanisms through which "novel combinations" are brought on to the market place: the heroic entrepreneur (Schumpeter, 1934) or the large bureaucratic company (Schumpeter, 1942). Yet, what Schumpeter has struggled to identify is the locus of novelty.

Where do innovations come from? Let me use the words of Marx and Engels to answer this question:

"The bourgeoisie cannot exist without constantly revolutionising the instruments of production, and thereby the relations of production, and with them the whole relations of society. Conservation of the old modes of production in unaltered form, was, on the contrary, the first condition of existence for all earlier classes"(Italics added by me).

(Marx and Engels, 1951, 1:36) ${ }^{1}$.

Despite the socio-economic peculiarities of the bourgeoisie, which create strong incentives for the accumulation of capital, it is the revolutionising the instruments of production, that is the constant endeavor to ameliorate and refine the production processes, that made the last century different. No longer is the workman with his/her physical and psychological peculiarities the milestone of the production process, but rather the machine, with its constituent phases governed

\footnotetext{
${ }^{1}$ Marx and Engles quotes' are taken from Rosenberg (1972)
} 
by the principles of science and engineering. The application of the principles of science to the analysis of each constituent phase paves the way to constant improvements in the details of an automatic system of machines (Marx, 1906, p.416). Therefore, "modern industry ... makes science a productive force distinct from labour and presses it into the service of capital" (Marx, 1906: 397).

The interaction between Science and Technology, or, to use the words of Mokyr (2002), between episteme (what we know) and techné (how we apply), has given rise, from an economic standpoint, to both opportunities and challenges. Opportunities arise from the very essence of Science. The quest for originality and plausibility in the contribution, synthesis in the approach, rigour in the methodology and universality in the implications of scientific discoveries (Polanyi, 1962) renders a scientific discovery a public good, not in the traditional economic meaning - non excludable and non rivalrous - but rather as source of diversity and flexibility (Callon, 1994). Science hence increases the understanding of the natural principles governing Technology and, with it, the range of applications of the set of techniques comprising Technology. Challenges stem from the different, often conflicting, norms governing the two systems, especially with regards to the appropriability of research outcomes (Dasgupta and David, 1994). Men of Science seek for reputation among their peers; scientific honours are reserved only to those whom, earlier than their peers and according to them, succeed in advancing the scientific understanding of natural principles. If epistemic communities define the set of incentives for the men of Science, the market for goods and services embodying the advancements in Technology defines rewards and incentives for the men of Technology. Prices are pivotal in the definition of their research agendas. Like for the men of Science, priority is key to succeed; yet, it is the market, and not the epistemic community, the ultimate judge of the value of their inventions. And the extent to which priority in the market is preserved defines their monetary rewards. Hence, the tension between the norms governing the two communities, a tension between publicity and secrecy, a tension between generalizability and exclusivity, renders the interaction between Science and Technology problematic.

\subsubsection{A brief history of the interaction between Science and Technology ${ }^{2}$}

The systematic use of scientific methods and discoveries in the way industrial corporations refine and diversify their product lines is a rather recent phenomenon of human history. It has its origins in the mid-nineteen century, with the emergence of the capital intensive industries of the second industrial revolution - especially the Chemical sector. It expanded quickly by the turn of the century as strategic response to institutional and technological changes: Antitrust legislations and the birth of modern Pharmaceuticals after the bacteriological revolution. It finally gained legitimization among decision makers, corporate and public, only during the interwar period, when it showed its full potential. Yet, in the last three decades a view emerged that excessive

${ }^{2}$ If not stated otherwise in the text, the story reported in this paragraph pertains the evolution of the interaction between science and technology in the U.S.A. as most studies are only available for this country. 
intellectual freedom granted to scientists - from both public and private institutions - could not be sustainable for corporate and economic performance. Accordingly, also higher education institutions, the most prominent producers of Science, have evolved and undergone substantial reorganizations to meet the needs of their sponsors, being national governments or corporations.

The first systematic innovative efforts in firms occurred in the second half of the nineteen century, when the new sectors of second industrial revolution came about. Large in scale to exploit the large necessary capital investments they needed to operate, companies in railroad transportation, dyestuff and minerals among others realized the potential benefits they could derive from professional scientists "in systematic problem solving and rationalization of industrial processes" (Smith, 1990). Improvements in transportation methods for crude oil, extraction of iron ores, syntheses of new dyes were among the main achievements of the first technical laboratories during the second half of the century. However, corporations were not yet organized for conducting systematically the full range of activities required for innovations to be developed fully in-house. Indeed, there existed at that time a large market for technologies, where small innovators, usually lacking financial resources, sold their patented innovations to incumbents (Burhop, 2010; Lamoreaux and Sokoloff, 2001). The goal of the corporate "scientists" was, therefore, to control invention, through incremental improvements on existing products and processes. Scientific findings and methods were the instruments for this purpose. The source of novelty lied mostly outside corporations, either in single inventors or in universities. Concurrently, modern universities emerged in the industrializing countries. Besides existing institutions, still embedded in the tradition of mediaeval universities, new departments, or eventually new schools as in the case of Germany and USA, were created. The new institutions - departments or schools - were often endorsed by local industrial communities which recognized the potential of educations in technical disciplines (Lecuyer, 1998; Murmann, 2003; Rosenberg and Nelson, 1994). Programs in electrical and chemical engineering were now offered by an increasing number of universities in the USA and Germany, the countries that would later on leapfrog Great Britain as new economic powerhouses of the twentieth century (Mowery, 1984).

In this first phase, therefore, industrial research laboratories were mostly users of scientific findings and methods, and knowledge transfer mostly occurred though graduates, and to a lesser extent technologies developed by academics.

By the turn of the nineteenth century and the beginning of the First World War, the major organizations in the chemical sector - and to a lesser extent in electrical engineering - had set up formal research laboratories (Smith, 1990). These were used strategically to defend market positions by continuously improving products whose patents came to expiration, and were part of a large reorganization of the production processes that followed the enforcement of the Sherman Antitrust Act (Chandler, 1990). Typical examples of the organization and operation of the first research laboratories in industrial corporations can be found in the German dyestuff industry, the pioneers of the modern science-based research laboratories (Murmann, 2003). Laboratories resembled to a large extent the academic laboratories in which the corporate personnel was 
trained. Scientific personnel worked on new methods to synthesize dyes - and later extending the research capabilities developed in the dyestuff to incorporate new advancements in bacteriological research. With universities, they kept close relations, exchanging scientific materials, personnel and provided financial and political support (Lenoir, 1998; Murmann, 2003).

During the interwar period, industrial laboratories expanded their operations from merely conducting development activities on existing product lines or products invented elsewhere, to conducting research for the explicit purpose of understanding and improving technologies. Science began to be considered the driving force behind the process of innovation. Companies hence granted industrial researchers the freedom to diversify their research programs in new directions. It is in these years that industrial scientists made major contributions in emerging scientific disciplines, such as polymers at DuPont and solid-state physics at the Bell Laboratories. However, the focus on development and commercialization of new products still remained prominent in the operations of industrial laboratories.

The implications of a closer relationship between the search for the basic understating of natural phenomena and its implementation in innovations became evident during World War II. The close collaboration between academic and industrial researchers, aimed at speeding up a successful conclusion of the conflict, achieved major advances in electronics and military medicine. The success of the Manhattan Project was emblematic in this respect. The atomic bomb, penicillin, radar and synthetic rubber are only a few of the innovations that were introduced during wartime. As a consequence, the role of Science in society changed drastically: scientific discoveries were believed to be the source of technological innovations. These arguments, pushed forward by Bush (1945), found support among decision-makers, who inaugurated three decades of almost unconditional support to the scientific enterprise of public research. For instance, federal support to academic research in the USA represented $24 \%$ of total academic $R \& D$ in 1935. It reached a peak of $73 \%$ in 1965 , and slowed down after then (Rosenberg and Nelson, 1994). The increase in public support for academic research had as consequence also a transformation of the nature of academic research. Universities became independent of local private financial support and scientists move towards more "basic" or "theoretical" puzzles, away from a tradition of serving the civilian industry (Rosenberg and Nelson, 1994).

From a corporate perspective, managers were also persuaded by the great innovative potentials of large investment in scientific research. Corporate laboratories now conducted academic-like type of research, where industrial researchers were left free to set up their own research agenda. At the same time, like their colleagues in Academia, corporate scientists delved into theoretical puzzles, and disregarded development and commercialization of new products as not belonging to the scientific tradition (Smith, 1990).

Yet, when European companies regained market shares after the war, and later on new competitors from Asia entered the market, companies had to reorganize their innovative enterprises by concentrating their efforts in transforming scientific achievements developed inhouse into marketable products. Not only were industrial scientists deemed culpable of the loss of 
competitiveness by American corporation on international markets, but also the system of public research in the USA was strongly criticized for their focus on research problems of little practical relevance (Coriat and Orsi, 2002; Jaffe, 2000). At the same time, the decline (if not disappearance) of the Soviet threat resulted in shortages of federal funds dedicated to research budgets (Feller, 1990). A financially restrictive technology policy was pursued by the US government since 1970 when federal funds accounted for $70.5 \%$ of the total R\&D expenditure, declining to $59.6 \%$ in 1997, with a drop in the amount of funds per researcher. Contemporaneously the industry share in university performed R\&D increased from $2.6 \%$ to $7.1 \%$.

These events reoriented funding strategies at universities and public research organizations and, consequently, brought to reconsider technology policies at federal level. In 1980, the USA passed a set of reforms aimed at strengthening the connections between Industry and Academia. The most representative of these reforms, the Bayh-Dole Act, provided a unified legal framework that allowed universities to retain intellectual property rights on the results of federally funded research. Ten years later, at the beginning of the 1990s, the same discussion took place in Europe. The introduction of the common European currency and the alignment to the Maastricht criteria pushed for changes in the mode of allocation of public funds for research: this resulted in a period of constant or decreasing level of budgets (Geuna, 2001). This shortage of resources dedicated to research has led to a change in raising funds strategies at PROs. Such reorientation in strategies has been accompanied in some countries by sets of reforms in IP laws openly informed by the US experience. These pieces of legislation aimed at reshaping the institutional context in which entrepreneurial activities by universities and faculty members would occur. The main argument underlying these reforms was that clear intellectual property rights were necessary for companies and universities to unbound the economic potential of scientific breakthroughs "shelved" in national laboratories. As a matter of fact, the culture of openness and the rewarding system based on peer recognition at work in Science were expected to create insufficient incentives for scientists to get involved in the development phase (Merton, 1972). Moreover, the absence of clear intellectual property rights would lead to underinvestment in public research from companies (Arrow, 1962). In the two decades following the institutionalization of IPRs in Science, universities worldwide expanded their operations into IPRs management. Along the already existing faculties and departments, new institutions - technology transfer offices, industry liaison offices, etc... - were created with the explicit purpose of coping with all aspects of commercialization of inventions stemming from academic research.

The process of "propertization" of Science has been widely associated with the incredible recovery of the world economy in the 1990s. This impressive economic performance was mostly driven by the sectors of the new economy - Information and Communication Technology, Biotechnology, Nanotechnology, etc... These sectors not only have solid groundings in Science, where advances on the technology side heavily depended on scientific discoveries (Narin et al., 1997), but also had their origins in academic laboratories. Nowadays, in the transition to a knowledge economy, universities, and every other institution concerned with the scientific 
advancement of knowledge, are addressed as main drivers of economic growth. In this respect, the Lisbon Strategy for the European Union stands as the most representative case. ${ }^{3}$

\subsubsection{The Lisbon Strategy}

In March, 2000, the European Council held a special meeting in Lisbon to set new strategic goals for the Union to be achieved by 2010. The council deliberated that the passage to a knowledgedriven economy was essential to reduce unemployment, achieve economic progress and increase social cohesion. The programme called for knowledge infrastructures, modernization of educational systems, and strengthening of innovative performance as all necessary actions to obtain sustainable economic growth. In the concluding document, the council deliberated among other things the following:

"Article 12: Given the significant role played by research and development in generating economic growth, employment and social cohesion, the Union must work towards the objectives set out in the Commission's communication "Towards a European Research Area". Research activities at national and Union level must be better integrated and coordinated to make them as efficient and innovative as possible, and to ensure that Europe offers attractive prospects to its best brains.[ ...] At the same time, innovation and ideas must be adequately rewarded within the new knowledge-based economy, particularly through patent protection."

Article 13: The European Council asks the Council and the Commission, together with the Member States where appropriate, to take the necessary steps as part of the establishment of a European Research Area to:

- develop appropriate mechanisms for networking national and joint research programmes on a voluntary basis around freely chosen objectives, in order to take greater advantage of the concerted resources devoted to R\&D in the Member States, and ensure regular reporting to the Council on the progress achieved; to map by 2001 research and development excellence in all Member States in order to foster the dissemination of excellence;

- improve the environment for private research investment, R\&D partnerships and high technology start-ups, by using tax policies, venture capital and EIB support;

- encourage the development of an open method of coordination for benchmarking national research and development policies and identify, by June 2000, indicators for assessing performance in different fields, in particular with regard to the development of human resources; introduce by June 2001 a European innovation scoreboard;

- facilitate the creation by the end of 2001 of a very high-speed transeuropean network for electronic scientific communications, with EIB support, linking research institutions and universities, as well as scientific libraries, scientific centres and, progressively, schools;

- take steps to remove obstacles to the mobility of researchers in Europe by 2002 and to attract and retain high-quality research talent in Europe;

\footnotetext{
${ }^{3}$ See next section and http://www.consilium.europa.eu/uedocs/cms_data/docs/pressdata/en/ec/00100-r1.en0.htm
} 
- ensure that a Community patent is available by the end of 2001, including the utility model, so that Community-wide patent protection in the Union is as simple and inexpensive to obtain and as comprehensive in its scope as the protection granted by key competitors.

The words innovation, research, knowledge are central in the agenda for growth. To achieve the proposed goals, the council emphasized the role of public research institutions and public policies as providers of the infrastructure enabling a successful transition to a knowledge economy. Figure 1.1 shows the results of the achievements after 10 years of the launch of the Lisbon Strategy. The top part of the figure reports the scores for all 27 countries in terms of Human Resources, measured as a composite index of the share of population with a doctoral degree, the share of population between 20 and 34 with tertiary education and share of youth aged 20-24having at least secondary education.

The middle part of the table instead measures the attractiveness of the research system (Open, Excellent and Attractive Research System) as synthesis of a weighted measure of international scientific publications, highly cited scientific publications and extra-EU $\mathrm{PhD}$ students. Finally the bottom part presents the availability of venture capital and the share of publicly funded R\&D (Finance and Support). The figure clearly shows pronounced differences persist among EU 27 countries in terms of knowledge infrastructure, especially in the quality and quantity of scientific research carried on (middle panel) and in the supporting role of public and private capital for research and entrepreneurship (bottom panel). Overall, Northern European countries appear to have a better knowledge infrastructure and better access to financial support for innovation. Eastern and Southern European countries on the opposite significantly lag behind in these indicators.

Figure 1.2 instead shows the innovative performance of EU 27 countries. A great deal of attention is given to SMEs, as the majority of economic activities in the EU is performed in this typology of companies. The upper part of the figure - Innovators - is a composite index capturing the role of SMEs in the introduction of innovations in different domains (process, product, organizational). The bottom part (Economic Effects) presents a measure of the economic impact of a wide range of innovative activities such as share of employment in knowledgeintensive sectors, share of high-tech export, sales of new products. Unlike Figure 1.1, there is no clear geographic pattern when we assess the contribution of SMEs to innovation. For instance, some countries like UK, France and the Netherlands, which have among the best knowledge infrastructure in Europe, fall behind the EU benchmark with other countries located in less developed areas of the EU 27. Germany instead stands out among EU countries for the role that SMEs have in innovation. The economic implication of innovative activities, as reported in the bottom part of the Figure 1.2, instead show that, with the sole exception of Belgium and the Netherlands, the countries that still struggle to reap the economic benefits from innovative activities are mostly located in the southern and eastern part of Europe. 
Figure 1.1: EU 27 Innovation Performance 2010: Enabling Infrastructure
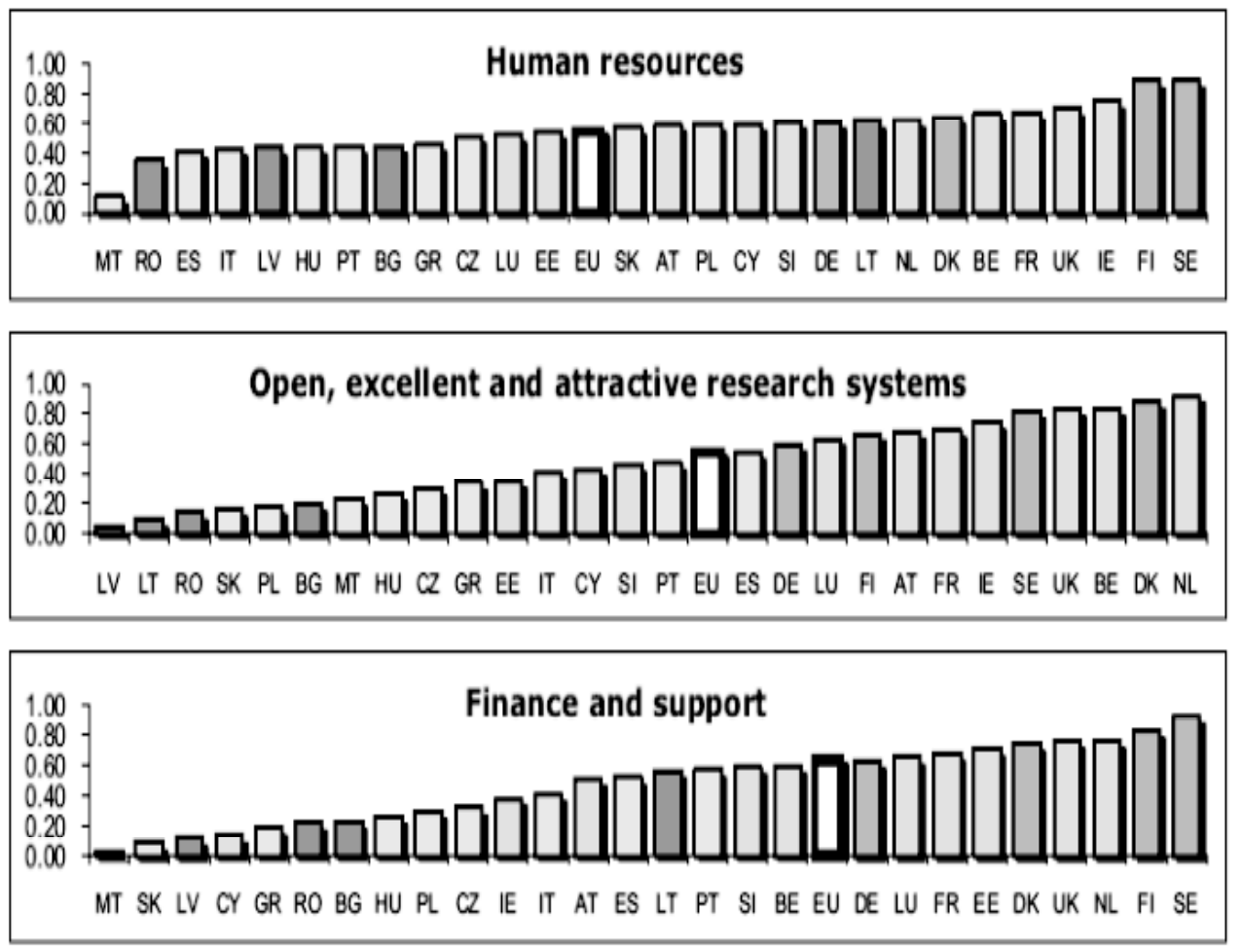

Source: Innovation Union Scoreboard 2010

Figure 1.2: EU 27 Innovation Performance 2010: Output
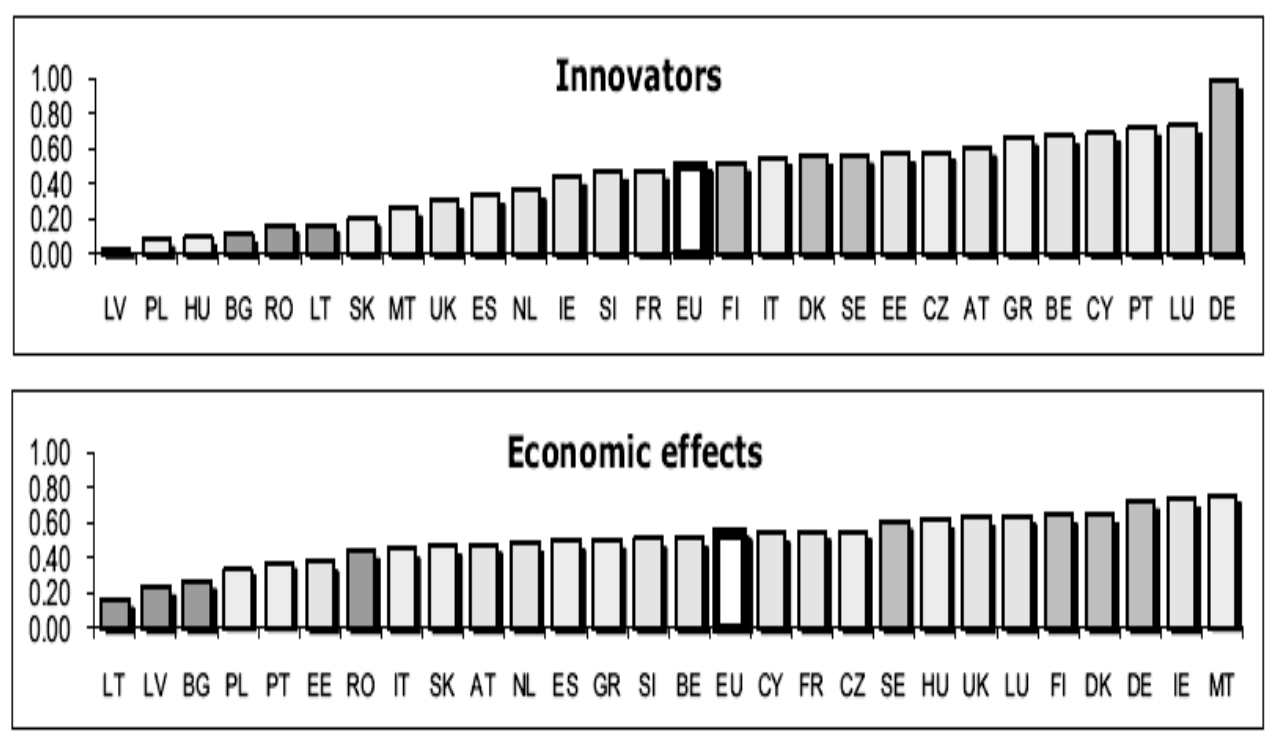

Source: Innovation Union Scoreboard 2010 


\subsection{The Dissertation}

\subsubsection{Setting the stage - the dissertation at a glance}

This dissertation is an empirical investigation of the opportunities and challenges that the close interaction between Science and Technology poses. It addresses four different puzzles currently crowding managers and policy-makers in different institutions, both from an economic and an institutional point of view.

In the first part, this dissertation explores two determinants of the process that should facilitate the exploitation of scientific knowledge: scientific eminence and entrepreneurship. By taking a basic view to the relation between Science and Technology, where the advancements in the former represent a necessary condition for the developments of the latter, scientific eminence can be conceived as an input of the process that transforms knowledge in profits and economic growth, whereas entrepreneurship as a throughput of this process.

Scientific eminence is only achieved when scientists systematically discover regularities in nature which are original in their contents, rigorous in their explorations and universal in their applications as assessed by the academic communities. It hence pertains to the inherent qualities of the improvements to the epistemic base, from which techniques can be built upon or improved. Technologists, who before others can have access to these new and superior pieces of knowledge, should be able to refine their techniques and consequently the outputs of their innovative efforts.

Yet, the process through which scientific advancements are assessed is, in itself, a tension between conformity to the state of the art and dissent from it. Scientific discoveries, hence, are both evolutionary and a revolutionary with regards to the way existing techniques are designed and assembled. Whereas existing organizations can easily incorporate evolutionary discoveries in their well-defined production processes, they have harder times when new discoveries require the reformulation of the existing productive logics. Entrepreneurs are not constrained by the rigidities of existing productive architectures. Therefore, they can redesign production processes so as to embed revolutionary advancements.

The second part of the dissertation brings the tension between the norms of Science and Technology on the institutional/legal ground, by looking at how members and results of Science interact with Intellectual Property Rights (IPRs), and patents in particular. The patent system grants monopoly rights to inventors for the use of their own inventions in exchange for the disclosure of the relevant information for the reproduction of the inventions. Patents, moreover, are granted for inventions that depart sensibly from the existing prior art, that is the existing knowledge of the whole set of Science, Technology and the relations between the two.

A common sense exists that the norms of Science would barely lead to scientific discoveries of direct and immediate relevance for Technology. Scientific originality seldom meets technological novelty. Hence, new sets of rules should be in place to redirect scientific endeavours towards technological needs. The ideal candidates to serve this purpose are IPRs, and specifically patents. If scientists are already prone to tackle novel problems and disclose their 
discoveries, patents should induce efforts from scientists towards the industrialization of their findings by providing economic rewards. In this vein, policy reforms addressing the matter of IPR at public laboratories have been promoted across the developed countries. Technological potentials of scientific discoveries would hence find their way on the marketplace more rapidly.

If scientific discoveries are embedded more rapidly in innovations whose inventors seek legal protection at patent offices worldwide, the possibility exists that the claimed novelty and originality of the innovation might overlap with the actual originality of its scientific grounding. The invention, then, would not match the patentability requirements and fall in to the public domain. Technologists might well be capable of assessing the existence of similar prior art, and accordingly, design their innovations to overcome this problem; yet, more than Technology, Science advances with more geographically distributed and cumulative contributions (the "shoulders of giants" metaphor).

\subsubsection{Across the chapters}

The dissertation is made of four independent studies describing the aforementioned puzzles. The autonomous structure of each chapter allows you, reader, to go through them in a self-chosen order.

The first study, presented in Chapter 2, tests the hypothesis that the presence of high-quality departments in scientific disciplines is conducive to higher innovative performances. The interest for universities as primary drivers in the transformation to a knowledge economy has to be traced to the extraordinary experiences of the Silicon Valley and the Route 128 around Boston, which also host some of the most prolific scientific universities worldwide. The history of technologies such as Chemicals at large suggests that, indeed, universities at the frontier of science are the most preferred partners by companies to conduct joint research projects and provide the job market with students trained on the latest scientific findings. Furthermore, micro-based evidence from the technology transfer literature shows a substantial divide in terms of commercial activities between star scientists and the rest. In this study, we run an econometric exercise on 86 European regions belonging to 7 countries between 1997 and 2007. The results of the study provide systematic support for the hypothesis that high-quality universities enhance local innovative activities. However, the very limited magnitude of the estimated effect casts some doubts on the effective abilities of European universities and companies to fruitfully exploit the full potential of the European Research Area. Finally, and rather interestingly, the mere presence of universities has no implications for innovation.

Chapter 3 examines the role that entrepreneurship, measured as sustained levels of entry, has in the economic exploitation of academic outputs. Unlike previous contributions, we do not restrain our attention to the sole role of research, as academic institutions perform different tasks. In essence, the commercialization of academic knowledge is affected by high information asymmetries between inventors and potential exploiters. Indeed, the incentive system in place within the academic community would rarely lead scientists to produce findings of immediate industrial application. High information asymmetries result in higher transaction costs among 
economic agents. In such a context, entrepreneurship is seen as a promising mechanism that ensures both the flow of radical knowledge into the economy and its economic exploitation.

The main rationale underlying this argument is that large players would oversee promising ventures because of having higher opportunity costs (investments in physical and relational assets devoted to current lines of business). In this study we test the hypothesis that new ventures, rather than large players, are more effective in the transformation of academic knowledge into economic growth. Specifically, we evaluate three outputs of academic activities - teaching, research, and Intellectual Property Rights (IPR) management - along with the ability of new ventures in transforming the mentioned outputs into improved economic performance. The analysis is carried out for the Italian provinces between 2001 and 2006 and applies spatial econometric techniques to account for the spatial dependence of our units of observations. We find that academic knowledge, in whatever form, yields nonsignificant effects on the growth rate of value added in the manufacturing sector. On the contrary, the effects of academic outputs are appreciable when they are associated with sustained entrepreneurial activities. In particular, the traditional mandate of scientific inquiry seems to provide new ventures with valuable commercial opportunities overseen by established companies.

The third study, presented in Chapter 4, evaluates a policy initiative passed in France in 1999 (the Innovation Act) aimed at encouraging academic institutions to protect and commercialize their scientists' inventions. The Innovation Act, like other similar initiatives passed in other European countries, owes its rationale to the U.S. Bayh-Dole Act. These actions rely on the postulate that assigning the property of patents to universities would enhance the involvement of Academia in the innovative process, which is expected to be rather scant. In addition, we explore the concurrent effects of an important organizational change such as the diffusion of technology transfer offices. For this study, we use a novel measure of scientists' contribution to inventive activities: patent applications at the European Patent Office (EPO) whose inventors are academic scientists between 1994 and 2002. The results show that by simply looking at patents applied by universities might be extremely misleading: universities own only a minor share of their scientists' patented inventions, around $11 \%$. The share of academic patents in public hands over the period examined rises to around 33\%, still much less than those controlled exclusively by business companies. This ownership distribution is due to institutional factors. Moreover, the results show that the Innovation Act, which indicates technology transfer via commercialization as a mission for French universities and provides both incentives and recommendation to this end, has increased the probability that universities will claim (their share of) property rights over their scientists' inventions. Larger effects are found for the decision to open a technology transfer office, which often pre-dates the Act. The findings suggest that any increase in universities' patenting rate may be due, at least in part, to a redistribution of ownership rights, rather than an increase in inventive activity.

The fourth study, in Chapter 5, investigates the presumed effect of scientific publications to prevent exclusive rights on similar inventions. This effect is expected to be more pronounced for publications from corporate scientists. Indeed, with the movement towards the knowledge 
economy, the management of the intellectual assets has gained more importance than the physical counterparts. Companies might be held-up by competitors' IPRs and thus limited in the use of their techniques. To preserve their freedom to operate their own technologies, companies create strategically prior art with the objective to prevent others from patenting related inventions. This presumes that corporate publications enter the pool of prior art which is relevant to judge the novelty of patent applications at the patent office and that corporate science has the power to block patent applications. This study analyses for the first time whether the presumed mechanism behind corporate publications as a means to pre-empt patents works. With focus on the semiconductor technology, the results show that scientific publications by corporations challenge the novelty of patent applications at the European Patent Office (EPO) significantly more than other pieces of prior art. Detailed information from the EPO patent examination procedure allows us to show that corporate publications threaten the novelty of patent applications if combined with other pieces of prior art like patents (rather than as standalone documents). This supports the view that corporate scientific publishing can be an effective means for firms to protect their freedom to operate if used as a complementary part of a firms' overall IP protection strategy as proposed by scholars in the field of law and management science. ${ }^{4}$

${ }^{4}$ The second chapter of this dissertation - Academic Knowledge and Regional Innovative Performance: Which role for Scientific Eminence - is the result of a joint work with Martin Carree (Maastricht University). It has been presented at the European Association of Researchers in Industrial Economics Conference in Ljubljana (2009). It is currently under revisions for a first submission to a journal. The chapter The Contribution of Universities to Growth: Empirical Evidence from Italy is the outcome of a joint work with Martin Carree and Enrico Santarelli from Università di Bologna. The work has appeared in the working paper series of the Economics Department of the Università di Bologna (Working Paper DSE $n^{\circ}$ 793). The work has been awarded as the best article at the Technology Transfer Society Conference in Augsburg (2011) and has been invited for submission to a special issue of the Journal of Technology Transfer. The work Institutional Change and Academic Patenting: French Universities and the Innovation Act of 1999 in chapter 4 of this dissertation has been written in collaboration with Francesco Lissoni (Università di Brescia) and Patrick Llerena (Université de Strabourg). The work has been presented at several conferences (Danish Research Unit in Industrial Dynamics Conference, Copenhagen 2008; Knowledge for Growth, Toulouse 2008 among others) and seminars (Katholieke Universitieit Leuven, 2009; University of California at Berkeley, 2011 among others) and it has been accepted for publication at the Journal of Evolutionary Economics. Finally, the chapter Corporate Science in the Patent System: an Analysis of the Semiconductor Technology, jointly written with Katrin Hussinger (Maastricht University) has circulated as Zentrum fuer Europaeische Wirschaftsforschung discussion paper 10-098 and has been presented extensively at seminars (KULeuven, Bocconi University, ETH Zuerich, etc...) and conferences (EPIP 2010, EARIE 2011). The paper is currently in the $3^{\text {rd }}$ round at the Journal of Economic Behavior and Organization. 


\section{Academic Knowledge and Regional Innovative Performance: Which Role for Scientific Eminence?*}

\subsection{Introduction}

The economic rationale of direct public intervention in R\&D is grounded in the informational properties of scientific knowledge (Arrow, 1962; Nelson, 1959). Scientific knowledge is considered as a non-rival and non-excludable good, and thus only partly appropriable. Scientific knowledge leaks out of laboratories, increases the pool of available knowledge and reinforces the production of innovations. This "market failure" argument implies that privately funded R\&D particularly the " $\mathrm{R}$ " component - is below the social optimum. Hence, governments fund basic research at universities and Public Research Organizations.

In this respect, a strand of literature has focused on the measurement of the positive externalities that publicly funded research generates on the outcomes of corporate innovations. Jaffe (1989) first initiated the systematic exploration of the real effects of academic knowledge on innovation. Jaffe used data on patents and $R \& D$ from private and public sources at state level in the U.S.A. and noticed that university R\&D has a double effect on the ability of firms to innovate: it contributes directly to corporate innovations and it shows an indirect or inducement effect on innovation as it also increases private R\&D. Following Jaffe, other studies in the field reinforced the spatial dimension of the process of innovation and shed further light on the determinants of the uneven distribution of innovation over space (Acs et al, 1992; Anselin et al., 1997; Audretsch and Feldman, 1996; Feldman and Florida, 1994; Varga 2000). For instance, Feldman and Florida (1994) showed that the agglomeration of specialized workforce, knowledge, institutions, and resources are conducive to higher innovative performances by firms. The result is reinforced by Audretsch and Feldman (1996; 1999), who display that although production activities tend to cluster where relevant academic research is the highest, a certain degree of diversity in the sources of knowledge, yet eventually compatible, is conducive to higher innovative performances. These findings are synthetically summarized by Varga (2000), who argues that a critical mass of agglomeration of production activities must exist for public research spillovers to be effective.

Although the results above surveyed on geographically mediated knowledge spillovers from public laboratories - especially academic ones - pertain exclusively the U.S.A., evidence for Europe, consistent with the U.S. findings, has been largely produced at country-level. Works for Austria (Fischer and Varga; 2003), Sweden (Andersson et al., 2009), France (AutandBernard, 2001; Piergiovanni and Santarelli, 2001), Germany (Firtsch and Slavtchek, 2007) and

\footnotetext{
* This chapter is based on a joint work with Martin Carree (Maastricht University).
} 
Spain (Barrio-Castro and Garcia-Quevedo, 2005) have mostly estimated a regional knowledgeproduction function relating corporate patents as approximation for innovation to various measures of academic activities ( $R \& D$ expenditures, $R \& D$ personnel, scientific publications, etc...) among other controls.

With some exceptions, the works surveyed above have overlooked the different institutional settings in which universities operate. For instance, in the U.S.A. the university system has historically deployed the dual mission of teaching and conducting research. As research funds are assigned through mechanisms of highly competitive procedures, a clear division has emerged between research universities and colleges with teaching mandates. In contrast, European universities have served the need of providing affordable tertiary education uniformly in space. In this setting, governments have filled the gap in research activities with a system of public research organizations (PROs) whose only mandate was research (CNRS, CEA, INSERM in France, Max Plank and Fraunhofer Society in Germany, CSIS in Spain, and CNR in Italy, among others). Nowadays, a large part of funding for universities is allocated for personnel salaries and equipment maintenance; moreover personnel are still largely hired according to educational needs.

Whenever academic R\&D in the USA is, hence, measured with federal funds, we are implicitly and indirectly observing the effects of scientific quality on the local innovative activities. The same rationale applies to measures of human capital in academic R\&D as the hiring of academic personnel is mostly related to the ability of raising external funds (Gurmu et al., 2010). Therefore, relying on traditional means of regular funds and personnel might lead to wrong estimations of the contribution of academic $R \& D$, if we do not consider other peculiarities of the output of public research.

In this work we explore the extent to which the quality of research carried out at universities influences the magnitude of knowledge spillovers in 86 European regions in 7 countries (Belgium, Germany, France, Finland, Spain, Italy and Portugal) between 1997 and 2007. To appreciate the influence of academic eminence on knowledge spillovers, we consider the latter as being mostly of pecuniary nature: academic knowledge mainly produces significant results when it leaks through market mechanisms (Agrawal, 2006; Audretsch and Stephan, 1996; Zucker et al, 1998a, 1998b). Scientific eminence is only achieved when scientists systematically discover regularities which sensibly expand the frontier of the epistemic base, from which techniques can be built upon or improved. Companies, that before others can have access to these new and superior pieces of knowledge should be able to refine their techniques and consequently the outputs of their innovative efforts (Rosenberg, 1982, Chapter 7). This assumption, furthermore, is justified by the findings of a burgeoning literature in the field of technology transfer (Agrawal and Henderson, 2002; Azoulay et al, 2009; Di Gregorio and Shane, 2003; Zucker et al, 1998b). Shortly, the studies above report that excellent research institutions are more involved in commercial activities and produce more and better technologies. Scientifically eminent universities can attract talented students (Saxenian and Hsu, 2001) and improve the 
capabilities of firms to appropriate research results (Cohen and Levinthal, 1990) via the creation of human capital.

In a traditional regional knowledge production function, we measure the number of EPO patent applications against innovative inputs. We split personnel in Public R\&D according to their employer: Universities and PROs. We also introduce a novel measure of regional scientific quality. Unlike widely available rankings, we define scientifically eminent departments those departments that have produced more than $50 \%$ of publications from European universities or departments whose scientific articles have received more citations than the average article in the field. The results show that the mere presence of personnel working in public research laboratories (universities and PROs) has no implications for innovative outputs. Rather, the scientific productivity of researchers and the visibility of their results - briefly, the quality of the research carried out at local universities - are crucial determinants for higher innovative performances.

The chapter is organized as follows: section 2.2 presents the rationale underlying our main hypothesis; section 2.3 describes the variables employed in the study and the methodology applied. Section 2.4 discusses the results from Pooled Ordinary Least Squares and Generalized Least Squares Random Effect. We conclude in section 2.5.

\subsection{Scientific eminence and knowledge spillovers}

One of the main lessons drawn from the U.S. experience is that academic research is a necessary condition for the development of a technology-intensive industrial base. The anecdotal evidence of highly dynamic and innovative industrial districts, such as the Silicon Valley in California and the Route 128 in Massachusetts, and their vicinity to some of the most prolific scientific universities worldwide, has spurred an extensive body of literature stressing the relevance of academic research for regional development and technical innovation (Jaffe, 1989; Jaffe, Trajtenberg and Henderson, 1993; Acs, Audretsch and Feldman, 1994; Zucker, Darby and Armstrong, 1998). The studies that followed for Europe, however, seemed to have missed that academic R\&D was performed at Stanford, UC Berkeley, MIT and Harvard. To fully appreciate the implications of scientific eminence of local universities for the production of innovations, we first need to conceptualize how scientific eminence can eventually affect the ability of corporations to better exploit the vicinity to prestigious academic institutions to generate valuable innovations.

The flow of skilled graduates to industry is probably the primary mechanism through which companies benefit from publicly funded $R \& D$ at higher education institutions. Universities provide teaching and training for future employees and hence enhance the qualification of the labor force (Nelson and Phelps, 1966). Yet, if scientific eminence is directly related to the process of new knowledge generation, it is far from clear whether it affects the ability of the faculty to provide more effective teaching and training. Indeed, academic programs are mainly grounded in 
consolidated research results. Hence, even lower research standing universities might still provide local firms with innovative inputs.

In this respect, anecdotal evidence from history provides notable examples of how scientific eminence might facilitate knowledge flows: the diffusion of molecular biology and the emergence of the biotechnology sector in the U.S.A. and U.K. (Orsenigo, 2001; Pisano, 2006), the diffusion of organic chemistry and the emergence of the chemical sector in Germany (Murmann, 2003) and in the U.S.A. (Furmann and MacGarvie, 2009). According to the authors, the process of diffusion of academic knowledge in these domains was faster in the above mentioned countries than elsewhere because academic programs were incorporating research results at the frontier of science. From a different perspective, stories of failures confirm this view. As detailed by Murmann (2003), the U.K. failed to become leader in the chemicals in the mid nineteenth century as national universities could not provide the industry with a qualified workforce, their educative efforts being devoted mostly to humanities. Similarly, Chesnais (1993, p. 197) argues that notwithstanding the public efforts France undertook to fill the technological gap with respect to the U.S.A., the teaching of the results of science, rather than the methods, at French universities was one of the causes of the technological lag of French companies with respect to US corporations.

If history suggests that scientific eminence have direct implications for the kind of knowledge that is transferred to students, the ability to attract students and faculty from other regions so as to enlarge the pool of available knowledge and means to transmit it is another mechanism. Universities with excellent research reputations can attract the most brilliant students and faculty, which in turn join the local labor market for graduates, reinforcing the process of knowledge transfer via the labor market. In this respect, Moser et al. (2011) exploit a natural experiment - the racial laws promulgated in 1933 in Germany - to demonstrate how the flow of skilled Jewish chemists to the U.S.A. increased innovation in the hosting country. More generally, Beeson and Montgomery (1992) study the relationship between universities and labor markets. They relate university R\&D funding and number of science and engineering degree programs at local universities and find that universities increase the skill level of local workforce and consequently wages and employment.

The recent involvement of higher education institutions in formal technology transfer has stressed the increasing importance of market mechanisms in the process of knowledge transfer to the industry. In this case, scientific eminence definitely plays a crucial role when it comes to technology development and transfer. Firms engage in cooperative agreements with universities to solve specific puzzles encountered during R\&D projects (Cohen et al., 2002); concurrently, they also entertain such relationships to benefit from access to students, insights on emerging technologies and enhancing their knowledge base (Caloghirou et al., 2001). Therefore, firms privilege scholars who hold central positions in their respective communities. A burgeoning body of literature has highlighted that highly productive scientists are also those who entertain frequent collaborations with firms: they manage contractual agreements with industrial partners, engage in consulting relationships, fund companies (Audretsch and Stephan, 1996; Di Gregorio and Shane, 
2003; Perkmann et al., 2011; Zucker et al, 1998). As a matter of fact, scientists with excellent publication records are more likely to be engaged in technological developments (Azoulay et al. 2005; Breschi et al., 2005).

However, to our knowledge, at least one study partly counterbalances the thesis that academic quality is a decisive factor in explaining the magnitude of local knowledge transfer. In a survey of Corporate R\&D managers, Mansfield (1995) and Mansfield and Lee (1996) provide evidence that only a few top universities are able to provide firms with basic results, whereas the majority of university-industry collaborations pertain to applied needs. Companies that seek for basic research tend to address to the best options they can afford or have access to, irrespective of the distance. On the opposite, applied R\&D services require frequent interactions, which limit the geographical reach of companies when looking for academic partners. Thus, companies tend to trade off quality for spatial proximity in case of applied needs, whereas the importance of proximity vanishes when one deals with basic research challenges.

Summarizing, the scientific eminence of the higher education institutions involved in R\&D activities seems to influence the extent to which knowledge externalities occur. Excellent research institutions are more involved in commercial activities, produce more and better technologies. The studies above indicate that scientifically eminent universities can attract talented students (Saxenian and Hsu, 2001) and improve the capabilities of firms to appropriate research results (Cohen and Levinthal, 1990) via the creation of human capital.

\subsection{Data $^{5}$ and Methods}

\subsubsection{Main Variables}

We examine the question of how innovative activities relate to the scientific eminence of higher education institutions conducting R\&D. In order to provide an answer to our question, we employ a regional knowledge production function introduced by Jaffe (1989) and test our assumption for the regions belonging to eight of the EU-15 countries during the period 1997-2007. Indeed, we excluded Ireland, Denmark and Luxemburg because they are not articulated in regions, whereas regional data on R\&D personnel in Universities were missing for Sweden, UK, the Netherlands and Austria. Finally, data for business R\&D personnel for Greece were not retrievable. For the purpose of institutional coherence and homogeneity, we used NUTS1 regional classification for Belgium and Germany and NUTS2 regional classification for Spain, France, Italy, Portugal and Finland. As far as regions in the selected countries are concerned, French Départments d'OutreMer, the Spanish enclaves of Ceuta y Melilla, the Portuguese islands of Açores and Madeira and the Finnish island of Aland are excluded.

Previous studies in the field have approximated private innovative efforts with patent count and innovation count variables. In this work, consistently with the majority of previous works, we will use patent counts as innovation count variables obtained through innovation surveys are

\footnotetext{
${ }^{5}$ If not stated otherwise, the source of the data in the present study is EUROSTAT.
} 
measure of innovation subjective to the choice of journal editors, and, in most of the cases, only available for one or few cross-sections. In addition, whenever innovation counts are extracted from trade and technical journals - the most notable example being the Small Business Administration innovation citation database - they only account for product innovations, neglecting the innovative efforts related to the production process. Yet, patent counts have also severe limitations. Whenever patent count variables are considered to be the output of $R \& D$ activities, they show high variance in their private and social value (Trajtenberg, 1990; Harhoff et al., 1999). Thus, patents tend to indicate inventions, and only a minor part of them actually refers to innovations. Furthermore, patents cover mainly product innovations rather than process innovations (Cohen et al., 2000). Moreover, surveys have shown that firms mostly employ other means to appropriate the returns from $\mathrm{R} \& \mathrm{D}$ activities and patents seem to be used mostly for strategic purposes (Cohen et al., 2002; Blind et al., 2009). Patent counts assign patents to the place of residence of inventors. As the territorial extension of our regions is quite broad, we do not expect this to introduce any sort of bias.

As discussed in section 2.2, we would expect that the presence of scientifically eminent universities should contribute to higher innovative performances, conditional on controlling for the presence of public R\&D personnel. Measuring scientific eminence or scientific quality has raised several criticisms among scholars, university managers and policy-makers. Critics have pointed to the lack of reliability, transparency and objectivity of the criteria employed, nonreplicability of the results as main limitations of the rankings available. ${ }^{6}$ Moreover, the onedimensional nature of the rankings has been considered uninformative of the complex organizations and mandates of universities. In this study we use the results of an evaluation exercise carried out by the Center of Higher Education (CHE), an independent German think thank (Berghoff et al., 2010). ${ }^{7}$ For the purpose of this study, we will focus on the disciplines related to the "hard sciences" covered by the exercise: biology, physics, chemistry and mathematics. ${ }^{8}$

${ }^{6}$ Wikipedia presents a brief presentation and discussion of the academic rankings and their limitations. Source: http://en.wikipedia.org/wiki/Academic_Ranking_of_World_Universities

${ }^{7}$ Shortly, the authors propose a multidimensional approach to define scientific as well as educational excellence in different scientific domains. The scientific domains of this analysis are Biology, Chemistry, Mathematics, Physics for the "hard" sciences and Economics, Political Sciences and Psychology for the social sciences. The authors consider the following scientific criteria: (1) scientific production between 1997 and 2007 (size); (2) citations (excluding self-citations) normalized to the international domain-specific standards (reception); (3) outstanding researchers (visibility); (4) projects in the Marie Curie programme (European dimension); (5) postgraduate mobility (European mobility); (6) teaching staff mobility within the ERASMUS prgramme in 2009 (teaching mobility); (7) accredited Erasmus-Mundus-Masters; (8) grants from the European Science Fundation in 2008 and 2009. Finally, the authors assign stars to those departments that contribute to at least $50 \%$ of the total achievement of each criterium, with the sole exception of criterium (2), in which stars are assigned when scientific articles are cited more often than the field-adjusted average international article.

${ }^{8}$ The choice of disciplines is definitely constrained by the availability of the data. However, biology and chemistry have proved to be relevant in the determination of science-industry links (Lissoni et al., 2008; Cohen et al., 2002; Owen-Smith and Powell, 2001). Moreover, these studies stress the importance of engineering and information technology as these disciplines are likely to produce research results which find industrial applications. 
Table 2.1: Regions with the highest number of "excellent" departments

\begin{tabular}{|c|c|c|c|c|c|c|c|c|c|}
\hline \multirow{3}{*}{ Region } & \multirow{3}{*}{ Country } & \multicolumn{8}{|c|}{ Disciplines } \\
\hline & & \multicolumn{2}{|c|}{ Biology } & \multicolumn{2}{|c|}{ Chemistry } & \multicolumn{2}{|c|}{ Physics } & \multicolumn{2}{|c|}{ Mathematics } \\
\hline & & Paper & Cites & Paper & Cites & Paper & Cites & Paper & Cites \\
\hline Île-de-France & FR & 4 & 4 & 2 & 2 & 3 & 3 & 3 & 3 \\
\hline Baden-Württemberg & D & 3 & 3 & 4 & 4 & 2 & 2 & 1 & 3 \\
\hline $\begin{array}{l}\text { North-Rhein } \\
\text { Westphalia }\end{array}$ & $\mathrm{D}$ & 2 & 2 & 1 & 1 & 3 & 3 & 3 & 4 \\
\hline Bavaria & $\mathrm{D}$ & 2 & 2 & 2 & 2 & 2 & 4 & 1 & 1 \\
\hline Berlin & $\mathrm{D}$ & 2 & 1 & 1 & 0 & 2 & 1 & 2 & 2 \\
\hline Catalonia & ES & 1 & 1 & 1 & 1 & 1 & 1 & 3 & 2 \\
\hline Hessen & $\mathrm{D}$ & 3 & 3 & 1 & 1 & 1 & 1 & 0 & 0 \\
\hline Flanders & $\mathrm{BE}$ & 2 & 2 & 1 & 1 & 1 & 0 & 1 & 1 \\
\hline $\begin{array}{l}\text { Community of } \\
\text { Madrid }\end{array}$ & ES & 0 & 0 & 2 & 1 & 2 & 1 & 2 & 1 \\
\hline Rhône-Alpes & FR & 1 & 1 & 1 & 1 & 2 & 2 & 0 & 0 \\
\hline Lazio & IT & 0 & 0 & 1 & 1 & 2 & 2 & 1 & 1 \\
\hline
\end{tabular}

Note: Only the first ten regions across all disciplines are presented. The total number of excellent departments is further broken down by discipline and by criterion. The criterion "Paper" identifies those departments that have contributed to at least $50 \%$ of total scientific output across European universities between 1997 and 2007 in the same discipline, whereas the criterion "Cites" applies to those departments whose works are cited more than the average international article in the field.

FR: France; D: Germany; ES: Spain; BE: Belgium; IT: Italy

We defined scientifically eminent departments those departments that belonged to the group of institutions which contributed to at least $50 \%$ of the total number of publications between 1997 and 2007 among all European Universities or departments whose scientific articles have received more citations than the average scientific article in the field (Crown indicator by CWTS in Leiden). We did not take into account other criteria as they only partially cover the final part of the period under analysis. The quality of the regional academic system (UNI_QUAL) is measured alternatively either as a dummy variable to account for the presence of an "excellent" department (UNI_QUAL1) in the region or as the ratio of most productive and most cited departments with respect to the number of departments in doctorate-awarding universities in the region (UNI_QUAL2). ${ }^{9}$ Information on the total number of relevant departments in each region was retrieved from ministerial sources for Italy, Spain, France and Portugal, Wikipedia for Finland and Belgium; finally, we used an assessment of the CHE on the scientific performance of

Unfortunately the CHE ranking does not provide any classification for these disciplines, and for the time being we will use physics and mathematics as approximations of them.

${ }^{9}$ Simply speaking, the second measure of scientific eminence can be defined as

UNI_QUAL_R $=\sum_{(\mathrm{i})} \sum_{(\mathrm{j})} \operatorname{Exc} \_$dep $/ \sum_{(\mathrm{i})} \sum_{(\mathrm{j})} \operatorname{Dep}$

where the subscript $j$ indicates one of the four disciplines and the subscript $i$ one of the two criteria we account for (publications and citations). Exc dep indicates departments indicated as excellent, whereas Dep the departments in the region. 
doctorate-awarding German universities to retrieve the total number of departments per discipline in German regions. Table 2.1 shows the 10 regions hosting the largest number of scientifically eminent departments.

\subsubsection{Methods and Remaining Variables}

Having presented and discussed the limitations of the key variables of this study, we move ahead to present our empirical strategy. We implement a traditional knowledge-production function as introduced by Griliches (1972) and adapted by Jaffe (1989) to account for spatial units of observations, which relates innovative inputs to innovative outputs. By assuming a Cobb-Douglas form of production function, and taking into account the different sources of innovative inputs, our model reads as follows

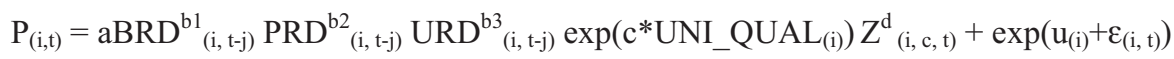

Applying a log-linear transformation to (1) we obtain

$$
\begin{aligned}
& \ln \left[\mathrm{P}_{(\mathrm{i}, \mathrm{t})}\right]=\ln \mathrm{a}+\mathrm{b} 1 \quad \ln \left[\mathrm{BRD}_{(\mathrm{i}, \mathrm{t}-\mathrm{j})}\right]+\mathrm{b} 2 \ln \left[\mathrm{PRD}_{(\mathrm{i}, \mathrm{t}-\mathrm{j})}\right]+\mathrm{b} 3 \quad \ln \left[\mathrm{URD}_{(\mathrm{i}, \mathrm{t}-\mathrm{j})}\right]+ \\
& \mathrm{c} \mathrm{UNI} \mathrm{QUAL} \\
& (\mathrm{i}) \\
& +\mathrm{d} \ln \left[\mathrm{Z}_{(\mathrm{i}, \mathrm{c}, \mathrm{t})}\right]+\mathrm{u}_{(\mathrm{i})}+\varepsilon_{(\mathrm{i}, \mathrm{t})}
\end{aligned}
$$

The subscripts $i, c, t$ and $j$ indicate respectively the 86 regions, the 7 countries, the 11 years and the lag with which innovative efforts are expected to translate in innovative outcomes. Regarding the lag, Anselin et al. (1997) for instance assume that R\&D expenditures immediately lead to inventive results. However, this can easily induce to endogeneous determinations of inputs and outputs. As a matter of fact, it is impossible to discriminate whether changes in successful innovations follow or precede changes in R\&D investments in the same year. To solve this problem of simultaneous occurrence of inputs and outputs, several studies in this strand have assumed a time lag of two years or more. Yet, the main reason for such a time lag is that the publication of patent applications takes from twelve to eighteen months after submission, which is the time patent officers need to verify the precondition for a patent to be granted. Nevertheless, in an attempt to characterize the lag structure between R\&D efforts and patenting at the firm level, Hall et al. (1986) have found that R\&D and patents are mostly concomitant since withinobservation variation of $\mathrm{R} \& \mathrm{D}$ is very small. These two views make us propend for setting $j$ at the lowest value possible to avoid simultaneity and to include the highest number of observations. We hence argue that a time lag of one year $(j=1)$ will be sufficient. A final methodological note is deemed for the variable UNI_QUAL. Our measure of scientific eminence of the universities is time invariant and concurrent with the time frame of the study.

Although this prevents us from running a panel regression with regional fixed effects to control for regional heterogeneity, there are reasons to expect that very little within-panel variability would emerge if we had time-variant measures of scientific eminence on short time spells. Furthermore, our right-hand variables do not show high variability over time; rendering fixed-effects panel estimates ineffective (see Table 2.3). We will get back to this issue soon. 


\begin{tabular}{|c|c|}
\hline Variable & Description \\
\hline $\mathrm{P}$ & $\begin{array}{l}\text { Number of patent applications at the European Patent Office (EPO) whose inventors reside } \\
\text { in the region } \\
\text { Workforce employed as R\&D personnel in the Business Sector measured as Full Time }\end{array}$ \\
\hline BRD & Equivalent (FTE) in the region \\
\hline PRD & $\begin{array}{l}\text { Workforce employed as R\&D personnel in the Public Sector - Higher Education excluded - } \\
\text { measured as Full Time Equivalent (FTE) in the region } \\
\text { Workforce employed as R\&D personnel in the Higher Education Sector measured as Full }\end{array}$ \\
\hline URD & $\begin{array}{l}\text { Time Equivalent (FTE) in the region } \\
\text { Dummy for the presence of departments that have contributed to at least } 50 \% \text { of all articles } \\
\text { published by European universities between } 1997 \text { and } 2007 \text { (Publication criterion) or that } \\
\text { have received more citations (excluding self-citations) than the average field-specific }\end{array}$ \\
\hline UNI_QUAL_1 & $\begin{array}{l}\text { international publication in Biology, Physics, Chemistry or Mathematics } \\
\text { Number of departments that have contributed to at least } 50 \% \text { of all articles published by } \\
\text { European universities between } 1997 \text { and } 2007 \text { (Publication criterion) or that have received } \\
\text { more citations (excluding self-citations) than the average field-specific international }\end{array}$ \\
\hline UNI_QUAL_2 & $\begin{array}{l}\text { publication in Biology, Physics, Chemistry or Mathematics divided by twice the number of } \\
\text { departments in the disciplines above in the region }\end{array}$ \\
\hline EMP & $\begin{array}{l}\text { Number of people employed in the region (in 1,000) } \\
\text { Sum of the squared shares of workforce in the regions in the following sectors: Agriculture } \\
\text { and Fishing; Industry except Construction; Construction; Wholesale and Retail trade, Hotels } \\
\text { and Restaurants, Transportation; Financial and Real Estate services: Public Administration }\end{array}$ \\
\hline HERF & and Community services. \\
\hline MANU & Share of regional workforce in Mining and Quarrying, Manufacturing and Energy \\
\hline
\end{tabular}

One of the advantages of using of a Cobb-Douglas production function is that the estimated coefficients are elasticities, hence indicating proportional changes in the output with respect to proportional changes in the factors of production. A positive value for $b 1, b 2$ and $b 3$ will enable us to assess the implications for innovation of different knowledge sources. In particular, $b 2$ and b3 might indicate the existence of useful knowledge transfer from public laboratories and academic laboratories to companies, being it technology transfer, consulting, contracted research, etc., and measure its magnitude. Most importantly for our analysis, a positive coefficient for $c$ will suggest an innovation premium for companies located in regions with scientifically eminent universities. $\mathrm{P}$ is the number of innovations introduced in the region. As an indicator of $\mathrm{R} \& \mathrm{D}$ efforts, we use the number of full time employees in R\&D. They are broken down by sector of performance, namely, the private sector (BRD), the public sector excluding higher education institutions (PRD) and higher education institutions (URD). ${ }^{10} \mathrm{R} \& \mathrm{D}$ data for Italy and France

${ }^{10}$ The reason to distinguish between public R\&D outside the academic system and public R\&D carried on in the academic system lies in the diverse organizations of the public research system in the countries under analysis. Until recently, a division of teaching and research existed in Western Europe between Universities and Public Research Organizations (PROs) such as CNRS in France, CNR in Italy, Max-Plank Institute in Germany, CSIS in 
were retrieved from the websites of the respective national bureaus of statistics, whereas corporate R\&D data for Germany were only available every second year; thus, we approximated missing observations by means of interpolation. Finally, data on R\&D personnel statistics are only available as of 2000 for Finland, Portugal whereas data for R\&D personnel in universities for Belgium is only available after 2002. ${ }^{11}$

$\mathrm{Z}$ is a vector of controls which includes other peculiarities of local economies that might drive higher innovative activities. In the first place, we introduce a control for the size of the regional economies. It is straightforward that larger economies innovate more in absolute terms; hence we include the number of regional workforce (EMP) to control for scale effects. Moreover, a vast literature in regional economics has proposed that economic activities external to the firm, yet internal to the economic system, are conducive to higher innovative activities. Two views have emerged. On the one hand, the concentration of similar economic activities generates positive externalities, labeled by Krugman (1991) as Marshal-Arrow-Romer externalities. On the other hand, according to Jacob (1969), positive externalities for innovation occur when pieces of knowledge from different sources are combined. To account for the implications of different industrial structures for innovation at the regional level, we introduce a measure of concentration of economic activities (HERF), being the Herfindahl concentration index based on the employment share of 6 industries. ${ }^{12}{ }^{13}$ We include the share of workforce in Industry (MANU) as crude approximation of the higher tendency of manufacturing activities to patent more than other sectors. Finally, a set of 10 time (T) and 6 country (C) dummies aim at controlling for macro trends in patenting across our sample. The former controls for the fact that, among other things like the introduction of the common currency in Europe and its implications for national budget policies, our time frame includes the years of the dot.com bubble which might have had a boost on patent applications. The latter, instead, would like to capture the diverse conditions and institutions that characterize innovation processes in different countries, such as inter-firms networks, financial and legal institutions, education and training systems, governance structures, innovation policies as stressed in the vast literature of national innovation systems (Lundvall, 1992).

Spain. Although European countries have embarked in a series of reforms that aimed at transforming existing PROs in funding agencies and transferring research duties - with equipment and personnel - to universities (Geuna, 2001), PROs are still active research players.

${ }^{11}$ We will touch upon this issue in some lines.

${ }^{12}$ The list of sectors is the following: Agriculture and Fishing; Industry except Construction; Construction; Wholesale and Retail trade, Hotels and Restaurants, Transportation; Financial and Real Estate services: Public Administration and Community services.

${ }^{13} \mathrm{We}$ are aware that the discussion on the relation between positive externalities and industrial structure requires a finer grained definition of sectors as the micro-mechanisms responsible for the externalities are expected to occur along the value chains of specific products. For instance Marshal has proposed that factors like the mobility of specialized workforce among different firms, the existence of specialized suppliers ease the flow of knowledge and hence the generation of positive externalities due to agglomeration economies. Unfortunately, however, these data are unavailable given the institutional breath of this study. 
Hence, the vector $\mathrm{Z}$ reads as

$$
Z_{(i, t)}=d 1 \operatorname{EMP}_{(i, t)} e^{d 2 H E R F}(i, t) e^{d 3 M A N U}(i, t) e^{f \Sigma T} e^{g \Sigma C}
$$

and its logarithmic transformation as

$$
\ln \left[Z_{(i, t)}\right]=d 1 \ln \left[\operatorname{EMP}_{(i, t)}\right]+\mathrm{d} 2 \operatorname{HERF}_{(\mathrm{i}, \mathrm{t})}+\mathrm{d} 3 \operatorname{MANU}_{(\mathrm{i}, \mathrm{t})}+\mathrm{f} \Sigma_{\mathrm{t}} \mathrm{T}_{\mathrm{t}}+\mathrm{g} \Sigma_{\mathrm{c}} \mathrm{C}_{\mathrm{c} \cdot} \cdot{ }^{14}
$$

The variables are presented in Table 2.2 whereas Table 2.3 describes them statistically. We regress (2) by Pooled Ordinary Least Squares (POLS), Random-Effects Generalized Least Squares (REGLS) and Least Squares Dummy Variable (LSDV). These three approaches differ mainly in their assumptions regarding the structure of the error term $\left(u_{(i)}+\varepsilon_{(i, t)}\right)$. The POLS assumes that the first component of the error term, $u_{(i)}$, can be constrained into one constant $u$, identical for every region, indicating the absence of unobserved regional characteristics. REGLS instead takes into account the unobserved regional characteristics and assumes that they are random and uncorrelated with the set of predictors in the model, i.e. $u_{(i)} \sim \operatorname{IID}\left(0, \sigma_{u}^{2}\right)$ (Green, 2008 , p.183). Yet, the assumption of independence from the set of predictors might not be tenable and this can well lead to biased estimates. In this case, the LSDV estimation of (2) will yield consistent estimates. As discussed above, however, the latter will eliminate not only the effects of the regional unobservables, but also those of all time-invariant covariates. In the next section we will first test for the existence of regional unobserved characteristics. Breusch and Pagan (1980) developed a Lagrange Multiplier test for the null hypothesis that $\sigma_{u}^{2}=0$. If we cannot reject the null hypothesis, then there will be no regional unobserved random effect and REGLS might be chosen instead. On the opposite, the existence of regional unobservables will lead us to the choice of REGLS. The LSDV estimates of (2) and the Hausman specification test for the null hypothesis that $u_{(i)}$ is orthogonal to the remaining set of predictors are presented. Concluding, the unbalanced nature of our panel can introduce biases in the estimation of the standard errors if data are not reported for reasons that are correlated with regional unobserved effects $u_{(i)}$. However, we do not expect this to be a problem in our case. In this panel, missing observations are systematic according to the country they belong to; we hence expect reasons for National Statistics Bureaus to not report R\&D data to EUROSTAT in same years for their regions to be uncorrelated with their patenting activities.

\subsection{Results}

Table 2.4 and table 2.5 report the POLS estimation results for 86 European regions observed between 1997 and 2007. The first column shows parameter estimates for the basic regional knowledge production function presented in equation (2). Specification (1) does not control for macro-economic effects and country effects.

\footnotetext{
${ }^{14}$ Obviously, we have augmented by 1 unit all variables that are transformed in logarithms, with the sole exception of EMP, which never takes the value of 0 .
} 
Table 2.3: Summary Statistics and Correlation Matrix

\begin{tabular}{|c|c|c|c|c|c|c|c|c|c|c|c|c|}
\hline & Variable & & Mean & S.D. & 1 & 2 & 3 & 4 & 5 & 6 & 7 & 8 \\
\hline \multirow[t]{2}{*}{1} & $\log (\mathrm{P})$ & overall & 4.533 & 1.851 & & & & & & & & \\
\hline & & between & & 1.836 & & & & & & & & \\
\hline \multirow[t]{2}{*}{2} & $\log (B R D)$ & overall & 7.766 & 1.745 & 0.913 & & & & & & & \\
\hline & & between & & 1.712 & & & & & & & & \\
\hline \multirow[t]{2}{*}{3} & $\log (\mathrm{PRD})$ & overall & 6.711 & 1.506 & 0.711 & 0.751 & & & & & & \\
\hline & & between & & 1.491 & & & & & & & & \\
\hline \multirow[t]{2}{*}{4} & $\log (\mathrm{URD})$ & overall & 7.647 & 1.282 & 0.684 & 0.743 & 0.816 & & & & & \\
\hline & & between & & 1.218 & & & & & & & & \\
\hline \multirow[t]{2}{*}{5} & UNI_QUAL_1 & overall & .406 & .491 & 0.544 & 0.531 & 0.520 & 0.508 & & & & \\
\hline & & between & & .494 & & & & & & & & \\
\hline \multirow[t]{2}{*}{6} & UNI_QUAL_2 & overall & .079 & .128 & 0.488 & 0.467 & 0.486 & 0.432 & 0.741 & & & \\
\hline & & between & & .128 & & & & & & & & \\
\hline \multirow[t]{2}{*}{7} & $\log (\mathrm{EMP})$ & overall & 13.699 & .918 & 0.767 & 0.807 & 0.836 & 0.865 & 0.561 & 0.462 & & \\
\hline & & between & & .920 & & & & & & & & \\
\hline \multirow[t]{2}{*}{8} & MANU & overall & .187 & .061 & 0.287 & 0.255 & -0.101 & 0.065 & 0.603 & -0.041 & 0.124 & \\
\hline & & between & & .060 & & & & & & & & \\
\hline \multirow[t]{2}{*}{9} & HERF & overall & .227 & .018 & 0.291 & 0.2177 & 0.245 & 0.183 & 0.231 & 0.287 & 0.144 & -0.431 \\
\hline & & between & & .018 & & & & & & & & \\
\hline
\end{tabular}

Specification (2) includes only the time dummies whereas specification (3) controls only for deviations from the average national patenting performance (country dummies). Finally specification (4) includes both macro effects - time and space. A first look at the measure of goodness-of-fit is quite explicative in assessing the different impacts of the two macro-effects listed above. The covariates related to the regional peculiarities of the innovative process account for $87.5 \%$ of the total variability. The inclusion of time effects augments the portion of variance to $88.2 \%$. The model has better fit when we control for country dummies: $94.8 \%$. Adding time dummies to country dummies only slightly improves the predicting power of the model (95.4\%). Table 2.6 and 2.7 present the results for the REGLS and, for exposure, the FE estimations. Like in previous tables, the explanatory power of the model is the highest when we control for both macro-economic effects. The Lagrange Multiplier test confirms the existence of regional unobserved heterogeneity; yet, the Hausman specification test rejects the hypothesis of strict erogeneity of the latter from the set of predictors. Our estimations are expected to be biased, and the FE estimates reported in columns (9) and (10) give a lower bound of the magnitude of the coefficients. Nevertheless, we hereby describe the findings from the REGLS. 
Table 2.4: Pooled OLS Regressions (UNI_QUAL_1)

\begin{tabular}{lcccc}
\hline Dep. Var: Log P & $(1)$ & $(2)$ & $(3)$ & $(4)$ \\
\hline Log BRD(-1) & $0.67^{* * *}$ & $0.662^{* * *}$ & $0.457^{* * *}$ & $0.439^{* * *}$ \\
& $(0.099)$ & $(0.101)$ & $(0.060)$ & $(0.061)$ \\
Log PRD(-1) & $0.161^{* *}$ & $0.179^{* *}$ & 0.009 & 0.037 \\
& $(0.078)$ & $(0.079)$ & $(0.049)$ & $(0.052)$ \\
Log URD(-1) & $-0.194^{* * *}$ & $-0.228^{* * *}$ & -0.065 & $-0.107^{*}$ \\
& $(-0.066)$ & $(-0.067)$ & $(-0.061)$ & $(-0.063)$ \\
UNI_QUAL_1 & 0.111 & 0.117 & $0.281^{* * *}$ & $0.281^{* * *}$ \\
& $(0.154)$ & $(0.154)$ & $(0.091)$ & $(0.091)$ \\
Log EMP & $0.407^{* *}$ & $0.434^{* *}$ & $0.633^{* * *}$ & $0.666^{* * *}$ \\
& $(0.188)$ & $(0.191)$ & $(0.118)$ & $(0.123)$ \\
MANU & $6.303^{* * *}$ & $6.388^{* * *}$ & $4.869^{* * *}$ & $5.277^{* * *}$ \\
& $(1.377)$ & $(1.437)$ & $(0.875)$ & $(0.898)$ \\
HERF & $20.148^{* * *}$ & $19.893^{* * *}$ & $8.79^{* * *}$ & $9.171^{* * *}$ \\
& $(3.457)$ & $(3.562)$ & $(2.410)$ & $(2.424)$ \\
Constant & $-11.624^{* * *}$ & $-12.246^{* * *}$ & $-9.9143^{* * *}$ & $-10.587^{* * *}$ \\
& $(-2.011)$ & $(-2.041)$ & $(-1.114)$ & $(-1.116)$ \\
\hline LR Tests: & - & $58.92^{* * *}$ & $750.88^{* * *}$ & $870.79^{* * *}$ \\
Year & No & Yes & No & Yes \\
Country & No & No & Yes & Yes \\
\hline R-squared & 0.875 & 0.882 & 0.948 & 0.954 \\
N & 850 & 850 & 850 & 850 \\
\hline
\end{tabular}

NOTE: *, ** and *** indicate respectively $10 \%, 5 \%$ and $1 \%$ significance levels. Standard errors reported in absolute values below the estimated coefficients. Standard errors are corrected for heteroskestasticity and clustered for regions.

When we look at the coefficients of the covariates across all tables, we observe that personnel employed in corporate research activities is a necessary prerequisite for achieving higher innovative performance. The coefficient ranges between 0.67 in specification (1) table 4, when no time or country control is included in POLS, to 0.177 in specification (8) in table 5, when we use a finer measure of university quality and both time and country dummies in REGLS. Hence, a 10\% increase in R\&D personnel in the private sector at the average results in almost $2 \%$ increase in innovative activities in the region. The impact of R\&D personnel in the business sector on regional innovation has much stronger effects than R\&D personnel employed in public laboratories. This result is not surprising as $R \& D$ personnel in the public sector does not work on problems of immediate industrial applicability and conducts other activities than just research (e.g. teaching for personnel in the Higher Education Sector). ${ }^{15}$

${ }^{15}$ In universities, scientists, when free from teaching duties, are mostly driven by their curiosity in setting priorities in their research agendas: science has priority over commercialization. Moreover, the incentives for innovators are significantly determined by peer recognition and career awards such as tenure rather than by monetary rewards (Merton, 1973). The corporate scientist, in contrast, is hired for the explicit purpose of generating knowledge with a commercialization potential, either direct or indirect, for the firm (Cohen and Levinthal, 1990). 
Table 2.5: Pooled OLS Regressions (UNI_QUAL_2)

\begin{tabular}{|c|c|c|c|c|}
\hline \multirow[t]{2}{*}{ Dep. Var: Log P } & \multicolumn{4}{|c|}{ Specifications } \\
\hline & (5) & (6) & (7) & (8) \\
\hline \multirow[t]{2}{*}{$\log B R D(-1)$} & $0.643 * * *$ & $0.64 * * *$ & $0.407 * * *$ & $0.396^{* * *}$ \\
\hline & $(0.103)$ & $(0.104)$ & $(0.066)$ & $(0.067)$ \\
\hline \multirow[t]{2}{*}{ Log PRD(-1) } & $0.152 *$ & $0.17 * *$ & 0.022 & 0.048 \\
\hline & $(0.082)$ & $(0.084)$ & $0.049)$ & $(0.052)$ \\
\hline \multirow[t]{2}{*}{ Log URD(-1) } & -0.119 & -0.164 & 0.034 & -0.018 \\
\hline & $(-0.099)$ & $(-0.108)$ & $(0.071)$ & $(-0.080)$ \\
\hline \multirow[t]{2}{*}{ UNI_QUAL_2 } & 0.496 & 0.517 & $0.696^{* *}$ & $0.708^{* *}$ \\
\hline & $(0.377)$ & $(0.376)$ & $(0.292)$ & $(0.288)$ \\
\hline \multirow[t]{2}{*}{ Log EMP } & $0.402 * *$ & $0.432 * *$ & $0.649 * * *$ & $0.682 * * *$ \\
\hline & $(0.181)$ & $(0.185)$ & $(0.120)$ & $(0.125)$ \\
\hline \multirow[t]{2}{*}{ MANU } & $6.686 * * *$ & $6.687 * * *$ & $5.719 * * *$ & $6.029 * * *$ \\
\hline & $(1.371)$ & $(1.426)$ & $(0.913)$ & $(0.947)$ \\
\hline \multirow[t]{2}{*}{ HERF } & $20.284^{* * *}$ & $19.892 * * *$ & $9.519 * * *$ & $9.802 * * *$ \\
\hline & (3.402) & (3.494) & $(2.433)$ & $(2.444)$ \\
\hline \multirow[t]{2}{*}{ Constant } & $-11.954 * * *$ & $-11.942 * * *$ & $-10.741 * * *$ & $-11.195^{* * *}$ \\
\hline & $(-1.889)$ & $(-1.923)$ & $(-1.073)$ & $(-1.093)$ \\
\hline LR Tests: & - & $54.26 * * *$ & $746.97 * * *$ & $852.38^{* * *}$ \\
\hline Year & No & Yes & No & Yes \\
\hline Country & No & No & Yes & Yes \\
\hline R-squared & 0.874 & 0.881 & 0.948 & 0.954 \\
\hline $\mathrm{N}$ & 850 & 850 & 850 & 850 \\
\hline
\end{tabular}

NOTE: *, ** and *** indicate respectively $10 \%, 5 \%$ and $1 \%$ significance levels. Standard errors reported in absolute values below the estimated coefficients. Standard errors are corrected for heteroskestasticity and clustered for regions.

The elasticities for personnel working in national research institutes are positive, yet nonsignificant. It might well be that national research centers undertake research venues which are relevant from a societal perspective, but still at an embryonic stage to deliver outcomes close to being commercialized. We notice an interesting result for academic R\&D personnel. In the the eight specifications in table 2.6 and 2.7, the coefficient ranges between negative and significant to positive and statistically relevant values, yet all around 0 . We can detect some regularities in this behavior. Its values are systematically higher when we measure scientific eminence as the ratio of high-quality departments over the total number of departments in the region (UNI_QUAL_2); however, its values decrease when we control for macro-economic effects in the regressions (time dummies). The very low coefficient is not new in the literature, as we are estimating a knowledge production function at such aggregate level, both geographically and technologically (Jaffe, 1989, p. 963). It must be stated that the measures of academic R\&D are referring to the effect of "size", as we include also indicators of its quality. If the scientific eminence of local universities eases the transformation of academic knowledge in innovations, we should expect a positive impact of measures of scientific quality of the academic R\&D on regional innovation performance. 
Table 2.6: Random-Effect GLS and Fixed Effect OLS Regressions (UNI_QUAL_1)

\begin{tabular}{|c|c|c|c|c|c|c|}
\hline \multirow[t]{3}{*}{ Dep. Var: Log P } & \multicolumn{6}{|c|}{ Specifications } \\
\hline & \multicolumn{4}{|c|}{ RE-GLS } & \multicolumn{2}{|c|}{ LSDV } \\
\hline & (1) & (2) & (3) & (4) & (9) & (10) \\
\hline \multirow[t]{2}{*}{$\log B R D(-1)$} & $0.278 * * *$ & $0.298 * * *$ & $0.278 * * *$ & $0.223 * * *$ & $0.116 * * *$ & $0.148 * * *$ \\
\hline & $(0.082)$ & $(0.079)$ & $(0.074)$ & $(0.067)$ & $(0.036)$ & $(0.033)$ \\
\hline \multirow[t]{2}{*}{ Log PRD(-1) } & 0.027 & 0.095 & -0.018 & 0.049 & 0.015 & $0.088^{* *}$ \\
\hline & $(0.067)$ & $(0.065)$ & $(0.040)$ & $(0.044)$ & $(0.049)$ & $(0.045)$ \\
\hline \multirow[t]{2}{*}{ Log URD(-1) } & 0.039 & $-0.038^{*}$ & 0.036 & $-0.051^{* *}$ & 0.024 & -0.045 \\
\hline & $(0.025)$ & $(0.023)$ & $(0.031)$ & $(0.024)$ & $(0.031)$ & $(0.029)$ \\
\hline \multirow[t]{2}{*}{ UNI_QUAL_1 } & $0.389^{*}$ & $0.415^{*}$ & $0.372 * * *$ & $0.415 * * *$ & & \\
\hline & $(0.225)$ & $(0.213)$ & $(0.111)$ & $(0.108)$ & & \\
\hline \multirow[t]{2}{*}{ Log EMP } & $0.889 * * *$ & $0.816^{* * *}$ & $0.815 * * *$ & $0.863 * * *$ & $0.764 * * *$ & $0.476^{*}$ \\
\hline & $(0.224)$ & $(0.216)$ & $(0.151)$ & $(0.155)$ & $(0.290)$ & $(0.282)$ \\
\hline \multirow[t]{2}{*}{ MANU } & 1.93 & $3.593 * *$ & $3.229 * * *$ & $4.463 * * *$ & $-4.596 * * *$ & $-3.274 * *$ \\
\hline & $(1.47)$ & -1.675 & $(0.898)$ & -1.033 & -1.260 & $(1.37)$ \\
\hline \multirow[t]{2}{*}{ HERF } & $10.833 * * *$ & $10.826^{* * *}$ & 4.39 & 3.934 & $5.662 *$ & 2.827 \\
\hline & -3.607 & -3.253 & -2.797 & -2.591 & -3.214 & -3.156 \\
\hline \multirow[t]{2}{*}{ Constant } & $-13.262 * *$ & $-12.973 * *$ & $-12.447 * * *$ & $-12.959 * * *$ & $-7.55^{*}$ & -3.775 \\
\hline & $(-2.499)$ & $(-2.344)$ & $(-1.714)$ & $(-1.641)$ & $(-4.117)$ & $(-4.091)$ \\
\hline Year Dummies (10) & No & Yes & No & Yes & No & Yes \\
\hline Country Dummies (6) & No & No & Yes & Yes & No & No \\
\hline \multicolumn{7}{|l|}{ Tests: } \\
\hline BreuschPagan LM $\chi^{2}(1)$ & $1846.75 * * *$ & $2109.06 * * *$ & $772.58 * * *$ & $1073.47 * * *$ & & \\
\hline Hausman $\chi^{2}(6)$ & $162.93^{* * *}$ & & & & & \\
\hline Hausman $\chi^{2}(16)$ & & $226.03 * * *$ & & & & \\
\hline R-squared & 0.792 & 0.825 & 0.938 & 0.946 & 0.976 & 0.982 \\
\hline $\mathrm{N}$ & 850 & 850 & 850 & 850 & 850 & 850 \\
\hline
\end{tabular}

NOTE: $*, * *$ and $* * *$ indicate respectively $10 \%, 5 \%$ and $1 \%$ significance levels. Standard errors reported in absolute values below the estimated coefficients. Standard errors are corrected for heteroskestasticity and clustered around region

Scientific eminence, as we approximate it, shows to be positively associated with higher patenting. The coefficients of the measures of scientific eminence here proposed show a positive relation with innovative activities, and this is only partly mitigated by accounting for country fixed effects in specification (7) and (8). This indicates that companies located in regions hosting top universities consistently innovate more and this consistency in higher innovative performance is rather uniform across different national systems of innovations. Accordingly, a standard deviation change in the number of excellent scientific departments translates in $1.5 \%$ more patents. Hence, it is the scientific productivity and the qualities of this output at European universities that enable companies enjoy the results of science. Notwithstanding the relevance of academic knowledge for corporate innovations, the magnitude of the coefficient (remember that a standard deviation is 1.6 times larger than the average) suggests that there is still a long way to go to exploit the full innovative potential of European universities. 
Table 2.7: Random-Effect GLS and Fixed Effect OLS Regressions (UNI_QUAL_2)

\begin{tabular}{|c|c|c|c|c|c|c|}
\hline \multirow[t]{3}{*}{ Dep. Var: Log P } & \multicolumn{6}{|c|}{ Specifications } \\
\hline & \multicolumn{4}{|c|}{ RE-GLS } & \multicolumn{2}{|c|}{ LSDV } \\
\hline & (5) & (6) & (7) & (8) & (9) & (10) \\
\hline \multirow[t]{2}{*}{$\log B R D(-1)$} & $0.243 * * *$ & $0.264 * * *$ & $0.231 * * *$ & $0.177^{* *}$ & $0.116^{* * *}$ & $0.148 * * *$ \\
\hline & $(0.079)$ & $(0.077)$ & $(0.072)$ & $(0.063)$ & $(0.036)$ & $(0.033)$ \\
\hline \multirow[t]{2}{*}{ Log PRD(-1) } & 0.001 & 0.079 & -0.024 & 0.048 & 0.015 & $0.088^{* *}$ \\
\hline & $(0.073)$ & $(0.073)$ & $(0.044)$ & $(0.050)$ & $(0.049)$ & $(0.045)$ \\
\hline \multirow[t]{2}{*}{ Log URD(-1) } & $0.062 * *$ & -0.027 & $0.077 * * *$ & -0.031 & 0.024 & -0.045 \\
\hline & $(0.029)$ & $(0.034)$ & $(0.029)$ & $(0.033)$ & $(0.031)$ & $(0.029)$ \\
\hline \multirow[t]{2}{*}{ UNI_QUAL_2 } & $1.639 * *$ & $1.718 * * *$ & $1.014 * * *$ & $1.214 * * *$ & & \\
\hline & $(0.653)$ & $(0.613)$ & $(0.368)$ & $(0.371)$ & & \\
\hline \multirow[t]{2}{*}{ Log EMP } & $1.018 * * *$ & $0.937 * * *$ & $0.948 * * *$ & $1.008 * * *$ & $0.764 * * *$ & $0.476^{*}$ \\
\hline & $(0.211)$ & $(0.207)$ & $(0.149)$ & $(0.149)$ & $(0.290)$ & $(0.282)$ \\
\hline \multirow[t]{2}{*}{ MANU } & 2.036 & $3.809^{* *}$ & $3.644 * *$ & $4.831 * * *$ & $-4.596 * * *$ & $-3.274 * *$ \\
\hline & -1.486 & -1.721 & $(0.941)$ & -1.125 & -1.260 & $(1.37)$ \\
\hline \multirow[t]{2}{*}{ HERF } & $10.312 * * *$ & $10.081 * * *$ & 4.592 & 3.607 & $5.662 *$ & 2.827 \\
\hline & -3.683 & -3.259 & -2.882 & -2.674 & -3.214 & -3.156 \\
\hline \multirow[t]{2}{*}{ Constant } & $-14.645^{* *}$ & $-13.659 * *$ & $-14.33 * * *$ & $-14.74 * * *$ & $-7.55^{*}$ & -3.775 \\
\hline & $(-2.305)$ & $(-2.202)$ & $(-1.618)$ & $(-1.57)$ & $(-4.117)$ & $(-4.091)$ \\
\hline Year Dummies (10) & No & Yes & No & Yes & No & Yes \\
\hline Country Dummies (6) & No & No & Yes & Yes & No & No \\
\hline \multicolumn{7}{|l|}{ Tests: } \\
\hline BreuschPagan LM $\chi^{2}(1)$ & $1915.02 * * *$ & $2150.93 * * *$ & $871.63 * * *$ & $1169.29 * * *$ & & \\
\hline Hausman $\chi^{2}(6)$ & $142.95 * * *$ & & & & & \\
\hline Hausman $\chi^{2}(16)$ & & $284.44 * * *$ & & & & \\
\hline R-squared & 0.787 & 0.821 & 0.937 & 0.943 & 0.976 & 0.982 \\
\hline $\mathrm{N}$ & 850 & 850 & 850 & 850 & 850 & 850 \\
\hline
\end{tabular}

NOTE: $*, * *$ and $* * *$ indicate respectively $10 \%, 5 \%$ and $1 \%$ significance levels. Standard errors reported in absolute values below the estimated coefficients. Standard errors are corrected for heteroskestasticity and clustered around region

Our control for scale effects in the production of patents, employment, has an elasticity of about 1. Regions with higher concentrations of manufacturing activities experience higher innovative outputs, as expected: a $1 \%$ increase of the share of workforce in the manufacturing sector (from $18.9 \%$ to $19.9 \%$ ) is related to around $4.5 \%$ more patent applications in the region. However, the FE estimates, unlike for the previous findings, suggests a negative relationship between changes in the manufacturing workforce and patenting. The latter might indicate that a process of de-industrialization is happening in regions which still preserve strong innovative capabilities. Concluding, regions characterized by diversified economic activities do not benefit from Jacobian externalities when we benchmark their patenting activity to the national one. ${ }^{16}$

${ }^{16}$ As already mentioned in footnote 15 , it is very difficult to pinpoint the nature of different types of knowledge externalities given the broad aggregation we use. Notwithstanding these limitations, we include a series of factors that should rather capture other forms of agglomeration externalities such as the extent to which a region is 


\subsection{Conclusions}

The goal of this work is to address a relevant research question: which role does scientific eminence play in the production of innovations? The question stems for the mostly neglected evidence that scientific as well as policy interest in the role of academic knowledge has been driven by the anecdotic evidence of a handful of highly innovative industrial clusters in the U.S.A. hosting some of the most prolific universities worldwide.

The results are three-fold. First of all, unlike most of the previous evidence, we find that the sole presence of personnel in universities exerts no influence on the production of innovations. Rather, the scientific productivity of researchers and the visibility of their results - briefly, the quality of the research carried out at local universities - are crucial determinants for higher innovative performances. Besides the mere rationale that knowledge needs to be generated to be further exploited, intellectually vibrant universities attract talents in the form of students and faculty. The latter, then, are more likely to be targeted by companies as information brokers between them and the academic community. Finally, personnel in public research organizations have not direct implications for corporate patenting: public research organizations have the explicit goal of correcting market failures in the production of knowledge. Therefore, research carried out at public laboratories has no immediate industrial relevance, but it rather responds to criteria of dynamic efficiencies (Adams, 1990). ${ }^{17}$

There are several elements of originality in this study. Firstly, it distinguishes between different magnitudes of academic knowledge spillovers according to their sources. Secondly, it explores the extent of academic knowledge spillovers across different institutional settings. The seven countries that comprise the study have different histories, different political backgrounds and different degrees of centrality in the European Union. For instance, Spain and Portugal have been under the control of conservative dictatorships until very recently, and, like Italy, are located at the geographical periphery of Europe. Germany, Belgium and France are at the center of the European common market and, like Italy, have been among the founders of it. Finland had lengthily been among the closest trading partners of the Soviet bloc. Germany, on the opposite, had to become one after the fall of the Berlin wall (through re-unification). The heterogeneity of the sample at hand renders the findings of the study rather "universal" in their implications.

These results have policy implications. National governments in Europe and the European Commission have acknowledged the economic importance of creating, supporting and protecting

specialized in manufacturing for M-A-R externalities and the employment of the region, which should approximate more general agglomeration externalities.

${ }^{17}$ Unrelated to the finding yet relevant for the discussion, public research organizations in most European countries have been partly transformed in funding agencies and their research duties transferred to universities. Nevertheless, they still employ a large fraction of the scientific manpower and control the most advanced laboratories. Although this has no relation with the insignificance of the results, it might be argued that the effects of public research organizations are partially captured by our coefficient of scientific quality as they are more likely to grant competitive funding to high-quality universities. 
a selected number of infrastructures for top level academic research. ${ }^{18}$ The RAE in the U.K. and the "Excellence Initiative" in Germany are just some of the initiatives in this direction. ${ }^{19}$ These initiatives have room to produce relevant economic impacts; yet, policy makers should be careful that leveraging only on the providers of scientific knowledge might not bear the expected results as we observed a very small effect of scientific eminence on innovations. ${ }^{20}$ Hence, these initiatives should go hand in hand with policies that promote a restructuring of the industrial base, the economic exploiters of scientific advancements.

Future extensions of the current work should tackle the implications of institutional heterogeneity of our units of observations. Spanish, German and Belgian regions for instance have direct responsibility of educational policies, and consequently more autonomy in terms of legislation and execution policies. Regions in other countries, instead, can only leverage on limited financial and legal resources to effectively produce any sensitive impact on the local higher educational system. In this respect, exploring the magnitude of the elasticity of mobility and consequent settlement of star scientists across academic systems (and especially nonmonetary incentives such as autonomy in managing research) might prove critical for local governments to have a rough account of the price to pay to improve the eminence of local academic universities and hopefully with it the ability of the local industry to have access to prime scientific knowledge.

${ }^{18}$ In Europe the system of government structural funds has been partially replaced by a more competitive manner of financing the public research system: indeed, since the late 1980s, the subvention of universities has relied more and more on problem-oriented and industry-oriented public programs rather than on public budgetary channels. This switch in sources of funds could be considered as the result of the shrinking of the public research budgets and the change in the rationale for science support occurred in Europe (Geuna, 2001).

${ }^{19}$ The French Presidency of the European Union for the fall semester of 2008 promoted two conferences, held in Strasbourg and Nice between September and November 2008, with the express goal of joining together experts and national representatives to discuss best practices in research evaluation. The two events were preceded by the creation of a standardized European register for quality assessment agencies in Brussels in March 2008.

20 "Expected results" refers to the great hope that policy makers have posited in Public Research for growth. See Section 4.2 of this document for a quick overview of recent policy initiatives and their rationale. 


\section{The Contribution of Universities to Growth: Empirical Evidence for Italy}

\subsection{Introduction}

How does knowledge spur economic growth? The theories of endogenous growth use the informational characteristics of knowledge as introduced by Arrow (1962) to explain endogenous growth trajectories (Romer, 1986; Lucas, 1988). According to these theories, it is the generation of knowledge that spurs growth and such knowledge is partially appropriable as it spills over into the hands of third parties that in turn use it to generate new knowledge and useful ideas.

Although endogenous growth theories have predicted general patterns of growth, they fail in explaining the several "paradoxes" that are currently crowding decision-makers' agendas. In fact, some scholars have contended that it is not investment in knowledge per se that spurs growth and thus competitiveness; rather, the critical facet of the economic relevance of knowledge is the commercialization of the results that knowledge produces (Acs et al., 2009; Audretsch and Keilbach, 2008; Braunerhjelm et al., 2010). These authors posit the existence of a "knowledge filter" between investment in new knowledge and its economic exploitation. Such a filter results from the inherent peculiarities of knowledge, as opposed to information itself. Knowledge generating activities produce uncertain economic results that are associated with high degrees of asymmetries between inventors and potential exploiters. High uncertainty and high asymmetries result in high transaction costs among economic agents (Audretsch, 2007).

These characteristics become even more evident when knowledge is generated in academic laboratories. A strand of literature in the sociology and economics of science fields stresses that the incentive system in place within the academic community would rarely lead scientists to produce findings of immediate industrial application (Dasgupta and David, 1994; Merton, 1973; Stephan, 1996). The recent involvement of universities in technological development has in fact shown that whenever academic findings display potential technological applications, they are at an early stage of development and tend to serve a variety of industrial purposes (Colyvas et al., 2002; Jensen and Thursby, 2001; Piergiovanni and Santarelli, 2001).

In such a context, entrepreneurship is seen as the main mechanism that ensures both the flow of radical technological change into the economy and the economic exploitation of the knowledge (Audtretsch, 1995; Klepper and Sleeper, 2005; Schumpeter, 1934). Schumpeter (1934) was the first to identify a mechanism, that he named "creative destruction", through which new and independent ventures bear the main responsibilities in the process of economic growth

- This chapter is based on joint work with Martin Carree (Maastricht University) and Enrico Santarelli (Universitá di Bologna) and has circulated as 
through innovation. The main rationale underlying this argument is that large players would oversee promising ventures because of being locked into existing products and production processes (Christensen, 1997; Hill and Rothearmel, 2003; Spulber, 2010).

In this study we test the hypothesis that entrepreneurship represents an effective mechanism to transform academic knowledge into economic growth. Specifically, we evaluate three outputs of academic activities: teaching, research, and Intellectual Property Rights (IPR) activities management, along with the importance of new ventures to transform the mentioned outputs into improved economic performance. The analysis is carried out for the Italian provinces between 2001 and 2006.

The study is organized as follows: Section 3.2 presents the existing literature on the importance of academic activities for growth and the relevance of new ventures in appropriating and exploiting economically academic outputs; Section 3.3 introduces the estimation strategy and describes the variables used in this work; Section 3.4 presents and discusses the estimation results; and Section 3.5 summarizes the main results in the chapter.

\subsection{Universities, Entry and Growth}

\subsubsection{Universities and Economic Growth}

The role of modern higher education institutions (universities henceforth) in the economic performance of firms, sectors, regions and countries can be approached from different perspectives.

Modern universities evolved from the medieval model in which they served as repositories of knowledge and wisdom, with the preservation and transfer of existing knowledge as their main goal. They were organized like guilds, where masters taught small groups of students. Although in the late $18^{\text {th }}$ century their mission was extended to educate civil servants to fill the administrative ranks of the newly formed European states, it was not until the mid- $19^{\text {th }}$ century that universities embraced a second mandate of institutionalizing the pursuit of scientific research through rational inquiry and experimentation. Universities then became an important source of academically trained graduates and scientific knowledge to meet the needs of industrial sectors emerging from the second industrial revolution. The two activities of teaching and performing basic research have been complemented by the more recent entrepreneurial activities of universities. Universities are no longer only suppliers of knowledge-intensive outputs such as students and research papers as they also proactively engage in research collaborations with private parties through licensing, sponsored research and new venture creations (Etzkowitz and Leyersdorf, 1998). Whereas the first transition in universities saw the emergence of new organizational forms such as research laboratories, the latter transition is resulting in the creation of technology transfer offices, university-industry research centers and incubators.

Education is the oldest contribution of academic activities to economic growth. It is usually associated with the formation of higher levels of human capital, viz. the development and refinement of specific individual knowledge and capabilities. The increase in human capital 
enables individuals to perform higher value-added tasks more efficiently and quickly, which translates in higher productivity of labour and capital (Becker, 1964; Barro, 1991; Lucas, 1988). Moreover, students may act as important channels through which knowledge is transmitted to the industry. For instance, several studies (including Nelson and Wright, 1992; Murnmann, 2003) show that students represent a critical conduit of the latest techniques and theoretical know-how from academic laboratories to the corporate ones in the chemical, mining and pharmaceutical industries. Also in the case of biotechnology, firm performance has been driven by the supply of highly skilled graduates in life sciences, as opposed to direct Research and Development (R\&D) expenditures, which has eased both the adoption of new process technologies and the commercialization of new products (Patel et al., 2006). Finally, and more remarkable for the purpose of the present study, the share of adult population with tertiary education has been shown by Sterlacchini (2008) to be the most effective factor enhancing the growth of GDP per capita recorded during the period 1995-2002 in the regions belonging to twelve EU countries.

Universities are also the most prominent producers of fundamental knowledge, which has been argued to be one of the main drivers of economic growth. The theories of endogenous growth built upon the informational characteristics of knowledge as introduced by Arrow (1962) suggest that the generation of knowledge would enhance the production of more efficient processes and products and hence spur growth (Romer, 1986, 1990). However, scholars in the economics of technical change field have long focused their attention only on R\&D activities performed in corporate laboratories to explain technology-driven growth. Indeed, knowledge produced in academic laboratories is of a somewhat different nature than corporate R\&D. Academic scientists pursue research goals that are informed by their personal curiosity and by the reward system in the academic community which is based on peer recognition rather than on monetary compensations (Merton, 1973). Hence it is not surprising that academic findings rarely have immediate industrial applications. Rather, they expand the theoretical pool of knowledge upon which technical advances of commercial value can be built (Fleming and Sorenson, 2004).

Adams (1990) shows that between 1949 and 1983 it took around 20 years for scientific advancements to be absorbed and exploited by industries and ultimately lead to productivity growth. The time lag of academic knowledge to result in economic gains has shortened in the last three decades. Three stylized facts highlight this convergence between science and technology: a) the higher productivity of corporate R\&D led by the increasing pervasiveness of scientific approaches in corporate $\mathrm{R} \& \mathrm{D}$ as opposed to trial-and-error methods (Arora and Gambardella, 1994); b) the rise of new science-based sectors in which the innovation process depends mostly on developments arising from academic R\&D, i.e. ICT and biotechnology, as key sectors in industrialized countries (Orsenigo, 2003; Zucker et al, 1998a; Pisano, 2006); and c) the increasing involvement of universities in commercialization activities such as sponsored research, technology licensing and equity positions in academic spinoffs (Shane, 2004; Henderson et al., 1998; Fini et al., 2009). Yet, the interest in the role of academic R\&D as driver of growth drew largely on the examples of ICT and biotech in California and Massachusetts, which host some of the most prolific scientific universities worldwide (Saxenian, 1994). 
The link between the quality of research outputs and the likelihood of generating technologically useful knowledge has received empirical support from a burgeoning body of literature in the field of technology transfer. Highly productive scientists engage in technological developments: they manage contractual agreements with industrial partners, engage in consulting relationships and fund companies (Agarwal and Henderson, 2002; Azoulay et al., 2009; Zucker et al., 1998b). Despite academic quality, university policies supporting commercialization activities seem to play a role. Faculty in universities that openly oppose any involvement in commercialization activities might exert little if any influence on the transfer of academic knowledge (Owen-Smith and Powell, 2001; Feldman and Desroches, 2003). Feldman and Desroches (2003) provide a detailed case of how the reluctance to allow commercial interests to influence faculty research agendas at the John Hopkins University, despite its scientific eminence, slowed down the emergence of a high-technology cluster in the Baltimore area.

\subsubsection{Entry, Knowledge and (Regional) Growth}

From an economic standpoint, the rate of new entry and entrepreneurial dynamics of markets have gained attention and importance in the last couple of decades ${ }^{21}$. Steady flows of new businesses add new capacities to the market and thereby represent a key source of economic growth. The dynamic consequences of high birth rates are not univocal: large numbers of new comers leave the market immediately after start-up but are also associated with the exit of older incumbents. Besides the direct effects of entry on growth, indirect effects from the supply-side can take place. High entry rates, by contesting established markets, force incumbents to make efficient use of resources (Baumol et al., 1988), limit the effectiveness of anticompetitive behaviours and foster incumbents' innovativeness (Geroski and Jaquemin, 1984). Moreover, new entrants have been found to be a major mechanism of new markets creation through the commercialization of radical innovations (Audretsch, 1995; Prusa and Schmitz, 1991). Accordingly, new ventures seem to be fitter than incumbents in exploiting knowledge which is characterized by high uncertainty and high information asymmetries.

Acs et al. (2009) propose a theoretical framework to account for the ability of new entrants to exploit radical knowledge developed elsewhere (i.e. large companies and research institutes) and transform it into economic growth. The authors posit the existence of a knowledge filter, which hampers the commercial exploitation of the full set of knowledge developed in research laboratories. The authors analyze the context of knowledge from corporate laboratories finding that, given the existence of sunk investments such as dedicated human capital, physical capital and vertical relationships, incumbents often neglect new opportunities as they are unwilling to face the risk of implementing new products or processes. Moreover, companies can rarely rely upon alternative mechanisms to compensate for the underexploited knowledge, such as markets for technologies. Transaction costs are inherently high when the technology to be traded is

21 See Thurik and Carree (2003) for a review of the determinants of the renewed economic interest in entrepreneurship. 
characterized by uncertainty about economic results and information asymmetries between the parties involved in the transaction (Arora and Gambardella, 2010). Yet, entrepreneurs, often former employees of incumbent firms, are expected to have lower opportunity costs and higher expectations about returns from commercialization of new knowledge than incumbent firms themselves ${ }^{22}$. Hence they are more prone to start up new companies to commercialize the new knowledge that the latter have created.

Academic knowledge shares most of the economic features of radical knowledge from corporate laboratories in that its applications are far from evident. According to the existing literature in the economics and management of technology transfer field, technologies created by academics are mainly at an early stage of development, general in purpose, characterized by high uncertainty about their actual applications and demand further development efforts from the buyers and inventors to be commercialized (Colyvas et al., 2002; Jensen and Thursby, 2001; Jensen et al., 2003). Although incumbents might possess the necessary capacity to absorb external knowledge (Cohen and Levinthal, 1990), idiosyncratic investments can restrict the range of acquirable knowledge. Hence, the same mechanisms that bring incumbents to oversee radical opportunities from corporate laboratories are expected to lead to underexploited academic knowledge. Evidence on the critical role of new ventures in exploiting radical academic technologies is supported by the early evolution of the electronics and biotechnology industries (Bania et al., 1993; Zucker et al. 1998a).

\subsubsection{The Italian case}

Regions may constitute a very useful unit of analysis for investigating the impact of the presence of university outputs and the rate of new entry of firms. The first can be seen as a measure for the 'academic climate' and the latter as a measure for the 'entrepreneurial climate'. We are interested whether one of the two or both simultaneously are important to promote economic growth. In this study we focus on Italian provinces, a sub-regional level of government introduced by Article 114 of the Italian constitution with statutory, regulatory and administrative competences, but not entitled to approve statutes or laws. There are in total 77 universities in 49 provinces in Italy. That means that slightly less than half of the Italian provinces have a university. The choice of this territorial unit of analysis is mostly driven by the availability of the data. Yet, it can provide useful perspectives for assessing the role played by entrepreneurship, new knowledge and other spatially bounded characteristics in enhancing local growth.

Two arguments to defend our decision to focus on administrative provinces can be provided. First, by specifically addressing the issue of spatial autocorrelation, we are able to explain to what extent the neighbouring provinces might have an effect on growth in the focal province, therefore providing an indirect measure of the reasonableness of the use of this administrative spatial cluster as unit of analysis. Second, the majority of Italian provinces include

22 The laser industry, the disk drive industry and the tire industry experienced this kind of evolution (Klepper and Sleeper, 2005; Buensdorf and Klepper, 2009; Agarwal et al., 2004). 
the capital city of the corresponding administrative region and these capitals are relatively large cities with the surrounding towns closely connected to that city for economic, social, cultural, and spatial reasons. As recently shown in a study performed for the European Commission (Europe Innova, 2010), the largest concentrations of entrepreneurial activities with favorable perspectives of growth in Europe are major urban areas, which attract the most talented workers.

\subsection{Estimation Strategy: Methods, Data and Variables}

\subsubsection{Methods}

In order to test the hypothesis that newly established ventures are critical in the conversion of academic knowledge into economic growth, we propose the following models that we estimate for 99 Italian provinces (NUTS3) ${ }^{23}$, indexed by $i$, between 2001 and 2006 (index $t$ ):

$$
\operatorname{Growth}_{(i, t)}=\mathrm{a}+\mathrm{b} \operatorname{Entry}_{(i, t)}+\mathrm{c} \text { University }_{(i, t-k)}+\mathrm{d} \operatorname{Entry}_{(i, t)} * \operatorname{University}_{(i, t-k)}+\mathrm{fZ}_{(i, t-1)}+\varepsilon_{(i, t)}
$$

We model growth in the province as a function of business entry in the same year and of the set of academic outputs described in Section 2. The measures of business entry and academic outputs are interacted to capture the contribution to growth of new ventures via the exploitation of the academic knowledge-base in the province. The set of variables $\mathrm{Z}$ controls for additional factors that can contribute to economic growth and will be detailed later in this section. Measures of university outputs are lagged by $k$ years. The value of $k$ varies according to the type of activity (details in section 3.2).

The treatment of units of analysis with spatial attributes presents some estimation challenges (Anselin, 1988; Glaeser and Kerr, 2009). Traditional linear estimation techniques might lead to inefficient and biased estimations as they do not take into account that observations can be spatially dependent and hence their assumptions not always satisfied. A strand of literature in spatial econometrics has proposed two classes of models as solutions for this problem: Spatial Error Models (SEM) and Spatial Autoregressive Models (SAR). SEM correct for the violation of uncorrelated error terms across observation and are indicative of the omission of spatially dependent covariates. If not treated, OLS would produce inefficient estimates. SEM models extend the equation to be estimated by decomposing the error term into one component that is spatially independent and another component that accounts for spatially dependent unobservables. SAR instead correct for both the violation of uncorrelated error terms and for the violation of the assumption of independent observations as SAR takes into account that economic activities in nearby regions can exert positive externalities. To account for these effects, SAR models include a spatially weighted measure of the dependent variable among the regressors.

23 Due to a substantial reorganization of the provinces located in Sardinia, we have excluded the provinces located in the region. Hence, we are left with 99 provinces which represent the remaining 19 Italian regions in 2001. There are 75 universities in 47 out of 99 provinces. Note that the number or provinces has slowly but steadily increased in the last decades. The number in 2011 is already 110. 
So, following Elhorst (2003), we extend the model (1) to account for spatial interdependence and additionally estimate the following two models:

$$
\begin{aligned}
& \operatorname{Growth}_{(i, t)}=\mathrm{a}+\mathrm{b} \operatorname{Entry}_{(i, t)}+\mathrm{c} \text { University }_{(i, t-k)}+\mathrm{d}_{\text {Entry }_{(i, t)}} * \operatorname{University}_{(i, t-k)}+\mathrm{fZ}_{(i, t-1)}+\mathrm{h} \mathrm{W} * \\
& \zeta_{(j, t)}+\mathrm{v}_{(i, t)}
\end{aligned}
$$

$$
\begin{aligned}
& \operatorname{Growth}_{(i, t)}=\mathrm{a}+\mathrm{b} \operatorname{Entry}_{(i, t)}+\mathrm{c} \text { University }_{(i, t-k)}+\mathrm{d}_{\text {Entry }_{(i, t)}} * \operatorname{University}_{(i, t-k)}+\mathrm{f} \mathrm{Z}_{(i, t-1)}+\mathrm{h} \\
& \mathrm{W}^{*} \operatorname{Growth}_{(j, t)}+\varepsilon_{(i, t)}
\end{aligned}
$$

where $\mathrm{W}$ is a 99x99 weighting matrix, which is calculated as 1 , if two provinces share a border, and 0 otherwise. Model (1) can be estimated using least squares techniques, while models (2) and (3) are estimated using maximum likelihood. Italian provinces may not suffer/benefit from strong spatial interdependence, because they have a capital city that is usually the main economic engine for the province and is in the majority of cases located in the center of the territory. In addition, we incorporate provincial dummies (fixed effects) into the models (1)-(3) which may take away commonalities in the error term or dependent variable of adjacent provinces. Nevertheless, we investigate the magnitude of the possible estimation bias due to spatial interdependence either in the error term or dependent variable.

\subsubsection{Data and Variables}

We employ two measures of economic growth. The first one is related to the so-called restricted industry (manufacturing, mining, and energy) in the province and is measured as the relative rate of growth of value added in the restricted industry:

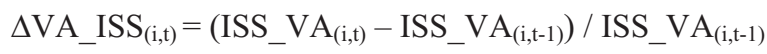

The second variable reflects the overall economic performance of a province and is calculated as the relative rate of growth of value added per province:

$$
\Delta \mathrm{VA}_{(\mathrm{i}, \mathrm{t})}=\left(\mathrm{VA}_{(\mathrm{i}, \mathrm{t})}-\mathrm{VA}_{(\mathrm{i}, \mathrm{t}-\mathrm{l})}\right) / \mathrm{VA}_{(\mathrm{i}, \mathrm{t}-\mathrm{l})}
$$

We measure entry rate differently for the two specifications. In the model for the restricted industry, we calculate entry as the gross number of new registrations in the manufacturing sector each year ( $t$ ranging between 2001 and 2006) per 1000 employees in the restricted industry in the province:

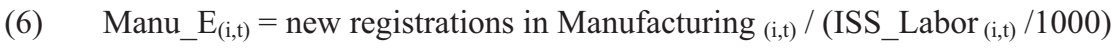

Entry in the model for the overall economy is calculated as the gross number of new registrations in the manufacturing sector and in the service sector per 1000 employees across all sectors in the province:

$$
\left.\mathrm{E}_{(\mathrm{i}, \mathrm{t})}=\text { new registrations in Manufacturing and Services }{ }_{(\mathrm{i}, \mathrm{t})} / \text { (Employment }_{(\mathrm{i}, \mathrm{t})} / 1000\right)
$$


The two specifications of gross rate of entry $\left(M a n u_{-} E_{(i, t)}\right.$ and $\left.E_{(i, t)}\right)$ are used to accommodate for the direct short-run impact of the entrepreneurial activities carried out in the province on economic growth. We also account for the share of new businesses in innovative industries to allow for potential growth premia stemming from high-technology initiatives, namely businesses driven by 'opportunity' rather than 'necessity'. The measures used are the share of high-tech manufacturing (High_Share) in the restricted industry specification and the share of high-tech manufacturing, knowledge-intensive services and technology-intensive services (Ki_Share) in the total growth specification. ${ }^{24}$ Information about entry in Italian provinces was retrieved from the database Movimprese, provided by UnionCamere, the Italian Association of Chambers of Commerce. It contains yearly new registrations and cancellations at each provincial Chamber of Commerce. Data are further organized per 2-digit NACE sector.

Three indicators of academic outputs are included in the analysis. First, we measure the educational mandate of universities (Students ${ }_{i, t-1}$ ) as the share of Science and Technology (S\&T) graduates at $t-1$ divided by the population in the province at $t-1$. We lag graduates by one year to account for the transition to the labour market. There are at least two effects of the presence of large teaching universities with respect to growth. Firstly, they signal the extent to which highquality human capital is present in the province. Yet, large portions of students per resident population can hamper economic growth as their spending power may be limited as compared to that of workers. Moreover, we interact Students with our measures of entry (Manu_E and E) to control for the ability of new ventures to exploit the economic potential of human capital embedded in university graduates. We do not expect the latter variable to have a sizeable influence on economic growth as new ventures may prefer to hire experienced workers to benefit from their social capital. Information on the number of students was retrieved from the statistical office of the Ministry of Higher Education and Research. ${ }^{25}$ It reports the number of graduates from each university, the faculty, the location of the teaching activities and whether the students attained vocational education. We retrieved data on graduates and assigned them to the location of the faculty which issued the degree, as during the last two decades a number of academic institutions have decentralized teaching activities towards adjacent provinces with the aim of meeting the local demand for education (Piergiovanni et al., 2011).

The second measure of academic output is related to scientific research $\left(\right.$ Publication $\left._{i, t-2}\right)$. It is constructed as the number of internationally recognized scientific productions in Science and Technology fields at $t-1$ divided by the number of graduates at $t-2$. The lags are chosen to reflect that it may take one year for scientific papers to be published. We use the number of graduates in Science and Technology as benchmark because personnel in universities is mostly hired according to teaching needs; hence, Publications provides an indirect measure of the intensity of the scientific activities at Italian universities. Moreover, the scientific productivity of the academic personnel may represent a crude proxy for the quality of the knowledge produced in

24 We follow the sectors aggregation used by EUROSTAT. Although four classifications are proposed high, medium high, medium-low and low tech - we grouped the first two in high-tech and the remaining in low-tech.

25 www.mur-statistica.it 
academic laboratories. Due to data constrains, we cannot use longer lags than two years, as statistics for graduates are available only as from 1998 on. The implications for growth are not so clear. Scientific productivity has been found to be a good predictor of technological solutions as theoretical advancements might either improve existing technologies or require new ones to tackle new scientific challenges (Fleming and Sorenson, 2004; Franzoni, 2007). Yet, empirical evidence points at longer time frames than two years to appreciate the impact of scientific knowledge on productivity gains (Adams, 1990). For academic knowledge to translate in economic growth it needs to be brought to the marketplace. We hence interact Publications and market entry to control for the diffusion of scientific knowledge via new ventures. We expect new ventures to introduce solutions of greater economic impact as compared to established companies. Data about scientific production was retrieved from the "Web of Knowledge", a database administered by the Institute for Scientific Information (ISI). We report all articles with at least one author affiliated to Italian universities. Data were then aggregated at provincial level, when necessary.

Thirdly, the direct involvement of universities in technological activity is included (IPRs $s_{i, t-}$ 4). Given the limited extent of the direct involvement by universities in IPR-related issues, it can hardly have a substantial effect on growth. However, technological activities at academic laboratories may indicate the orientation of academic research towards industrial applications and the propensity to collaborate with external partners. This can become beneficial for established companies and new ventures which may not encounter institutional frictions. As patenting is an occasional activity at universities, hence subject to high disturbances in the short run, IPRs is obtained as the annual average of the number of national patent applications from universities in the previous four years over the average number of scientific articles in the same years. This long time frame is justified by the long time lag with which patents are cited (Czarnitzki et al, 2011; Sampat et al., 2003). We interact IPRs and entry to assess the effects of entrepreneurial policies by universities towards technology development on the economic contributions of new ventures. Information about university patenting was obtained from Patjunkie, a web-based patent search engine realized by the Bologna University based research group IRIS ${ }^{26}$. We are aware that this measure is strongly biased downward as Italian academic professors tend to leave ownership of their inventions to companies (Lissoni et al., 2008). However, the main focus of our analysis is to account for the orientation of university policies towards commercialization.

We control for the provincial industrial structure as it can affect the growth rate of local economies and the extent to which agglomeration economies emerge. We use three measures to account for industrial composition and innovativeness of the regional (provincial) economies. Due to data constraints, as a proxy of the presence of manufacturing (ISS) in the province we use the share of the labor force in the whole restricted industry sector (source: ISTAT). Furthermore, the ability of the secondary sector to absorb and exploit knowledge ultimately depends on its current innovative performance (Cohen and Levinthal, 1990).

26 http://www.evpat.net/patjunkie/search.asp 
Table 3.1: Summary Statistics

\begin{tabular}{|c|c|c|c|c|c|}
\hline Variables & & Mean & Std. Dev. & Min & Max \\
\hline \multirow[t]{2}{*}{ D_Va_Indss } & overall & 0.019 & 0.048 & -0.117 & 0.182 \\
\hline & within & & 0.043 & -0.095 & 0.191 \\
\hline \multirow[t]{2}{*}{ D_Va } & overall & 0.043 & 0.031 & -0.049 & 0.142 \\
\hline & within & & 0.029 & -0.035 & 0.134 \\
\hline \multirow[t]{2}{*}{ Log_Vapc(t-1) } & overall & 3.897 & 0.112 & 3.561 & 4.149 \\
\hline & within & & 0.044 & 3.751 & 3.996 \\
\hline \multirow[t]{2}{*}{ D_Vaindss(t-1) } & overall & 0.023 & 0.054 & -0.117 & 0.224 \\
\hline & within & & 0.049 & -0.103 & 0.193 \\
\hline \multirow[t]{2}{*}{ D_Va (t-1) } & overall & 0.047 & 0.031 & -0.049 & 0.142 \\
\hline & within & & 0.029 & -0.041 & 0.133 \\
\hline \multirow[t]{2}{*}{ Manu_e (t) } & overall & 7.135 & 3.575 & 2.564 & 26.963 \\
\hline & within & & 1.485 & 0.223 & 16.312 \\
\hline \multirow[t]{2}{*}{ High_Share(t) } & overall & 0.168 & 0.064 & 0.035 & 0.387 \\
\hline & within & & 0.027 & 0.083 & 0.269 \\
\hline \multirow[t]{2}{*}{$E(t)$} & overall & 8.377 & 1.964 & 5.114 & 22.654 \\
\hline & within & & 0.861 & 5.068 & 12.721 \\
\hline \multirow[t]{2}{*}{ Ki_Share(t) } & overall & 0.223 & 0.065 & 0.084 & 0.595 \\
\hline & within & & 0.059 & 0.04 & 0.551 \\
\hline \multirow[t]{2}{*}{ B_Services (t-1) } & overall & 0.119 & 0.025 & 0.072 & 0.23 \\
\hline & within & & 0.005 & 0.103 & 0.132 \\
\hline \multirow[t]{2}{*}{ Pat_Iss (t-1) } & overall & 0.130 & 0.073 & 0 & 0.623 \\
\hline & within & & 0.033 & -0.028 & 0.532 \\
\hline \multirow[t]{2}{*}{ ISS(t-1) } & overall & 0.222 & 0.094 & 0.06 & 0.442 \\
\hline & within & & 0.008 & 0.186 & 0.250 \\
\hline \multirow[t]{2}{*}{ Students (t-1) } & overall & 1.641 & 3.695 & 0 & 30.038 \\
\hline & within & & 0.894 & -5.079 & 8.111 \\
\hline \multirow[t]{2}{*}{ Publications (t-2) } & overall & 0.646 & 2.169 & 0 & 18.317 \\
\hline & within & & 0.463 & -2.601 & 8.184 \\
\hline \multirow[t]{2}{*}{ IPRs (t-4) } & overall & 0.004 & 0.014 & 0 & 0.167 \\
\hline & within & & 0.011 & -0.035 & 0.143 \\
\hline
\end{tabular}

We control for the degree of innovativeness of the industrial sector (PAT_ISS). This measure is defined as the number of national patents granted per 1000 employees in the restricted industry sector and it is lagged by one year (source: $U M B I$ ). A widespread presence of the business services sector indicates the existence of agglomeration economies due to diversification. We include for this purpose the share of workforce employed in the business services sector(Business_Services). Finally, we control for the heterogeneity of productivity and income across Italian provinces by incorporating the logarithm of the one-year lagged level of value added per capita $\left(L \_V A P C\right)$ and we include the one-period lagged dependent variable $\left.\left(\Delta V A_{-} I S S_{(i, t-1)} ; \Delta V A_{(i, t-1)}\right)\right)^{27}$ All controls are lagged by one year.

27The inclusion of a lagged dependent variable in a fixed effects model may give rise to biases. However, since the dependent variable is a change and we are not interested in the coefficient for the lagged dependent variables, the biases should be minimal. See also Bun and Carree (2005). 
Table 3.2: Correlation Matrix

\begin{tabular}{llcccccccccccccc}
\hline & Variables & 1 & 2 & 3 & 4 & 5 & 6 & 7 & 8 & 9 & 10 & 11 & 12 & 13 & 14 \\
\hline 1 & d_vaindss & 1 & & & & & & & & & & & & & \\
2 & d_va & 0.38 & 1 & & & & & & & & & & & \\
3 & Log_VAPC & -0.06 & -0.13 & 1 & & & & & & & & & & & \\
4 & d_vaindss & 0.11 & 0.23 & -0.13 & 1 & & & & & & & & & \\
5 & d_va_lag & 0.08 & 0.16 & -0.09 & 0.44 & 1 & & & & & & & & \\
6 & Manu_E & 0.1 & 0.13 & -0.58 & 0.08 & 0.05 & 1 & & & & & & & \\
7 & E & 0 & 0.14 & -0.31 & 0.03 & 0.07 & 0.67 & 1 & & & & & & \\
8 & High_Share & -0.06 & 0.03 & 0.5 & 0.02 & 0.06 & -0.34 & -0.18 & 1 & & & & & \\
9 & Ki_Share & -0.02 & -0.07 & 0.03 & -0.06 & -0.04 & -0.05 & -0.05 & 0.01 & 1 & & & & \\
10 & B_Services & -0.08 & -0.11 & 0.37 & -0.11 & -0.05 & -0.17 & -0.03 & 0.24 & 0.04 & 1 & & & & \\
11 & Pat_ISS & 0.01 & -0.02 & 0.37 & -0.05 & -0.03 & -0.18 & -0.18 & 0.3 & -0.01 & 0.37 & 1 & & & \\
12 & ISS & -0.12 & -0.03 & 0.33 & -0.04 & -0.02 & -0.57 & -0.11 & 0.25 & -0.01 & 0.05 & 0.14 & 1 & & \\
13 & Studentss & -0.02 & -0.1 & 0.15 & -0.03 & -0.08 & -0.09 & -0.01 & 0.12 & 0.02 & 0.4 & 0.14 & 0.06 & 1 & \\
14 & Publications & -0.03 & 0.03 & 0.12 & 0.01 & 0.04 & -0.08 & -0.07 & 0.07 & 0.01 & 0.18 & 0.18 & 0.03 & -0.08 & 1 \\
15 & IPRs & -0.02 & 0.02 & -0.11 & -0.02 & -0.01 & 0.11 & 0.05 & -0.07 & 0.05 & -0.02 & -0.01 & -0.03 & -0.02 & 0.05 \\
\hline
\end{tabular}

Table 3.1 presents summary statistics (i.e., mean, standard deviation, minimum, and maximum) for all variables included in the empirical analysis. The correlation matrix can be found in Table 3.2. The dependent variables of the analysis show little correlation (0.38), and also the correlation among the explanatory variables is a source of little concern: there are very few correlations above 0.4 (Log_VAPC with Manu_E and High_Share; Manu_E and ISS; Students and Business_Services) and are moderate to low, implying little multicollinearity problems.

\subsection{Results}

Table 3.3 shows the spatial dependence of the variables, both in their original form and 'within' (taken into deviation of the province mean over time). We report the Moran's I test (Moran, 1950) to measure spatial dependence, which is calculated as follows:

$$
\text { Moran's } I=(x-\mu)^{\prime} \mathrm{W}(\mathrm{x}-\mu) /(\mathrm{x}-\mu)^{\prime}(\mathrm{x}-\mu)
$$

where $x$ is the column vector of the variable of interest, $\mu$ is the mean of $x$ and $W$ is the weighting matrix. The first columns of the table shows the cross-sectional dependences of the original variables, whereas the later columns present the same for the 'within's. The Moran's I test suggests the existence of spatial dependence in the case of value added growth in the Manufacturing sector. A log-likelihood test on LSDV (fixed effects) against the pooled OLS indicates the existence of province-specific fixed effects. Hence, we will only report the estimations for FE-W (Fixed Effects - Within) and the SEM and SAR transformations. 
Table 3.3: Test of Spatial Dependence

\begin{tabular}{lrrrr}
\hline & \multicolumn{2}{c}{ Original } & \multicolumn{2}{c}{ Within } \\
\cline { 2 - 5 } Variables & Moran I & p-value & Moran I & p-value \\
\hline d_vaindss & -0.031 & 0.14 & -0.05 & 0.035 \\
d_va & 0.004 & 0.42 & -0.009 & 0.399 \\
Log_VAPC & -0.013 & 0.339 & 0.027 & 0.138 \\
d_vaindss (t-1) & 0.07 & 0.004 & 0.058 & 0.013 \\
d_va_lag (t-1) & 0.024 & 0.169 & 0.022 & 0.185 \\
Manu_E & 0.038 & 0.066 & 0.008 & 0.36 \\
E & 0.038 & 0.065 & -0.013 & 0.34 \\
High_Share & 0.036 & 0.08 & -0.013 & 0.335 \\
Ki_Share & 0.014 & 0.276 & -0.015 & 0.315 \\
B_Services & 0.097 & 0 & 0.03 & 0.121 \\
Pat_ISS & 0.04 & 0.058 & -0.054 & 0.021 \\
ISS & 0.086 & 0.001 & 0.002 & 0.446 \\
Studs & 0.167 & 0 & 0.065 & 0.005 \\
Pubs & 0.066 & 0.004 & 0.004 & 0.404 \\
IPRs & -0.004 & 0.459 & -0.007 & 0.424 \\
\hline
\end{tabular}

We do not observe spatial dependence in the case of value added growth across all sectors. This result may not be surprising for two reasons. Firstly, the service sector covers almost three quarters of the Italian GDP (ISTAT, 2009) and services tend to serve local markets. Secondly, the spatial peculiarity of Italian provinces (with the dominant capital city), minimizes the existence of inter-provincial productivity gains.

Table 3.4 reports the results from the fixed effect estimations of the growth equations in the restricted industry sector (Equations (1)-(3)). Table 3.5 reports the fixed effect estimation outputs of the growth equations for the whole economy. The first part of both tables illustrates the estimates for the basic model; the right side of the table adds the interactions of the measures of academic activities with business entry. The models for economic growth in the restricted industry have weaker explanatory power than the models for total economic growth. The regressions for value added growth across all sectors show a better goodness of fit (R-squared around 58\%) versus that for value added growth in the restricted industry (R-squared around $23 \%)$. As expected, the growth rate of value added in the restricted industry shows significant spatial interdependencies. Furthermore, a log-likelihood test indicates a higher explanatory power of SAR as compared to SEM at the $10 \%$ confidence level. Finally, a LR test rejects the existence of spatial dependence in Table 5. Although we present all estimations for the sake of completeness, we will only discuss the findings of the FE-W SAR for the value added growth in the restricted industry (Table 3.4) and the estimates of the FE-W for the growth in value added for all sectors (Table 3.5). 
Table 3.4: Growth in value added (restricted industry).

\begin{tabular}{|c|c|c|c|c|c|c|}
\hline & FE-W & FE-W SEM & FE-W SAR & FE-W & FE-W SEM & FE-W SAR \\
\hline Log_VAPC(t-1) & $\begin{array}{c}0.3448 * * * \\
(0.1026)\end{array}$ & $\begin{array}{c}0.3438 * * * \\
(0.0961)\end{array}$ & $\begin{array}{c}0.3353 * * * \\
(0.0964)\end{array}$ & $\begin{array}{c}0.3561 * * * \\
(0.1026)\end{array}$ & $\begin{array}{c}0.3567 * * * \\
(0.0973)\end{array}$ & $\begin{array}{c}0.3473 * * * \\
(0.0976)\end{array}$ \\
\hline d_va (t-1) & $\begin{array}{l}-0.0717 \\
(0.0467)\end{array}$ & $\begin{array}{l}-0.0610^{*} \\
(0.0358)\end{array}$ & $\begin{array}{l}-0.0679 * \\
(0.0356)\end{array}$ & $\begin{array}{l}-0.0711 \\
(0.0466)\end{array}$ & $\begin{array}{l}-0.0599^{*} \\
(0.0357)\end{array}$ & $\begin{array}{l}-0.0671^{*} \\
(0.0356)\end{array}$ \\
\hline Manu_E(t) & $\begin{array}{l}-0.0019 \\
(0.0015)\end{array}$ & $\begin{array}{l}-0.0012 \\
(0.0013)\end{array}$ & $\begin{array}{l}-0.0014 \\
(0.0012)\end{array}$ & $\begin{array}{l}-0.0015 \\
(0.0015)\end{array}$ & $\begin{array}{l}-0.0007 \\
(0.0014)\end{array}$ & $\begin{array}{c}-0.001 \\
(0.0013)\end{array}$ \\
\hline High_Share(t) & $\begin{array}{l}-0.1047 \\
(0.0686)\end{array}$ & $\begin{array}{c}-0.1161 * * \\
(0.0592)\end{array}$ & $\begin{array}{l}-0.1122 * \\
(0.0588)\end{array}$ & $\begin{array}{l}-0.1014 \\
(0.0691)\end{array}$ & $\begin{array}{l}-0.1127^{*} \\
(0.0592)\end{array}$ & $\begin{array}{c}-0.1087^{*} \\
(0.0588)\end{array}$ \\
\hline B_Services (t-1) & $\begin{array}{c}-1.4364 * * \\
(0.6273)\end{array}$ & $\begin{array}{c}-1.3742 * * * \\
(0.526)\end{array}$ & $\begin{array}{c}-1.4116^{* * *} \\
(0.525)\end{array}$ & $\begin{array}{c}-1.4453 * * \\
(0.6225)\end{array}$ & $\begin{array}{c}-1.3916 * * * \\
(0.5332)\end{array}$ & $\begin{array}{c}-1.4183 * * * \\
(0.5321)\end{array}$ \\
\hline Pat_ISS (t-1) & $\begin{array}{l}0.0722 * \\
(0.0434)\end{array}$ & $\begin{array}{l}0.0789 * \\
(0.0479)\end{array}$ & $\begin{array}{c}0.0757 \\
(0.0472)\end{array}$ & $\begin{array}{c}0.0708 \\
(0.0432)\end{array}$ & $\begin{array}{c}0.0771 \\
(0.0479)\end{array}$ & $\begin{array}{c}0.0742 \\
(0.0472)\end{array}$ \\
\hline ISS (t-1) & $\begin{array}{c}-1.6678 * * * \\
(0.2927)\end{array}$ & $\begin{array}{c}-1.6255^{* * *} \\
(0.2466)\end{array}$ & $\begin{array}{c}-1.6377 * * * \\
(0.2457)\end{array}$ & $\begin{array}{c}-1.6673 * * * \\
(0.2907)\end{array}$ & $\begin{array}{c}-1.6232 * * * \\
(0.2471)\end{array}$ & $\begin{array}{c}-1.6363 * * * \\
(0.2461)\end{array}$ \\
\hline Students (t-1) & $\begin{array}{c}0.0034 \\
(0.0025)\end{array}$ & $\begin{array}{c}0.0035^{*} \\
(0.002)\end{array}$ & $\begin{array}{c}0.0034 * \\
(0.002)\end{array}$ & $\begin{array}{l}0.0049 \\
(0.004)\end{array}$ & $\begin{array}{l}0.0052^{*} \\
(0.0029)\end{array}$ & $\begin{array}{l}0.0051^{*} \\
(0.0029)\end{array}$ \\
\hline Publications (t-1) & $\begin{array}{c}0.0022 \\
(0.0026)\end{array}$ & $\begin{array}{c}0.0007 \\
(0.0035)\end{array}$ & $\begin{array}{c}0.009 \\
(0.0035)\end{array}$ & $\begin{array}{l}0.0042 \\
(0.007)\end{array}$ & $\begin{array}{c}0.003 \\
(0.0073)\end{array}$ & $\begin{array}{c}0.0031 \\
(0.0073)\end{array}$ \\
\hline IPRs (t-4) & $\begin{array}{l}-0.1781 \\
(0.1186)\end{array}$ & $\begin{array}{l}-0.1997 \\
(0.1457)\end{array}$ & $\begin{array}{l}-0.1996 \\
(0.1452)\end{array}$ & $\begin{array}{c}-0.063 \\
(0.2571)\end{array}$ & $\begin{array}{l}-0.0446 \\
(0.3098)\end{array}$ & $\begin{array}{l}-0.0847 \\
(0.3088)\end{array}$ \\
\hline Students*E & & & & $\begin{array}{l}-0.3274 \\
(0.4051)\end{array}$ & $\begin{array}{c}-0.3579 \\
(0.456)\end{array}$ & $\begin{array}{c}-0.357 \\
(0.4498)\end{array}$ \\
\hline Publications*E & & & & $\begin{array}{l}-0.0003 \\
(0.0011)\end{array}$ & $\begin{array}{c}-0.0004 \\
(0.001)\end{array}$ & $\begin{array}{l}-0.0003 \\
(0.001)\end{array}$ \\
\hline IPRs*E & & & & $\begin{array}{l}-0.0088 \\
(0.021)\end{array}$ & $\begin{array}{l}-0.0123 \\
(0.0243)\end{array}$ & $\begin{array}{l}-0.0087 \\
(0.0242)\end{array}$ \\
\hline Spatial Residuals & & $\begin{array}{l}-0.0380 * \\
(0.0211)\end{array}$ & & & $\begin{array}{l}-0.0399 * \\
(0.0212)\end{array}$ & \\
\hline Spatial Growth & & & $\begin{array}{c}0.0456^{* *} \\
(0.0178)\end{array}$ & & & $\begin{array}{c}0.0461 * * * \\
(0.0178)\end{array}$ \\
\hline Time Dummies & Yes & Yes & Yes & Yes & Yes & Yes \\
\hline R-squared & 0.2298 & & & 0.2309 & & \\
\hline Log-Likelihood & $1,097.608$ & $1,099.242$ & $1,100.891$ & $1,098.031$ & $1,098.809$ & $1,101.381$ \\
\hline $\mathrm{N}$ & 594 & 594 & 594 & 594 & 594 & 594 \\
\hline
\end{tabular}

Significance at the $1 \%, 5 \%$, and $10 \%$ level is indicated by ***, $* *$, and $*$, respectively. Standard errors, reported below coefficients, are robust to heteroskedasticity and clustered around provinces.

\subsubsection{Economic Growth in the Restricted Industry Sector}

The results in table 3.4 indicate that productivity gains have spatial interdependencies in the context of the restricted industry. The coefficients associated with the spatially lagged dependent variables and spatial error component are both significant, as expected from the Moran's I test in table 3.3. The measures of new business formations have a negative effect on the growth of value added. In the first place, business entry shows negative effects on the rate of growth of value 
added, although nonsignificant. Furthermore, the share of new businesses in the high-tech sector is negatively and significantly correlated with our growth measure. These findings contradict the existing evidence on the direct effects of entry on economic growth in the short-run (Fritsch and Mueller, 2008), which predicts an immediate positive impact of entry on economic growth. The results can have several interpretations. Firstly, entry in the restricted industry in Italian provinces might be mainly driven by necessity, rather than opportunity. This interpretation, although plausible, cannot be defended with the measures at hand as necessity entrepreneurship is mainly observable through lower exit rates (Santarelli et al, 2009). Secondly, the indirect effects of entry might prevail over the direct ones. New ventures push inefficient existing capacities out of the market and are responsible for market turbulence. This explanation seems to be the most reasonable as high shares of high-tech ventures may be responsible for a process of sectoral transformation. ${ }^{28}$

The presence of universities can per se have beneficial implications for the rate of growth in value added in the restricted industry. The presence of graduates is positively correlated with value added growth in the restricted industry, significantly at the $10 \%$ confidence level. The provision of graduates to the labour market is not only beneficial for the competitiveness of the local manufacturing base, but also for the adjacent provinces. The coefficients related to the scientific production and commercial orientation of research are all nonsignificant. Given the specialization in traditional sectors of the Italian manufacturing sector, the absent contribution of scientific and technological outputs to value added growth does not come as surprise. Moreover, at least in the case of Italian provinces, we do not observe any superior ability of new ventures to exploit commercially the knowledge produced in universities, irrespective of the efforts the latter take to facilitate the transfer of it. The set of controls sheds some light on the process of structural change occurring in Italy. Provinces with a strong presence of manufacturing activities witness lower growth rates in value added. The innovative intensity of the manufacturing industry in the province is positive and feebly insignificant, in line with an industrial base formed by mostly small firms in sectors with low propensity to patent. Increases in the presence of business services activities are associated with decreases in the growth of value added in the restricted industry. Ceteris paribus, the growth rate in the restricted industry is more accentuated in richer provinces, mostly located in the Centre-North, with the coefficient for value added per capita being positive and significant.

\subsubsection{Overall Economic Growth}

Table 3.5 reports the results for the total growth rate of value added at the provincial level. We will mention here only the differences with the estimates found for the restricted industry.

${ }^{28}$ Quatraro (2009) details the process of structural change that occurred in Italian regions between 1980 and 2000. The author documents a process of de-industrialization in the early-industrialized Northwest regions with consequent transformation to a knowledge-based economy, and an increasing specialization in manufacturing activities in the Northeast and Central regions focused on traditional sectors. Furthermore the author shows that a process of recent industrialization is occurring in the developing South. 
Table 3.5: Growth in value added (all sectors).

\begin{tabular}{|c|c|c|c|c|c|c|}
\hline & FE-W & FE-W SEM & FE-W SAR & FE-W & FE-W SEM & FE-W SAR \\
\hline Log_VAPC(t-1) & $\begin{array}{c}0.2903 * * * \\
(0.0581)\end{array}$ & $\begin{array}{c}0.2860 * * * \\
(0.0475)\end{array}$ & $\begin{array}{c}0.2861 * * * \\
(0.0477)\end{array}$ & $\begin{array}{c}0.2869 * * * \\
(0.0584)\end{array}$ & $\begin{array}{c}0.2824 * * * \\
(0.0476)\end{array}$ & $\begin{array}{c}0.2833 * * * \\
(0.0477)\end{array}$ \\
\hline d_va (t-1) & $\begin{array}{c}-0.1669 * * * \\
(0.0383)\end{array}$ & $\begin{array}{c}-0.1645 * * * \\
(0.0367)\end{array}$ & $\begin{array}{c}-0.1638 * * * \\
(0.0372)\end{array}$ & $\begin{array}{c}-0.1789 * * * \\
(0.0394)\end{array}$ & $\begin{array}{c}-0.1762 * * * \\
(0.0367)\end{array}$ & $\begin{array}{c}-0.1757 * * * \\
(0.0372)\end{array}$ \\
\hline$E(t)$ & $\begin{array}{l}0.0011 \\
(0.001)\end{array}$ & $\begin{array}{l}-0.001 \\
(0.001)\end{array}$ & $\begin{array}{l}-0.001 \\
(0.001)\end{array}$ & $\begin{array}{l}-0.0020^{*} \\
(0.0011)\end{array}$ & $\begin{array}{l}-0.0019 * \\
(0.0011)\end{array}$ & $\begin{array}{l}-0.0019 * \\
(0.0011)\end{array}$ \\
\hline Ki_Share(t) & $\begin{array}{l}-0.0033 \\
(0.0148)\end{array}$ & $\begin{array}{l}-0.0062 \\
(0.0132)\end{array}$ & $\begin{array}{c}-0.0042 \\
(0.013)\end{array}$ & $\begin{array}{l}-0.0031 \\
(0.0147)\end{array}$ & $\begin{array}{l}-0.0058 \\
(0.0131)\end{array}$ & $\begin{array}{l}-0.0039 \\
(0.0129)\end{array}$ \\
\hline B_Services (t-1) & $\begin{array}{c}0.7206 * * \\
(0.3297)\end{array}$ & $\begin{array}{c}0.7685 * * * \\
(0.2582)\end{array}$ & $\begin{array}{c}0.7240 * * * \\
(0.2564)\end{array}$ & $\begin{array}{c}0.8576 * * \\
(0.3316)\end{array}$ & $\begin{array}{c}0.9016^{* * *} \\
(0.2621)\end{array}$ & $\begin{array}{c}0.8588 * * * \\
(0.2602)\end{array}$ \\
\hline Pat_ISS (t-1) & $\begin{array}{c}0.0197 \\
(0.0236)\end{array}$ & $\begin{array}{c}0.0146 \\
(0.0235)\end{array}$ & $\begin{array}{l}0.0191 \\
(0.023)\end{array}$ & $\begin{array}{c}0.02 \\
(0.0234)\end{array}$ & $\begin{array}{c}0.0151 \\
(0.0233)\end{array}$ & $\begin{array}{c}0.0194 \\
(0.0229)\end{array}$ \\
\hline ISS (t-1) & $\begin{array}{l}-0.0113 \\
(0.1504)\end{array}$ & $\begin{array}{c}0.0129 \\
(0.1171)\end{array}$ & $\begin{array}{l}-0.0074 \\
(0.1163)\end{array}$ & $\begin{array}{c}0.0127 \\
(0.1481)\end{array}$ & $\begin{array}{l}0.0377 \\
(0.117)\end{array}$ & $\begin{array}{c}0.0158 \\
(0.1159)\end{array}$ \\
\hline Students (t-1) & $\begin{array}{c}-0.002 * * \\
(0.001)\end{array}$ & $\begin{array}{c}-0.0019 * * \\
(0.001)\end{array}$ & $\begin{array}{c}-0.002 * * \\
(0.001)\end{array}$ & $\begin{array}{c}-0.0028 * * * \\
(0.0011)\end{array}$ & $\begin{array}{l}-0.0028 \\
(0.0017)\end{array}$ & $\begin{array}{l}-0.0027 \\
(0.0017)\end{array}$ \\
\hline Publications (t-1) & $\begin{array}{c}0.0032 * * * \\
(0.0006)\end{array}$ & $\begin{array}{l}0.0030 * \\
(0.0017)\end{array}$ & $\begin{array}{l}0.0029 * \\
(0.0017)\end{array}$ & $\begin{array}{l}-0.0043 \\
(0.0042)\end{array}$ & $\begin{array}{l}-0.0048 \\
(0.0062)\end{array}$ & $\begin{array}{l}-0.0045 \\
(0.0062)\end{array}$ \\
\hline IPRs (t-4) & $\begin{array}{c}0.0914 \\
(0.0666)\end{array}$ & $\begin{array}{l}-0.0921 \\
(0.0696)\end{array}$ & $\begin{array}{l}-0.0926 \\
(0.0696)\end{array}$ & $\begin{array}{c}-0.8640 * * * \\
(0.3131)\end{array}$ & $\begin{array}{c}-0.8377 * * \\
(0.326)\end{array}$ & $\begin{array}{c}-0.8496 * * * \\
(0.3255)\end{array}$ \\
\hline Students*E & & & & $\begin{array}{c}0.1107 \\
(0.1626)\end{array}$ & $\begin{array}{c}0.1257 \\
(0.2275)\end{array}$ & $\begin{array}{c}0.0995 \\
(0.2259)\end{array}$ \\
\hline Publications*E & & & & $\begin{array}{l}0.0008 * \\
(0.0005)\end{array}$ & $\begin{array}{c}0.0009 \\
(0.0007)\end{array}$ & $\begin{array}{c}0.0008 \\
(0.0007)\end{array}$ \\
\hline IPRs*E & & & & $\begin{array}{c}0.0815 * * \\
(0.0353)\end{array}$ & $\begin{array}{c}0.0785 * * \\
(0.0337)\end{array}$ & $\begin{array}{c}0.0799 * * \\
(0.0337)\end{array}$ \\
\hline Spatial Residuals & & $\begin{array}{l}-0.0307 \\
(0.0206)\end{array}$ & & & $\begin{array}{l}-0.0294 \\
(0.0208)\end{array}$ & \\
\hline Spatial Growth & & & $\begin{array}{l}-0.0197 \\
(0.0125)\end{array}$ & & & $\begin{array}{l}-0.0184 \\
(0.0124)\end{array}$ \\
\hline Time Dummies & Yes & Yes & Yes & Yes & Yes & Yes \\
\hline R-squared & 0.5853 & & & 0.5887 & & \\
\hline Log-Likelihood & $1,526.719$ & $1,527.824$ & $1,527.96$ & $1,530.732$ & $1,531.733$ & $1,531.817$ \\
\hline $\mathrm{N}$ & 594 & 594 & 594 & 594 & 594 & 594 \\
\hline
\end{tabular}

Significance at the $1 \%, 5 \%$, and $10 \%$ level is indicated by $* * *, * *$, and *, respectively. Standard errors, reported below coefficients, are robust to heteroskedasticity and clustered around provinces.

Entry in manufacturing and services at first does not show any significant impact on economic growth. Yet, contrary to what we observed for the restricted industry, it turns significant with positive implications for growth when it is interacted with measures of academic outputs. There is not any sign of growth premia from entry in knowledge-intensive sectors, the latter being still in a process of consolidation in large parts of the country (Quatraro, 2009). Large increases in the fractions of graduates in science and technology disciplines are associated with 
decreases in the growth rate of value added. Two possible reasons can account for this finding. The first reason is that rather than capturing the presence of human capital in the local economy, which has possible implications from the supply side of the economy, our measure of educational mandate of universities highlights the consequences accruing from the demand side: large fractions of graduates indicate large presences of students, with low spending power. The second reason is that the increases in the number of graduates reflect recent changes in education policies that followed the implementation of the so-called Bologna Process. Universities have decentralized part of their teaching activities in provinces with poor economic performances to meet the local demand for higher education. Yet, the economic results of this delocalization policy have proven to be rather unsatisfactory (Piergiovanni et al., 2011). If the output of teaching activities is controversial in terms of economic performance, the coefficient for the production of scientific knowledge is positive and significant. Consistent with Piergiovanni et al. (2011), this finding shows that more than just the presence of academic institutions in the province, what really matters in relation to economic growth is their relative quality. Involvement of universities in IPR management activities does not show any effect on the rate of growth in value added. The interaction between entry and the outputs of academic activities confirms the positive impact of sustained entrepreneurial regimes for the economic exploitation of scientific knowledge in its traditional form.

The effect is significant for provinces hosting universities at the forefront in the production of scientific knowledge. On the opposite, entrepreneurial attitudes of universities, that we measure in terms of their involvement in IPRs management activities, are beneficial for economic growth when they are accompanied by a business climate that encourage the creation of new ventures in the private sector. This result can well be explained by the fact that in Italy, like in most other European countries, universities have little control on the commercial activities of their faculties, who usually leave exclusive ownership of their inventions to business parties, typically large firms (Della Malva et al., 2007). Thus, policies that institutionalize the commercial exploitation of academic technologies appear to reduce the costs of access to university labs to newly formed ventures. Patenting, which was found to significantly accelerate value added growth in restricted industry, does not affect total value added growth in the provinces. On the contrary, the growth in the workforce in the business services sector has a positive and significant influence on the rate of growth of value added. The two outcomes are mainly explained by the decreasing relevance of manufacturing activities as the tertiary sector, which does not make use of patents, represents the largest share of the whole economy (ISTAT, 2009). Provinces with higher than average value added per capita, mostly located in the more developed North and Center of the country, grow at a faster rate. This result indicates that the economic divide between the developed areas of the country and the South has increased during the period of analysis. 


\subsection{Concluding Remarks}

In the transformation to a knowledge based economy, universities stand as key players as they are a key locus of knowledge production. Yet, for knowledge to contribute to economic growth, it needs to spill from academic institutions over the economy in the form of new entrepreneurial ventures. By using spatial econometric techniques, this work has tested the hypothesis that new business entrants are critical in the economic exploitation of academic knowledge and its contribution to economic growth. This hypothesis has been derived from the theoretical framework proposed by Acs et al. (2009) and Braunerhjelm et al. (2010), which extend traditional models of endogenous growth by accounting for knowledge transmission channels. According to the authors, new business entrants are critical conduits of radical knowledge, like academic knowledge, into economic outcomes as they face lower opportunity costs than incumbent firms when confronted with radical opportunities.

We have measured the contribution of three main outputs of academic mandates, namely teaching, research and technological development, to the rate of growth in value added for 99 Italian provinces between 2001 and 2006, both in the restricted industry and across all sectors. Controlling for several characteristics of the economic structure of the provinces, we have found that scientific knowledge, only in the form of newly educated workforce, yields significant effects on the growth rate of value added in the restricted industry. The effects of academic outputs are appreciable across all sectors when they are associated with sustained entrepreneurial activities in the province. In particular, the traditional mandate of scientific inquiry seems to provide new ventures with valuable commercial opportunities overseen by established companies: as new companies are not constrained by existing productive architectures, entrepreneurs are more likely to identify and exploit opportunities. Furthermore, entrepreneurial policies which favor the Industry-Science links appear to be effective for the economic exploitation of academic knowledge by new ventures: when risk-taking endeavours are systematic from both the private and the public actors, then scientific knowledge can generate positive economic externalities. However, these findings fail to hold when we limit our analysis to value added growth in the restricted industry, for which the presence of high entry rates turns out to be detrimental.

This work has undoubtfully limitations. One on which we would like to shed some light is our measure of entry. Unlike other studies, we claim caution in the interpretation of sustained entry regimes per se as having positive implications for the economic prosperity. Concerns arise from the peculiarity of our measure. We measure new registrations, whereas previous studies measured new firms with employees on payroll, hence a selective subset of all new registrations. There are reasons to expect the sole number of registration might introduce quite some noise in the economic interpretation of the phenomenon of new business creation; yet, a noise which would underestimate the actual effects of entry on economic growth. One source of noise might come from strategic reasons behind the registration of new firms - for instance keeping economic activities strategically downsized for labour-related policies and tax reasons, to benefit from 
subsidies and hence registering more firms to account for one economic activity. ${ }^{29}$ Another reason for expecting noise is that entrepreneurs might realize that their ventures are not as promising as initially thought, and they can realize it before making the initial investment in production capacities. Hence, new registrations remain "on paper" and do not translate in any form of transaction which would appear in national accounts.

To conclude, our findings suggest that neither entrepreneurship as such nor academic knowledge alone contribute to sustained economic growth in the case of Italian provinces. It is only when entrepreneurs have access to scientific knowledge and universities are prone to collaborate with external parties that their ventures significantly stimulate growth. Thereby, new ventures appear to be effective conduits of scientific knowledge into economic outcomes.

29 The current legislation on Labour protection in Italy creates a double system of duties for employers. Companies hiring less than 15 people can lay off employees on the premise of bad economic performance. This rationale is not allowed for companies larger than 15 employees, which can apply for subsidies for their workforce during economic downturns. Furthermore, fiscal pressure on corporate activities in Italy is among the highest and the most complicated in Europe (Paying Taxes 2009, Price Waterhouse Coopers). 


\section{Institutional Change and Academic Patenting: French Universities and the Innovation Act of 1999`}

\subsection{Introduction}

Since the 1980s, various policy initiatives have been undertaken in most European countries with the aim of strengthening the links between academia and industry, and to increase technology transfer efforts by academic institutions and faculty members. Many of such initiatives have touched upon intellectual property right (IPR) legislation and its relationship to university policy, with the introduction of incentive schemes to induce academic scientists to commercialize more actively their research results, most often through patenting and licensing. All of these reforms share the assumption that European universities and scientists do not undertake enough IPRmediated technology transfer, especially when compared to their US counterparts (Mowery and Sampat, 2005).

Recent studies, however, have shown that European policy-makers' assumptions may derive from lack of attention to the legal and institutional differences between the university systems of the two continents. In particular, too much faith has been placed in available statistics on the number of patents owned by universities (university-owned patents) as opposed to patents covering inventions by academic scientists, but assigned to the individual scientists, public research organizations and, above all, business companies (university-invented patents; surveys by Geuna and Nesta, 2006; and Verspagen, 2006). Lissoni et al. (2008) suggest that universityowned patents in France, Italy and Sweden are no more than $11 \%$ of all academic patents (whether university-owned or merely university-invented), as opposed to $60-80 \%$ academic patents owned by business companies. This implies that European universities may contribute to technology transfer activity by producing inventions, the IPRs of which they choose (for institutional, strategic or managerial reasons) to leave entirely in their public or private partners' hands.

When it comes to measuring the effect of patent-inducing policies, therefore, we may be interested not only to measuring whether they have indeed produced an increase in patenting by universities, but also whether such increase may derive from a patent property shift (from public partners and business companies to universities) and not only from an increase in the number of patented inventions. More generally, the number of European academic patents in the hands of

- This chapter previously circulated as KITeS working paper n.29/2010. It is based on a joint work with Francesco Lissoni (Universitá di Brescia) and Patrick Llerena (Universitè de Strasbourg) and it is forthcoming at Journal of Evolutionary Economics. 
business companies is so high that they have necessarily to be taken into account in any evaluation effort.

In this paper we build upon Lissoni et al. (2008) in order to assess the impact on patent ownership patterns of IPR-related reforms. In particular, we explore the consequences of the French government's introduction, in 1999, of the Innovation Act, which promoted, among other things, a more aggressive patenting activity by universities. In particular, we test whether the Act (also known as "Loi Allegre") has significantly increased the likelihood of a French academic patent being assigned to a university rather than to a business company or a public research organization. We also assess, in the same respect, the effect of the creation of a technology transfer office within the academic inventor's university.

The study is organized as follows. In section 2, we provide a brief review of the IPR-related aspects of science policy reforms introduced in France over the past 10 years, with special emphasis on the Innovation Act. We also provide some comparative information on similar policies introduced in the USA and in Europe. In sections 3 and 4, respectively, we present the data and the econometric model used to examine the effect of the new law. Section 5 illustrates and discusses our results, and section 6 concludes and outlines the directions of our future research.

\subsection{IPR-related reforms of university policy}

\subsubsection{The international experience}

Policy-makers' attention to IP aspects of academic research is mainly due to the visibility of the US experience, where universities' contributions to inventing and patenting have increased substantially over the last quarter of a century, following legislative changes introduced in $1980 .^{30}$

Among such changes, the introduction of Public Law 96-517, better known as the BayhDole Act, stands out. This Act, among other things, allowed US universities to retain IPRs over the inventions resulting from federally-funded research and established the government's marchin right, that is, the right to arrange for licensing of patents left unexploited by academic administrations. The Act was meant to provide a unique set of rules for universities which, until then, had had to cope with several funding agencies (such as the National Institutes of Health, the Department of Defence, or the National Science Foundation), each of them with a different IPR policy (Mowery et al., 2001). It was also meant to provide universities with both stick and carrot incentives to commercialize their inventions. ${ }^{31}$ More generally, the Bayh-Dole Act complemented another set of policies, all aimed at reinforcing the US IP regime, based upon a more severe enforcement of rules against patent infringements and the extension of patentable matters to

\footnotetext{
${ }^{30}$ See Henderson et al. (1998), Jensen and Thursby (2001), and Mowery et al. (2004).

${ }^{31}$ As a matter of fact, the stick, that is, the march-in right, has hardly, if ever, been used (Rai and Eisenberg,
} 2003). 
living organisms and software, two fields where the academic contribution to invention is more than noticeable (Kortum and Lerner, 1999; Jaffe, 2000). After the introduction of the Act, the number of patents issued to universities increased from 264 in 1979 to 2436 in 1997 (NSF, 2006), so that university-owned patents now represent $5 \%$ of the total number of patents issued to US assignees. In addition, the number of universities with a technology transfer office has grown from 150 in 1991 to 400 in 1997 (AUTM, 2004).

In Europe, the British government was the first one to emulate the US initiatives, with the introduction, in 1985, of the right of universities to patent in their own name and commercialize the results of their own faculty's research. Previously, the British Technology Group, a public agency, had the nominal exclusivity on inventions by academics (Clarke, 1995). Shortly afterwards, at a time of constant or decreasing levels of public financing of universities in Continental Europe, academic institutions were encouraged to look at markets for technologies as a source of complementary funding (Geuna, 2001). ${ }^{32}$ Such strategic reorientation has often gone along with the introduction of IP law reforms aimed at increasing universities' and academics' incentives to patenting. Between 2000 and 2002, for example, Germany, Austria, and Denmark all abolished the professor's privilege, a typical institution of German and Scandinavian law, with the explicit aim of increasing the number of university patents (while, on the other hand, Italy introduced it in 2001, and with the same objective). ${ }^{33}$ In the same spirit, many countries have introduced incentive schemes and training programs for IPR awareness and management, as described by Lissoni and Franzoni (2009).

\subsubsection{The French experience}

In France, no specific reform of the IP regime over academic inventions has ever taken place. Rather, issues related to IPR management by universities have been dealt within broader reforms of the national science system. These have touched upon the relationship between academic institutions and large public research organizations (PROs). Therefore, before examining the specific IP-related reforms in which we are interested, it is necessary to discuss the role of universities in the French national system of innovation, and how it has changed over recent times.

${ }^{32}$ In Europe, the system of government structural funds has been partially replaced by a more competitive manner of financing the public research system: indeed, since the late 1980s, the subvention of universities has relied more and more on problem-oriented and industry-oriented public programs rather than on public budgetary channels. This switch in sources of funds could be considered a result of the shrinking of public research budgets and change in the rationale for science support occurring in Europe.

33 The professor's privilege exempts university professors from standard provisions concerning business employees' inventions. National legislations worldwide usually state that IPRs over employees' inventions belong to the employer, as long as the employees' job description includes innovation activities, as with R\&D workers and scientists in general. Countries that admit the professor's privilege allow an exception for university professors, who can retain all IPRs over their inventions, and have no or limited disclosure duties towards their employers (that is, their universities). For a discussion, see Lissoni et al. (2009). 


\subsubsection{The French universities' position in the national system of innovation}

Differently from their US counterparts (but also from many European ones, such as the British or the Dutch), French universities have always struggled to establish themselves as central actors in the public research system, let alone to gain the necessary autonomy for the purpose. This difficulty has deep historical roots (Neave, 1993). After all existing universities had been abolished under the Revolutionary regime at the end of the eighteenth century, a new university (one for the entire country) was established by Napoleon in 1808. Under the name of Imperial University (or University of France), the latter had exclusively teaching tasks for the education of medical doctors, teachers and lawyers, while the Grandes Ecoles, a peculiar French institution, were charged with the formation of the technical and administrative elites. ${ }^{34}$ It was only in 1896 that the Imperial University was disbanded and regional faculties gained the status of universities, but still with no autonomy from the central government. Their research activities were conducted in small personal laboratories by a professor with a few assistants and most often needed funding from external partners (as had happened with Pasteur's laboratory in Lille in 1854). French universities had to wait until the 1970 s to gain some rights to self-organize their teaching and research activities, but even then had no freedom in terms of finance and real estate management, let alone the handling of IPR matters. The latter, therefore, were quite neglected or left in the hands of PROs.

PROs, in fact, have long been the dominant force of the French public research system since World War II, but also one which more recent policies have tried to integrate within academic institutions, in particular, universities. The Center National de la Recherche Scientifique (CNRS) was originally established in 1939 with the express goal of supporting academic research and/or performing research through its own labs. Over the years, a similar role came to be played by INSERM (the National Institute of Health and Medical Research) in the medical sciences, and by other, smaller PROs. During the 1960s, both demographic factors and a call for democratization of education led to massive university enrolment, which called for the isolation of larger and better endowed laboratories from teaching. As a result, successive governments pushed the CNRS to establish a system of partnerships with universities and their staff, on the basis of a periodic evaluation by CNRS committees. This kind of mechanism, which has been extended over time, led, on the one hand, to splitting the academic environment between teaching and research departments, and, on the other hand, to integrating a substantial part of PRO personnel into university research groups. Larger and better connected departments now receive financial and material assistance from CNRS, which results in a vertical hierarchy of university labs: those staffed only by CNRS personnel and funded directly by CNRS; those staffed by both CNRS and university personnel; and finally those exclusively staffed by

${ }^{34}$ The Grandes Ecoles still play the same highly selective role. They are commonly divided into Ecoles d'ingénieurs (Schools of Engineering,), Ecoles de Commerce (Business Schools, or ESC) and Ecoles Normales Supérieurs (ENS, which offer degrees in hard sciences, social sciences, and humanities). 
university personnel, with little or no access to CNRS funds (Larédo and Mustar, 2001). A similar arrangement has been enacted for INSERM.

In the last decade, the whole system has witnessed several changes: the members of academic staff in universities have increased to more than 50000 units, whereas the totality of PROs now employs less than 35000 scientists. For a comparison, consider the 1970s, when the CNRS alone had as many researchers as the entire university system. Moreover, a second trait of the academic system, the Grandes Ecoles' separation from research, seems to have decreased. Finally, successive reforms have created a complex system of universities with different educational and research aims. According to the DEP/MENESR ${ }^{35}$ classification, we can distinguish between Grands Etablissements, Schools of Engineering, Instituts Nationaux Polytechniques, Universities with a Medical School, Universities without a Medical School, and Scientific Universities. This distinction is loosely based on two criteria: the statutory norms according to which they operate, and their disciplinary orientation. Statutory norms set both the Grands Etablissements and the Schools of Engineering apart, due to the reduced number of students they admit; while the latter are devoted to Engineering disciplines, the former are, from the disciplinary viewpoint, a heterogenous set. The Instituts Nationaux Polytechniques (3 in total) are also specialized in engineering education and correspond to a localized grouping of engineering schools (Grenoble, Toulouse, Nancy). As for disciplinary orientation, Universities are fully interdisciplinary (with the possible exception of medicine), while Scientific Universities are specialized in the hard sciences. In this classification scheme, the Grandes Ecoles mentioned above fall into either the School of Engineering category or the Grands Etablissements category, according to their specialization.

\subsubsection{Technology transfer and the Innovation Act of 1999}

The French public research system has often been criticized for being unable to transfer the results of its world-renowned research to industry. University-industry technology transfer was long characterized by strong intervention of the central government, whose large programs aimed chiefly at promoting the national independence of strategic sectors such as electronics, defense and nuclear technologies. These programs were put into practice by CNRS and INSERM and other large PROs, as well as by ad hoc agencies (such as CEA for atomic energy, INRA for agricultural research, and CNES for telecommunications), under direct control of the government.

The French government's attention towards the innovation role of the public research system increased significantly in the 1970s and bore its early fruits at the beginning of the 1980s, when the Mitterand presidency pushed through the Research Act (Loi d'Orientation et de Programmation), which listed among the explicit science policy objectives the commercial

${ }^{35}$ DEP/MENESR (Direction de l'Evaluation et de la Prospective / Ministere d'Education Nationale, de l'Enseignement Superieur et de la Recherche) is the official statistical Bureau of the Ministry of Education and Research. The classification we use here was last updated in 2003 and, although it serves mainly statistical purposes, it reflects the legal classification produced by the higher education reforms introduced in 1968, when the old faculties and institutes were reorganized into modern departments (Le Feuvre and Metso, 2005; Bach and Llerena, 2010). 
valorization and diffusion of public laboratories' research results (art. 14, Public Law 82-610). The same indications were extended to universities two years later (Public Law 84-52). These actions led to the creation of a dedicated agency for the transfer of research results from PROs ANVAR - and the proliferation of regional centers of innovation - CRITTs - responsible for easing access to the pool of local competences developed in universities. None of these interventions, however, achieved satisfactory results, at least according to the policy-makers' viewpoint (Larédo and Mustar, 2001). As for intellectual property, this did not figure prominently in the government's agenda for university-industry technology transfer. Neither IPR legislation nor any law on universities and PROs specifically addressed the issue of patents over publicfunded research results. The new Code de la propriété intellectuelle of 1992 never mentioned explicitly the case of academic scientists, whose economic rights over inventions were implicitly disciplined by the same rules applicable to R\&D employees; universities and PROs (as employers) formally retained full control over inventions resulting from their scientists' research, to the extent that the latter was conducted as part of the scientists' contractual duties as university/PRO employees. As a matter of fact, large PROs dealt actively with their scientists' inventive activity, either through internal Technology Transfer Offices (TTOs) or subsidiary companies in charge of patent management; universities did not have this type of organizations, and left IPR matters in their professors' hands (Gallochat, 2003; see also Carayol, 2006).

In the mid-1990s, the government was still deeply concerned with cooperation and knowledge transfer between the public research system and industry (Vavakova, 2006). Several consultations and proposals (Fillon in 1994 and d'Aubert in 1997) led to the approval of Public Law 99-597, also known as the Innovation Act or "Loi Allegre", from the name of the Minister of Research at the time. This piece of legislation was profoundly influenced by an earlier ministerial report (the Guillaume report in 1998), which stressed that a number of barriers hampered the flow of knowledge between public research and industry, among them a far too limited use of IPR instruments by universities.

The Innovation Act was not a piece of IPR legislation comparable to the Bayh-Dole Act, as it left the Code de la propriété intellectuelle unchanged, and at the same time introduced a number of provisions that went well beyond intellectual property. However, it aimed, among other things, to increase both the IPR awareness within the public research system and the rate of commercialization of academic inventions. A number of provisions were included in order to encourage universities and PROs to retain the IPRs over their scientists' inventions, or at least to share them with industrial partners (Gallochat, 2003).

First, the Innovation Act added explicitly the commercial exploitation of patents and licences to the universities' mission, on the same footing as teaching and research (art. 1, IV, comma for PROs and art. 2, IV, comma for universities).

Second, it introduced the possibility for both universities and PROs to create internal TTOs (called SAICs: Services d'Activités Industrielles et Commerciales), and both to staff them with 
external personnel and to run them according to business-like budgetary and accounting rules. (art. 2, I, comma for universities). ${ }^{36}$

In order to encourage PROs and universities, which had set up TTO-like subsidiaries, to switch to SAICs, and to retain control of intellectual property, a favorable taxation rule was introduced. According to this, subsidiaries' industrial and commercial activities were subject to taxation, whereas those of SAICs were not, as long as intellectual property was owned or coowned by the PRO or university. ${ }^{37}$

Immediately after approval of the Innovation Act, the Ministry of Research diffused a set of guidelines for university-industry cooperation, which included the recommendation to adopt an intellectual property charter (so that, especially in universities, IPR matters could be explicitly regulated) as well as negotiation with companies of "joint ownership agreements" over the results of collaborative R\&D. According to the Code de la propriété intellectuelle, such agreements are necessary in order to allow for flexibility in managing co-owned patents. ${ }^{38}$

\subsubsection{How to evaluate the impact of the Innovation Act on academic patenting in France?}

In order to assess the impact of the Innovation Act on academic patenting in France, we need to consider that history, both remote and recent, still weighs on French universities. It is clear that the Innovation Act is just one of many steps taken in France over the years in order to promote more autonomy for universities, and less dependence on CNRS and INSERM.

Therefore we expect to observe that its introduction helped universities to retain the property of a higher share of academic patents by withdrawing them from the exclusive control of the largest PROs. We also expect that French universities started engaging in tighter negotiation over IPRs with their business partners. Although the Innovation Act did not introduce financial autonomy for universities, but rather room and tools for limited self-financing via the market for technologies, it legitimized the use and exploitation of IPRs. More generally, handling complex IPR contracts, managing the related costs and income and setting personal incentives for academic inventors, are still tasks well beyond the possibilities of many French academic institutions.

Our two hypotheses to be tested, therefore, are the following:

(1) The Innovation Act, by strengthening academic institutions with regards to IPRs, has increased the share of academic patents owned or co-owned by such institutions;

${ }^{36}$ Before the Innovation Act, internal TTOs had to be run according to the same public law rules that disciplined the entire activity of universities and PROs. Such rules limited flexibility in recruitment (staff of TTOs had to come from within the organization, and be paid according to wage grids fixed by the government, and mainly related to seniority) and budgeting/accounting (which were intended to allow for governmental control of expenses, rather than business-like management of research and licensing contracts).

${ }^{37}$ This implies that R\&D contracts that left all IPRs in the industrial partners' hands were subject to taxation, while those that provided for universities' co-ownership or full ownership were not. These changes were scheduled to take place starting 1 January 2003.

${ }^{38}$ In principle, co-owned patents can be managed only through co-owners' unanimous decisions. This would make it difficult to license or sell them. Joint ownership agreements allow one partner to waive some decision rights to the others, so that managerial decisions can be taken more swiftly. 
(2) For the same reasons, the Innovation Act has reduced both the share of academic patents owned exclusively by PROs and the share controlled exclusively by business companies.

In addition, we stress that the Innovation Act followed a decade of earlier reforms, many of which had already encouraged the most research-intensive universities to set up their own TTOs, although possibly in the form of subsidiaries rather than SAICs. Thus, the impact of the Innovation Act can be appreciated only by controlling for the creation date of such offices, the impact of which may have been quite significant with respect to individual universities' IPR policy.

Finally, it is important to stress that data constraints do not allow us to test whether the Innovation Act increased the number of academic patents overall, whether retained by universities or assigned to PROs or business companies. The nature of such constraints, and the reason why they are so binding, will be made clear in the next section.

\subsection{Data}

Data for this study come from the KEINS database, which provides information on academic patenting in several European countries, and is part of the larger EP-INV database. ${ }^{39}$

The French section of the KEINS database contains detailed information on faculty members who appear as inventors of one or more patents applied for at the EPO (European Patent Office) between 1994 and 2002. It is the result of a matching exercise of names and surnames of scientists and engineers active within academic institutions, with names and surnames of inventors, as reported on EPO patents.

Data on French academic scientists and engineers originate from the Ministry of Education and were provided by BETA (Bureau d'Economie Théorique et Appliquée), a joint research unit of the University of Strasbourg and CNRS. They refer exclusively to tenured staff on active duty in 2005, to whom we will often refer, for the sake of simplicity, as "professors". In particular, the database contains information on 32006 professors in natural, medical, and engineering sciences, and includes variables such as their date of birth, university affiliation, and discipline, as well as their date of nomination to the current academic rank (either "maître de conférence" or "professeur").

After matching inventors from the EP-INV database with professors in the ministerial records, we filtered out incongruous matches by employing age and discipline filters. The age filter excluded all matches in which the professor turned out to be younger than 21 at the time of the patent filing. The discipline filter was based on a list of "incompatible" academic disciplines and IPC 3-digit codes of the patent. ${ }^{40}$ We then moved on to check for homonymic cases, in which two matched individuals share the same name and surname, but are not the same person. Given

${ }^{39}$ Lissoni et al. (2006) describe in detail the methodology for the classification of patents by inventor in the EP-INV database as well as the methodology applied to build the KEINS database on academic inventors.

40 IPC stands for International Patent Classification. It is a 12-digit contents-based classification system produced by WIPO (the World Intellectual Property Organization) and adopted by the EPO as the key tool for classifying patents according to the technological field they address. 
the large numbers of matches to check, we chose to focus only on those pairs wherein the inventor's latest patent had been filed after 1993, based on the assumption that additional information on the related individuals would be easier to retrieve. This choice left us with 3951 inventor-professor matches. For 2400 of them, we collected information either through direct contact (after retrieving the professor's e-mail address from the web) or by examining all onlineavailable information (the professor's CV, publications or mentioning in the patent applicant's website). ${ }^{41}$ For another 484 matches, the required information was provided by academic coinventors (as when professor A, co-inventor with professor B of a given patent, provided information on the latter, who had turned out to be unreachable). For the remaining 1067 matches, corresponding to 587 professors and 1215 patents, either no information was available, or the professors never answered our e-mails or telephone calls, so we excluded all of them from the analysis. ${ }^{42}$ As shown in Table 4.1, we ascertained that more than 1700 patent applications filed at the EPO between 1994 and 2002 relate to inventions and co-inventions by 1208 French faculty active in 2005 . They represent $3.27 \%$ of all French patents. As discussed in Lissoni et al. (2008), these values place France very much in line with other European countries (such as Italy and Sweden), and possibly not very far behind the USA. Most of the academic patents are in the fields of Instruments, Chemistry and Pharmaceuticals, respectively $20.07 \%, 25 \%$ and $28.5 \%$ (see Table 4.2). Their inventors come mainly from academic disciplines related to the life sciences and electronics (Table 4.3), and represent $2.33 \%$ of all French inventors. These findings are in line with those by Lissoni et al. (2008) for Italy and Sweden and Lissoni et al. (2009) for Denmark, and comparable to what was found by Thursby et al. (2009) for the USA. ${ }^{43}$

${ }^{41}$ Additional information on the universities employing our academic inventors was collected from the database of CURIE, the French network of technology transfer offices.

${ }^{42}$ Dropping patents by non-respondents minimizes Type I errors (where the hypothesis is that an inventorprofessor match signals an academic patent), but introduces Type II errors which lead to underestimation of the number of academic patents in any given year. This is one more reason not to rely on our data for a precise estimation of university scientists' contribution to patenting in France, as explained at the end of section 2. As for possible biases with respect to the main research question of the paper (whether the Innovation Act increased universities' propensity to retain the intellectual property of their scientists' invention), we observe that:

- $\quad$ the distribution of non-respondents' patents per year is very similar to that of respondents' patents (Pearson correlation index is over $92 \%$ );

the distributions per technological classes and type of ownership are also very similar.

Thus, we do not expect that including non-respondents' patents in the analysis would have improved our results, indeed quite the opposite. Finally, we suspect that many non-respondents who were not academic inventors simply did not bother to let us know, so that many non-responses are equivalent to negative responses.

${ }^{43}$ Patents by non-respondent professors, which we excluded from the analysis, exhibit a distribution by technology class which is more similar to that of non-academic patents than to academic ones. This suggests that non-respondents' patents are more likely not to be academic ones 
Table 4.1: French academic patenting activity between 1994 and 2002

\begin{tabular}{lccc}
\hline & Patents & Inventors & Patent Productivity \\
\hline Total Inventors & 53285 & 51839 & 1.028 \\
Academic Inventors & 1744 & 1208 & 1.444 \\
\hline Share of Academia & $3.27 \%$ & $2.33 \%$ & \\
\hline
\end{tabular}

Table 4.2: French patents and academic patents, by technology class

\begin{tabular}{|c|c|c|c|c|c|c|}
\hline Technology Class & $\begin{array}{l}\text { All patents, } \\
\text { no. and } \% \\
\text { (A) }\end{array}$ & $\begin{array}{c}\text { Academic } \\
\text { patents, } \\
\text { no. and } \%(\mathrm{~B})\end{array}$ & $\begin{array}{c}\text { All } \\
\text { inventors, } \\
\text { no. (C) }\end{array}$ & $\begin{array}{l}\text { Acad. } \\
\text { inventors, } \\
\text { no. (D) }\end{array}$ & $\mathrm{B} / \mathrm{A}$ & $\mathrm{D} / \mathrm{C}$ \\
\hline Electronics & $\begin{array}{c}12991 \\
(24.38 \%)\end{array}$ & $\begin{array}{c}251 \\
(14.39 \%)\end{array}$ & 14448 & 218 & $1.93 \%$ & $1.51 \%$ \\
\hline Instruments & $\begin{array}{c}6823 \\
(12.80 \%)\end{array}$ & $\begin{array}{c}350 \\
(20.07 \%)\end{array}$ & 9189 & 341 & $5.13 \%$ & $3.71 \%$ \\
\hline Chemistry & $\begin{array}{c}6729 \\
(12.63 \%)\end{array}$ & $\begin{array}{c}436 \\
(25.00 \%)\end{array}$ & 8951 & 343 & $6.48 \%$ & $3.83 \%$ \\
\hline Pharmaceuticals & $\begin{array}{c}5363 \\
(10.06 \%)\end{array}$ & $\begin{array}{c}497 \\
(28.50 \%)\end{array}$ & 6352 & 399 & $9.27 \%$ & $6.28 \%$ \\
\hline Process Engineering & $\begin{array}{c}6784 \\
(12.73 \%)\end{array}$ & $\begin{array}{c}138 \\
(7.91 \%)\end{array}$ & 7941 & 145 & $2.03 \%$ & $1.83 \%$ \\
\hline Machinery - Transport & $\begin{array}{c}9431 \\
(17.70 \%)\end{array}$ & $\begin{array}{c}58 \\
(3.33 \%)\end{array}$ & 10456 & 44 & $0.61 \%$ & $0.42 \%$ \\
\hline Others & $\begin{array}{c}5164 \\
(9.69 \%) \\
\end{array}$ & $\begin{array}{c}14 \\
(0.80 \%)\end{array}$ & 4889 & 11 & $0.27 \%$ & $0.22 \%$ \\
\hline Total & $\begin{array}{c}53285 \\
(100 \%)\end{array}$ & $\begin{array}{c}1744 \\
(100 \%)\end{array}$ & 62226 & $1501^{\circ}$ & $3.27 \%$ & $2.33 \%$ \\
\hline
\end{tabular}

NOTE: Patents are classified according to the DT7/OST reclassification of IPC (OST, 2004)

The sum of all academic inventors exceeds their actual number, as given in Table 3.1, because some inventors patent in more than one technology class

Table 4.3: Academic patents by aggregated disciplines

\begin{tabular}{llcc}
\hline \multicolumn{1}{c}{ Aggregated Disciplines } & Patents & Inventors & Professors \\
\hline Mathematics & 72 & 35 & 6270 \\
Physics & 125 & 67 & 2660 \\
Chemistry & 545 & 321 & 3829 \\
Earth science & 2 & 1 & 1090 \\
Biology & 356 & 228 & 5445 \\
Life science & 397 & 246 & 6181 \\
Engineering & 32 & 31 & 2052 \\
Electronics & 383 & 279 & 4324 \\
\hline All disciplines & 1912 & 1208 & 31851 \\
\hline
\end{tabular}

NOTE: The sum of all patents by discipline patents is higher than the actual number of patents, due to the fact that inventors from different disciplines appear as co-inventors of the same patents 
When it comes to examining time trends, we can only start our observations from 1994. In fact, our counting of academic patents relies on archival information on academic scientists active in 2004-05, which means that we do not have information on the identity of retired scientists. As a consequence, the older the patents we examine, the less likely we are to identify correctly those invented by such scientists. Therefore, we are bound to underestimate the number of academic patents produced back in time. Our data also suffer from right censoring, as the available patent data at the time of our collection stopped in 2001/02 (indeed, not even all patent applications with priority date in these two years - which we consider jointly - had been published). Although caution in drawing conclusions is to be recommended, Figure 4.1 shows that some positive trends may be detected in the number of academic patents after 1994 (the first year for which our data can be trusted for measuring the extent of the phenomenon), especially in Pharmaceuticals, Chemistry, and Electronics. The 2001/02 dip may be entirely due to a statistical artefact, for the reasons explained above.

However, this trend does not translate into an increasing weight of academic patenting over total patenting by domestic inventors, as shown in Figure 4.2. This suggests a lack of impact of the Innovation Act on academic patenting, but our data cannot substantiate this evidence, nor can they be explained by it, due to the short time window they cover. So, as already stated in section 4.2 , we prefer to leave it for future research. ${ }^{44}$ We classify assignees of academic patents into three categories: Companies (C), which include both business companies (French and foreign) and individual inventors; ${ }^{45}$ Public research organizations (PRO), which include all institutions known in France as Etablissements Public à Caractère Scientifique et Technique (EPST; such as CNRS or INSERM) or Etablissements Public à Caractère Industriel et Commercial (EPIC), and are listed as such on the website of the French Ministry of Research; Universities (UNI), as listed in the same database from which we extracted the professors' names and information. They can be divided according to the DEP/MENSER classification we introduced in section 4.2.2.1. ${ }^{46}$

${ }^{44}$ While right censoring may be less of a problem when investigating patent ownership trends (which depend mainly on shorter-term decisions by university administrators and negotiation with industrial partners or PROs), it is certainly a problem when examining patent numbers. In this case, in fact, the latter turn out to be an indicator of research output, which is affected by research inputs and change over a longer time frame.

${ }^{45}$ Patents assigned to individuals, most often the academic inventors themselves, are only 3.6\% of French academic patents (see: Lissoni et al., 2008). This is expected, due to the absence of any legal provision similar to that of the professor's privilege, as discussed in section 2. At the same time though, it may be that several patents formally assigned to business companies are de facto owned by their inventors, who control the companies and possibly set them up with the precise intention of using them as vehicles for retaining control of their patents. For these reasons, we have considered the two types of ownership as one. Note also that introducing a separate category for so few patents would not have helped the econometric exercise we run in section 4, the observations in the category being too few to return significant results.

${ }^{46}$ Since patents can be co-assigned to multiple assignees, a patent may fall into more than one of the abovementioned categories at the same time, whenever it has more than one assignee, and two or more of such assignees belong to different categories. We will come back to this problem in section 4 . 
Figure 4.1: Number of academic patents by technological class, 1994-2001/02

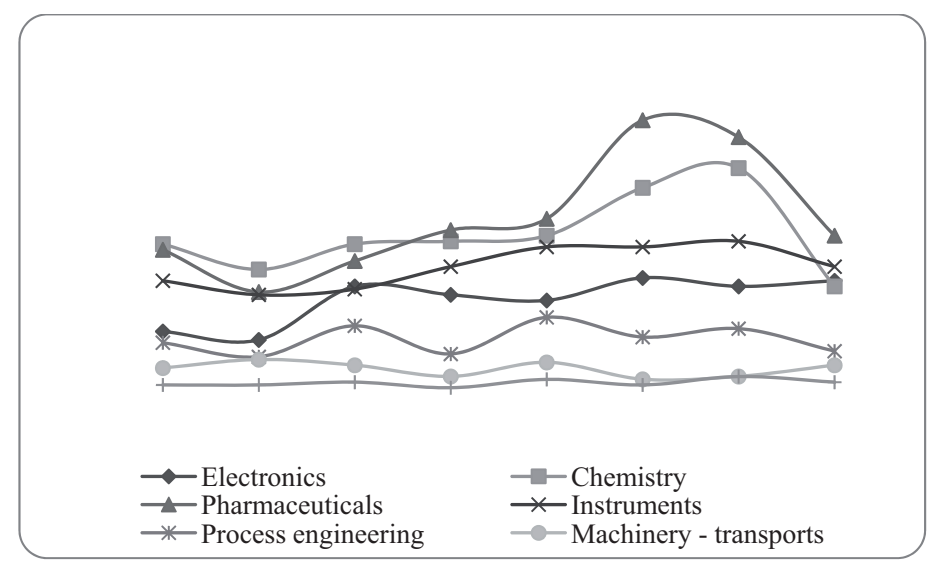

Figure 4.2: Share of academic patents over all patents, by techn. class, 1994-2001/02

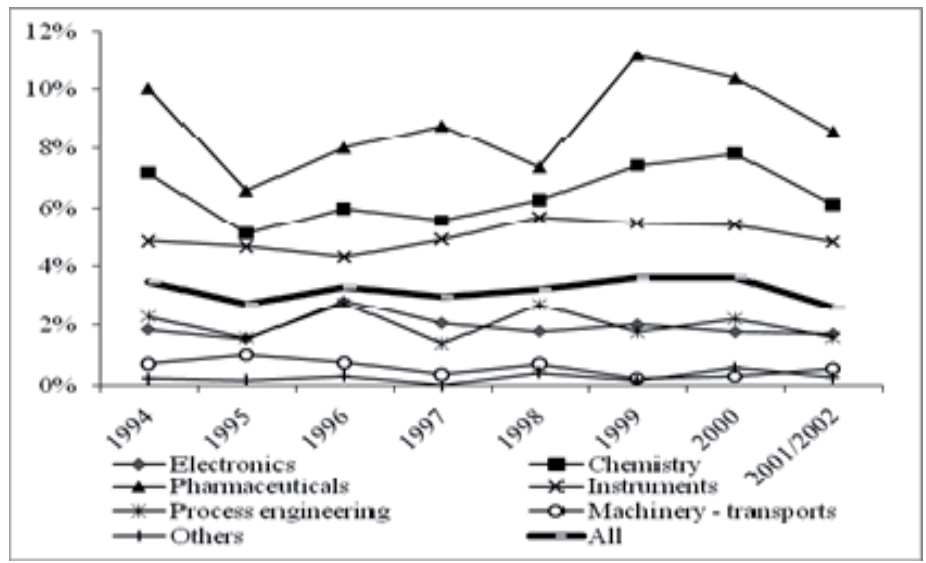

Table 4.4: Academic patents by Applicants and DT-7/OST technology domains

\begin{tabular}{lcccccc}
\hline & \multicolumn{5}{c}{ Type of Applicant } \\
\cline { 2 - 7 } Technology Classes & $\mathrm{C}$ & PRO & UNI & \%C & $\%$ PRO & $\%$ UNI \\
\hline Electronics & 237 & 44 & 23 & $77.96 \%$ & $14.47 \%$ & $7.57 \%$ \\
Instruments & 331 & 86 & 49 & $71.03 \%$ & $18.45 \%$ & $10.52 \%$ \\
Chemistry & 391 & 85 & 25 & $78.04 \%$ & $16.97 \%$ & $4.99 \%$ \\
Pharmaceuticals & 378 & 209 & 93 & $55.58 \%$ & $30.74 \%$ & $13.68 \%$ \\
Process engineering & 110 & 40 & 25 & $62.86 \%$ & $22.86 \%$ & $14.28 \%$ \\
Machinery - transports & 55 & 4 & 7 & $83.33 \%$ & $6.06 \%$ & $10.61 \%$ \\
Others & 13 & 1 & 0 & $92.86 \%$ & $7.14 \%$ & $0.00 \%$ \\
\hline Total & 1515 & 469 & 222 & $68.68 \%$ & $21.26 \%$ & $10.06 \%$ \\
\hline
\end{tabular}

NOTE Patents co-owned by different typologies of applicants are counted as many times as the typologies of applicants. 
Table 4.5: Academic patents, by technology and type of inventor's university

\begin{tabular}{lcccccccc}
\hline \multirow{2}{*}{ University Type } & \multicolumn{7}{c}{ Technology Classes } \\
\cline { 2 - 9 } & Elec. & Instr. & Chem. & Pharma. & Eng. & M\&t & Others & All \\
\hline School of Engineering & 30 & 27 & 54 & 23 & 30 & 8 & 0 & 172 \\
& $17.40 \%$ & $15.70 \%$ & $31.40 \%$ & $13.40 \%$ & $17.40 \%$ & $4.70 \%$ & $0.00 \%$ & $100.00 \%$ \\
Grand Etablissement & 21 & 8 & 5 & 5 & 1 & 6 & 1 & 47 \\
& $44.70 \%$ & $17.00 \%$ & $10.60 \%$ & $10.60 \%$ & $2.10 \%$ & $12.80 \%$ & $2.10 \%$ & $100.00 \%$ \\
Inst. National & 20 & 20 & 39 & 8 & 17 & 5 & 0 & 109 \\
Polytechnique & $18.30 \%$ & $18.30 \%$ & $35.80 \%$ & $7.30 \%$ & $15.60 \%$ & $4.60 \%$ & $0.00 \%$ & $100.00 \%$ \\
University, with medical & 139 & 251 & 215 & 470 & 70 & 26 & 12 & 1183 \\
school & $11.70 \%$ & $21.20 \%$ & $18.20 \%$ & $39.70 \%$ & $5.90 \%$ & $2.20 \%$ & $1.00 \%$ & $100.00 \%$ \\
& 24 & 35 & 71 & 25 & 13 & 10 & 0 & 178 \\
University, no medical & $13.50 \%$ & $19.70 \%$ & $39.90 \%$ & $14.00 \%$ & $7.30 \%$ & $5.60 \%$ & $0.00 \%$ & $100.00 \%$ \\
school & 38 & 59 & 116 & 31 & 28 & 5 & 1 & 278 \\
Scientific university & $13.70 \%$ & $21.20 \%$ & $41.70 \%$ & $11.20 \%$ & $10.10 \%$ & $1.80 \%$ & $0.40 \%$ & $100.00 \%$ \\
\hline
\end{tabular}

NOTE: The sum of all patents exceeds the actual number of academic patents due to the fact that patents can be invented by professors affiliated to different typologies of universities. El=Electronics; Instr=Instruments; Chem=Chemicals; Pharma= Pharmaceuticals; Eng=Process Engineering; M\&T=Machinery \& Transport

Table 4.4 shows that companies command the highest share of academic patents, with around $69 \%$ of them. The PROs' share comes second, with over $21 \%$ of the patents, leaving universities with no more than $10 \%$ of academic patents (patents co-owned by $n>1$ types of applicant are counted $n$ times). Note that this result does not differ much from the findings by Gering and Schmoch (2003) for Germany, another country where public research system PROs (especially the Max Planck Institute) play a key role. ${ }^{47}$ It is worth pointing out that the ownership distribution of academic patents is not uniform across technologies. Universities appear as applicants of about $14 \%$ of academic patents in the Pharmaceutical domain and of $10.5 \%$ in Instrumentation, but only of 5\% in Chemistry. Companies have a disproportionately high share of academic patents in Chemistry (78\%), Machinery and Transportation (83\%), and Electronics (78\%). Patent applications by PROs are mainly in the field of Pharmaceuticals (30.7\%).

Research in the literature of technology transfer has shown that university characteristics matter when dealing with university patenting (Owen-Smith and Powell, 2001; Feldman and Desrochers, 2003). We take this into account in Table 4.5, which is based upon the DEP/MENSER classification we introduced in section 2.2.1. We note that faculty members of Universities with Medical School patent chiefly in Pharmaceuticals (40\% of their patents), whereas only around $10 \%$ of patents by scientists from other academic institutions are in the same field.

\footnotetext{
${ }^{47}$ Patents by non-respondent professors, which we excluded from the analysis, exhibit a distribution by type of owner which is more similar to that of non-academic patents than academic ones.
} 
Figure 4.3: Property distribution of academic patents over time

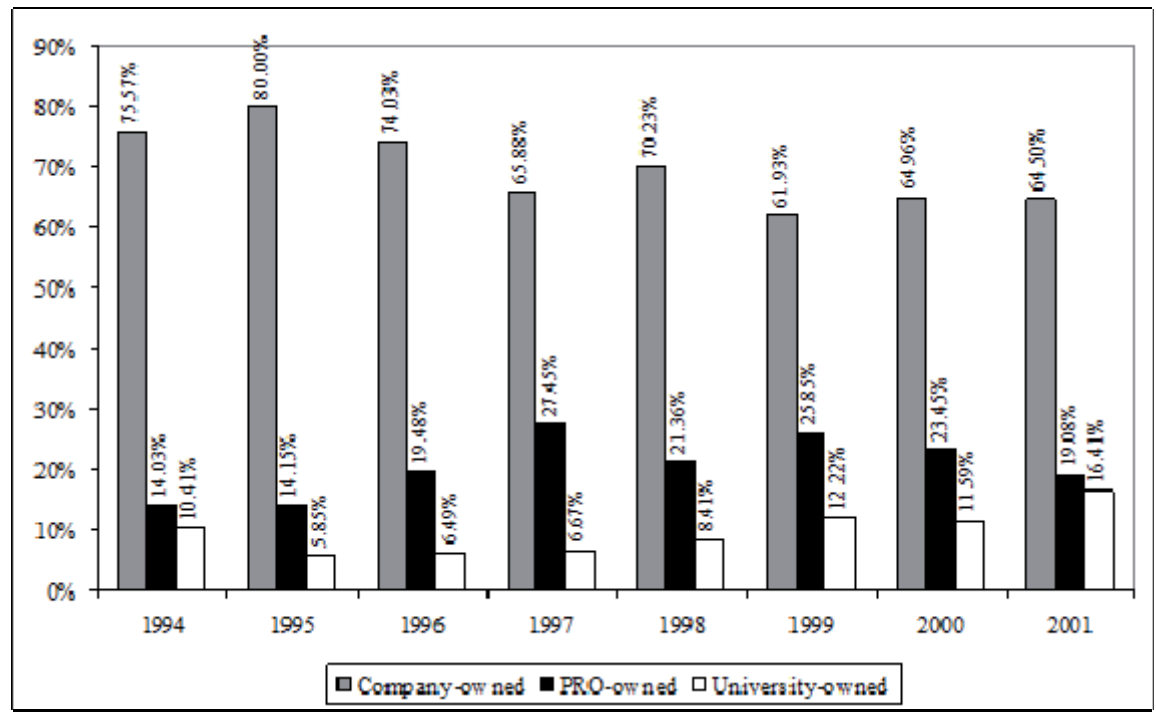

The patenting activity in Scientific Universities and Universities without Medical School is mainly concentrated in Chemistry (about 40\%). Grandes Etablissements appear to be most involved in patenting in Electronics (45\% of their patents). At the same time, we note that Universities with Medical School are responsible for around $60 \%$ of French academic patents (1183 out of 1967).

Figure 4.3 provides details on the ownership distribution of academic patents over time. We note that academic patent applications by Companies decline from $75.57 \%$ in 1994 to $64.50 \%$ in 2001, although in absolute values they increase from 167 in 1994 to 240 in 2000. In contrast, the universities' share increases from $10.4 \%$ in 1994 to $16.42 \%$ in 2001 , sharply increasing from $8.41 \%$ in 1998 to $12.22 \%$ in 1999 .

\subsection{Analysis}

In order to assess whether the introduction of the Innovation Act in 1999 has changed the IPR practices of French universities, we perform several econometric exercises. In particular, we run both logistic and multinomial logistic regressions, with the type of applicant for the academic patent (Company, PRO, or University) as the dependent variable. The key explanatory variables are two time-related dummies, one which distinguishes between patents applied for before/after the introduction of the Innovation Act, the other that marks the absence/presence, in the application year, of a TTO within the academic inventor's university. Controls include technological classification of the patent and a set of characteristics (such as type and size) of the inventor's university, as well as regional dummies to control for local characteristics of the regions wherein the universities are located. 


\subsubsection{The dependent variable}

We run two series of regressions, each one with a different specification of the dependent variable, namely a different classification of patent ownership. Note that most patents have a single applicant, but many have more than one (which is often the case when universities are involved in ownership).

In the first series of regressions (logistic), we adopt a binary dependent variable and distinguish only between university-ownership ( $\mathrm{UNI}=1)$ and non-university ownership (UNI=0). All patents having at least one university among applicants belong to the former category. This means we focus on universities' claim of their share of IPRs, without distinguishing between exclusive ownership and co-ownership, as a result of the introduction of the Innovation Act and controls.

In a second set of regressions (multinomial logistic), we classify patents into three ownership categories, which result from a combination of the types of owners described in section 3 . Each category is assigned a discrete value (from 1 to 3), as follows. Ownership by a PRO, either exclusive or jointly with a Company (OWNERSHIP=1); Exclusive ownership by a company (OWNERSHIP =2); University ownership, either exclusive or joint with a PRO or a company $(\mathrm{OWNERSHIP}=3)$

The main reason for not treating exclusive university ownership as a separate category, but only together with the case of joint ownership with PROs and companies, is that very few patents are assigned exclusively to universities. As explained in section 2, the most research-intensive among French universities usually host a number of Unités Mixtes de Recherche (UMRs), which are research joint ventures with CNRS, INSERM or other large PROs. Technology transfer from UMRs thus result in a relatively high number of patents jointly owned by the relevant PRO and the university. A more limited number of patents is jointly owned by a university and a company, too few for setting them apart, hence the decision to group all of them under the value OWNERSHIP=3. Similarly, the patents jointly owned by a PRO and a company are very few, so we decided to group them under the value OWNERSHIP=1, which leaves all patents with value OWNERSHIP $=2$ as those where no public property (via a university or a PRO) is involved. ${ }^{48}$

\subsubsection{The independent variables}

Time-related regressors: the key explanatory variables of interest in the regression are: $\underline{\mathrm{ACT}}$ which takes zero value if the patent was applied for between 1994 and 1998 and value one in the following years (that is, after the introduction of the Innovation Act).

${ }^{48}$ In an early version of this work, we employed five categories, the three of this study and two more including co-ownership between Companies and PROs and co-ownership between Companies and Universities. However, tests for independence of irrelevant alternatives rejected the latter. 
Table 4.6: Independent variables, descriptive statistics

\begin{tabular}{|c|c|c|c|c|c|c|c|c|}
\hline \multirow[b]{2}{*}{ Variables } & \multicolumn{2}{|r|}{ Total } & \multicolumn{2}{|c|}{ PROs } & \multicolumn{2}{|c|}{ Companies } & \multicolumn{2}{|c|}{ Universities } \\
\hline & Mean & Std Dev & Mean & Std Dev & Mean & Std Dev & Mean & Std Dev \\
\hline ACT & 0.44 & $(0.50)$ & 0.47 & $(0.50)$ & 0.40 & $(0.49)$ & 0.58 & $(0.50)$ \\
\hline 1994 & 0.11 & $(0.31)$ & 0.08 & $(0.27)$ & 0.12 & $(0.32)$ & 0.10 & $(0.30)$ \\
\hline 1995 & 0.09 & $(0.28)$ & 0.06 & $(0.24)$ & 0.10 & $(0.30)$ & 0.06 & $(0.25)$ \\
\hline 1996 & 0.12 & $(0.32)$ & 0.10 & $(0.30)$ & 0.13 & $(0.34)$ & 0.07 & $(0.26)$ \\
\hline 1997 & 0.12 & $(0.32)$ & 0.15 & $(0.36)$ & 0.11 & $(0.32)$ & 0.07 & $(0.26)$ \\
\hline 1998 & 0.14 & $(0.35)$ & 0.14 & $(0.35)$ & 0.14 & $(0.35)$ & 0.11 & $(0.32)$ \\
\hline 1999 & 0.16 & $(0.37)$ & 0.20 & $(0.40)$ & 0.14 & $(0.34)$ & 0.21 & $(0.41)$ \\
\hline 2000 & 0.17 & $(0.37)$ & 0.19 & $(0.39)$ & 0.15 & $(0.36)$ & 0.19 & $(0.39)$ \\
\hline 2001 onwards & 0.11 & $(0.32)$ & 0.08 & $(0.27)$ & 0.11 & $(0.31)$ & 0.19 & $(0.39)$ \\
\hline TTO & 0.64 & $(0.48)$ & 0.61 & $(0.49)$ & 0.63 & $(0.48)$ & 0.77 & $(0.42)$ \\
\hline Schools of Eng. & 0.15 & $(0.36)$ & 0.12 & $(0.33)$ & 0.17 & $(0.37)$ & 0.14 & $(0.35)$ \\
\hline Univ. w/ Medical Schools & 0.60 & $(0.49)$ & 0.70 & $(0.46)$ & 0.55 & $(0.50)$ & 0.67 & $(0.47)$ \\
\hline Univ. w/out Medical Schools & 0.09 & $(0.28)$ & 0.06 & $(0.23)$ & 0.10 & $(0.30)$ & 0.06 & $(0.25)$ \\
\hline Scientific Univ. & 0.16 & $(0.37)$ & 0.12 & $(0.33)$ & 0.19 & $(0.39)$ & 0.12 & $(0.33)$ \\
\hline Largest & 0.25 & $(0.43)$ & 0.26 & $(0.44)$ & 0.22 & $(0.42)$ & 0.35 & $(0.48)$ \\
\hline Large & 0.29 & $(0.46)$ & 0.32 & $(0.47)$ & 0.29 & $(0.45)$ & 0.30 & $(0.46)$ \\
\hline Medium & 0.37 & $(0.48)$ & 0.36 & $(0.48)$ & 0.39 & $(0.49)$ & 0.25 & $(0.43)$ \\
\hline Small & 0.09 & $(0.29)$ & 0.07 & $(0.25)$ & 0.10 & $(0.30)$ & 0.10 & $(0.30)$ \\
\hline Instruments & 0.20 & $(0.40)$ & 0.18 & $(0.39)$ & 0.21 & $(0.41)$ & 0.20 & $(0.40)$ \\
\hline Pharma - Biotech & 0.29 & $(0.45)$ & 0.42 & $(0.49)$ & 0.21 & $(0.41)$ & 0.44 & $(0.50)$ \\
\hline Chemicals & 0.14 & $(0.35)$ & 0.10 & $(0.30)$ & 0.17 & $(0.38)$ & 0.10 & $(0.30)$ \\
\hline Electronic & 0.25 & $(0.43)$ & 0.20 & $(0.40)$ & 0.29 & $(0.45)$ & 0.12 & $(0.32)$ \\
\hline Machinery - Process Tech & 0.12 & $(0.33)$ & 0.10 & $(0.31)$ & 0.12 & $(0.33)$ & 0.15 & $(0.36)$ \\
\hline \# Observations & \multicolumn{2}{|c|}{1744} & \multicolumn{2}{|c|}{383} & \multicolumn{2}{|c|}{1157} & \multicolumn{2}{|c|}{204} \\
\hline
\end{tabular}

In a different specification of the model, we substitute the variable ACT with YEAR DUMMIES, taking 1999 as reference year. TTO takes a value equal to one if the patent was applied after the university had introduced an internal regulation regarding IPR and technology transfer matters, either internally or as external entities, and zero otherwise ${ }^{49}$. We expect ACT

${ }^{49}$ The TTO dummy is a university-specific one, which is based upon information on the opening year of TTOs in French universities taken from the BETA-EcoSc database. If a patent lists only one academic inventor, or several academic co-inventors from the same university, assigning a value to TTO is a straightforward exercise (this happens for $89 \%$ of the cases, that is, 1552 out of 1744 patents). However, patents invented by more than one academic inventor from different universities may present us with the problem of choosing between different possible values for the TTO dummy, as long as the relevant universities opened their technology transfer offices in different years. In these cases, we first set aside university-owned patents, with just one university as assignee, and set the value of TTO according to information on the latter (2.3\% of the cases). When this criterion cannot be applied, we select the most senior among the academic co-inventors of the patent, and set the value of TTO according to information on this senior scientist's university ( $5.3 \%$ of cases). This choice is based on the assumption that, at the time of the patent, the more junior co-inventors used to work with the most senior one at her university, either as PhD, PostDoc or young Assistant Professors, and moved on to their present institute later on. If this assumption proves untenable (the junior co-inventor's move to her present institute pre-dates the patent application), 
and TTO to bear a positive influence on the probability for UNI to take value 1 in the logistic regressions and for OWNERSHIP to take value 3 in the second series of (multinomial logistic) regressions. Similarly, when substituting year dummies to ACT, we expect dummies for years before 1999 to bear a negative and significant sign in both series of regressions.

Institutional differences: We control for the academic inventors' affiliation to one or other type of academic institutions by turning such classification into a set of dummies, which are based upon the DEP/MENESR classification, according to the affiliation of the patent's inventor: School of Engineering (to which we add the Instituts Nationaux Polytechniques and the Grands Etablissements, the technology transfer activity of which occurs mainly in Engineering), Universities with Medical School, Universities without Medical School, and Scientific Universities. If more than one academic co-inventor is listed on the same patent, and they come from institutes of different type, then the dummy takes value 1 according to the assigning procedure described in Footnote 11. The reference category is Universities with Medical School.

Size: We control for university size by classifying the various institutions as largest, large, medium and small, according to quartile distribution of the number of medical, science and engineering faculties in $2005 .{ }^{50}$ We thus employ dummies for each size category. The reference category is largest and we expect such universities to be more likely than others to apply for patents in their own name, being better staffed when it comes to administrative issues. In addition, we expect such universities to have greater bargaining power vis a vis large PROs such as CNRS, when it comes to negotiations over IPR attribution.

Patent's technological field: This set of controls consists of dummies for the technology class of the patents, which we derived by elaborating a re-classification of IPC (International Patent Classification, used by the EPO) provided by the Observatoire des Sciences et des Techniques (OST, 2004). In particular, we use the following five dummies: Pharma-Biotech, Instruments (Scientific and Measurement), Chemicals, Electronics and Machinery and Process Technologies, the latter being the reference category.

Regional dummies: Finally, we control for potential differences in the regional environment of the various universities by means of a set of 21 dummies, one for each mainland region of France.

we assume that decisions on ownership attribution of the patent had been taken by the academic inventor from the university with the most expertise in handling IPR matters (the latter being measured by the total number of all patents produced by the university). This choice, which is highly subjective, applies only to $3.3 \%$ of the patents.

${ }^{50}$ Note that information on faculty size relates only to 2005 , the only year for which we have information on universities. In principle, professors' mobility may have been such that relative size in the past differed from that of 2005. However, the largest universities of the 1990s, such as Paris VI, Lyon I, Toulouse III, Grenoble I or Strasbourg I, were and still are the largest at the time we wrote the paper. Also, we found no mention in the literature of significant structural changes across French universities in the years of our interest. 


\subsection{Results and discussion}

\subsubsection{The binary model of patent assignment}

Table 4.7 reports the results of our logistic regression exercise on the probability of an academic patent being assigned to the inventor's university, either exclusively or jointly with another type of assignee (either a PRO or a company); for the sake of simplicity, we will often refer to this as a university's "probability of patenting". We report estimates of marginal effects of explanatory variables calculated as means for continuous variables and changes from 0 to 1 for dichotomous variables. We employ four specifications. In column (A), we consider only the effect of the Innovation Act (ACT), while in column (C) we also test for the opening of a Technology Transfer Office in the inventor's university (TTO). In columns (B) and (D), we conduct similar exercises, but we substitute variable ACT with year dummies, with 1999, the year when the Act was passed, as the reference case. We expect dummies for years $>1999$ to be positive, and/or dummies for years $<1999$ to be negative.

Estimates in column (A) suggest a positive and significant effect of the Innovation Act on the probability that universities will apply for their inventors' patents; in particular, we estimate an increase of probability of around $5.7 \%$. The controls for university typology do not capture any variation in patent assignment. ${ }^{51}$ However, the size of universities seems to matter, as we observe that small and medium universities' probability of patenting is, respectively, $5.3 \%$ and $6.8 \%$ lower than that of the largest universities (the reference case). Finally, universities are less likely to apply for patents in Electronics and Chemicals than in Pharma-Biotech, Scientific Instruments, and Machinery-Process Technology. We interpret differences between Electronics and Chemicals on the one hand, and Pharma-Biotech and Scientific Instruments, on the other hand, as resulting from differences in the inventive process and funding, and in the relationship between patented invention and commercial product. ${ }^{52}$

When substituting ACT with year dummies (column B), universities are found to have been less likely to apply for patents before 1999: the dummies associated with the years between 1995 and 1998 are all negative and significant, while the year dummies after 1999 are not significant.

${ }^{51}$ This result is not overly surprising as controls for technological fields are the strongest explanatory factor among our controls (see results for specification 2). At the same time, we noted earlier (Table 3.5) that university types differ for the technological fields in which their inventors sign patents.

${ }^{52}$ Patents in Electronics and Chemicals are more likely to originate from consultancy and contract research than happens in other fields, with commercial sponsors claiming all IPRs. In addition, patented inventions may cover only a small section of larger, more complex product and process technologies than in Pharmaceuticals or Instruments, where a patent document may point more clearly to a marketable drug or scientific or measurement tool; the longer the distance between patent and product, the less interest the university may have in retaining the patent and trying to license it, as opposed to selling it straight away for a lump sum payment. 
Table 4.7: Results of the Logistic regressions

\begin{tabular}{|c|c|c|c|c|}
\hline & $(\mathrm{A})$ & (B) & (C) & (D) \\
\hline \multirow[t]{2}{*}{ Act } & $0.057 * * *$ & & $0.047 * * *$ & \\
\hline & $(0.014)$ & & $(0.014)$ & \\
\hline \multirow[t]{2}{*}{1994} & & -0.022 & & -0.016 \\
\hline & & $(0.021)$ & & $(0.022)$ \\
\hline \multirow[t]{2}{*}{1995} & & $-0.044 * *$ & & $-0.042 * *$ \\
\hline & & $(0.019)$ & & $(0.019)$ \\
\hline \multirow[t]{2}{*}{1996} & & $-0.051 * * *$ & & $-0.049 * * *$ \\
\hline & & $(0.017)$ & & $(0.017)$ \\
\hline \multirow[t]{2}{*}{1997} & & $-0.052 * * *$ & & $-0.048 * * *$ \\
\hline & & $(0.017)$ & & $(0.017)$ \\
\hline \multirow[t]{2}{*}{1998} & & $-0.040 * *$ & & $-0.040 * *$ \\
\hline & & $(0.018)$ & & $(0.017)$ \\
\hline \multirow[t]{2}{*}{2000} & & -0.013 & & -0.018 \\
\hline & & $(0.020)$ & & $(0.018)$ \\
\hline \multirow[t]{2}{*}{2001 onwards } & & 0.033 & & 0.020 \\
\hline & & $(0.027)$ & & $(0.025)$ \\
\hline \multirow[t]{2}{*}{ TTO } & & & $0.056^{* * *}$ & $0.056^{* * *}$ \\
\hline & & & $(0.015)$ & $(0.015)$ \\
\hline \multirow[t]{2}{*}{$\begin{array}{l}\text { School of } \\
\text { Engineering }\end{array}$} & 0.073 & 0.068 & 0.034 & 0.029 \\
\hline & $(0.049)$ & $(0.047)$ & $(0.041)$ & $(0.039)$ \\
\hline \multirow[t]{2}{*}{$\begin{array}{l}\text { University w/out } \\
\text { Med School }\end{array}$} & 0.043 & 0.039 & 0.041 & 0.036 \\
\hline & $(0.044)$ & $(0.043)$ & $(0.043)$ & $(0.042)$ \\
\hline \multirow[t]{2}{*}{ Scientific University } & -0.026 & -0.026 & -0.025 & -0.025 \\
\hline & $(0.023)$ & $(0.022)$ & $(0.023)$ & $(0.023)$ \\
\hline \multirow[t]{2}{*}{ Large } & 0.001 & 0.000 & 0.018 & 0.016 \\
\hline & $(0.021)$ & $(0.021)$ & $(0.023)$ & $(0.023)$ \\
\hline \multirow[t]{2}{*}{ Medium } & $-0.068 * * *$ & $-0.067 * * *$ & -0.037 & -0.037 \\
\hline & $(0.023)$ & $(0.023)$ & $(0.025)$ & $(0.025)$ \\
\hline \multirow[t]{2}{*}{ Small } & $-0.053 * *$ & $-0.050 *$ & -0.012 & -0.008 \\
\hline & $(0.025)$ & $(0.026)$ & $(0.039)$ & $(0.041)$ \\
\hline \multirow[t]{2}{*}{ Pharma-Biotech } & 0.007 & 0.007 & 0.014 & 0.013 \\
\hline & $(0.022)$ & $(0.022)$ & $(0.022)$ & $(0.022)$ \\
\hline \multirow[t]{2}{*}{ Instruments } & -0.028 & -0.029 & -0.024 & -0.025 \\
\hline & $(0.020)$ & $(0.019)$ & $(0.020)$ & $(0.019)$ \\
\hline \multirow[t]{2}{*}{ Electronic } & $-0.054 * * *$ & $-0.054 * * *$ & $-0.049 * * *$ & $-0.050 * * *$ \\
\hline & $(0.017)$ & $(0.017)$ & $(0.017)$ & $(0.017)$ \\
\hline \multirow[t]{2}{*}{ Chemicals } & $-0.080 * * *$ & $-0.078 * * *$ & $-0.074 * * *$ & $-0.073 * * *$ \\
\hline & $(0.017)$ & $(0.017)$ & $(0.017)$ & $(0.017)$ \\
\hline Regional Dummies & \multicolumn{4}{|c|}{ Included } \\
\hline \# Observations & \multicolumn{4}{|c|}{1744} \\
\hline Goodness-of-fit & $\chi 2(315)=436.3 * * *$ & $\chi 2(732)=906.9 * * *$ & $\chi 2(362)=519.0 * * *$ & $\chi 2(787)=1015.3^{* * *}$ \\
\hline
\end{tabular}

NOTE: $*=10 \%$ significance, $* *=5 \%$ significance, $* * *=1 \%$ significance. Standard errors are reported in parentheses below coefficient.

Results are reported as marginal effects calculated as changes from 0 to 1 of dummy variables. 
Universities' probability of patenting before 1999 is estimated to be between $4 \%$ and $5.2 \%$ lower than in 1999 and afterwards. As for the other controls, they do not change much with respect to column (A). Moving to column (C), we notice that the inclusion of TTO captures all the variation attributed to university size in columns (A) and (B); this is because, as expected, the larger universities were the first to open a technology office. The presence of a TTO increases a university's patenting probability to 5.6\%. Note that controlling for TTO diminishes, but does not cancel or cut drastically, the impact of the Innovation Act (the marginal effect of ACT is only $1 \%$ lower in column $\mathrm{C}$ than in column A). Results on the technology classes of the patents do not change much. The last specification (column D) confirms the results of the previous specifications: the opening of a TTO mitigates the effects of the Act and captures the variation due to university characteristics, while it does not affect other covariates' marginal effects.

The significance of ACT, along with the positive and significant impact of TTO, confirms the importance of institutional changes, both at the micro and macro levels, in increasing university administrations' IPRs awareness. Note that these results do not change when we employ year dummies to control for the temporal consistency of the positive result found for ACT. We also find that the opening of a technology transfer office has the strongest impact among university characteristics on the decision to retain ownership over academic inventions.

\subsubsection{The multinomial model of patent assignment}

Table 4.8 presents the results (estimated marginal effects) for multinomial logistic regressions. The three-value OWNERSHIP dependent variable allows us to assess whether the increase of patent ownership by universities (as described by the logistic regressions of section 4.5.1) has occurred at the expense of ownership by PROs and/or companies. We run two different specifications, which we indicate as (1) and (2). In both specifications, we assess the effect of the Innovation Act jointly with that of a university's opening of a TTO. In specification (1), we do so by means of the ACT dummy, whereas in specification (2), we make use of the year dummies, as described above. The results for each specification are reported in three separate columns, as we calculate and report the marginal effects of the independent variables for all three types of ownership considered, respectively PROs, Companies, and Universities.

The main results we obtain can be summarized as follows. The Innovation Act did not significantly diminish the probability for an academic patent to be owned by a PRO, and possibly increased it for a short while, other things being equal. While the marginal effect for ACT [specification (1), first column] is positive but not significant, the year dummies for year $<1999$ are all negative [specification (2), second column]. This suggests that, in the 1990s, before the Act was introduced, PROs had a lower probability for reclaiming ownership or co-ownership of academic patents away from universities. Remember that OWNERSHIP $=1$ in the case the academic patent is owned by a public organization, possibly jointly with a company, but not jointly with a university, in which case OWNERSHIP=3. The year dummy for 2001, however, also bears a negative and significant sign, which may suggest that the effect of the Act, besides being weak, may not have lasted long. It is also possible that the Act did not affect negotiations 
over IPR assignment between PROs and universities, whereas the more general reform of the relationships between the two (as described in section 4.2.2) did, albeit not consistently over time. This interpretation is coherent with the descriptive findings by Lissoni et al. (2008), who find that PROs' share of academic patents declined sharply through the 1980s and early 1990s (that is, before the Innovation Act) and bounced back, albeit limitedly, later on.

Exclusive property of academic patents by companies (OWNERSHIP=2) appears to have been negatively affected by the Innovation Act, which diminished its probability by $7.3 \%$ [marginal effect of ACT, specification (1), third column]. This seems confirmed by specification (2) (fourth column), where marginal effects of year dummies show that the probability of having an academic patent in the exclusive hands of private parties was between $12 \%$ and $14.5 \%$ higher in 1994-1996 than in 1998 and the following years; in the latter, we observe some weak increases in 1998 and 2001.

As for universities, the interpretation of the results is even more straightforward. As in the binary model (section 4.5.1), the probability of exclusive or joint ownership by universities increases after the Innovation Act, whether we consider specification (1) (fifth column) or specification (2) (sixth column). In the latter, we observe that universities' probability of patenting is significantly lower between 1995 and 1998 than in 1999, and does not increase or decrease significantly later on.

Overall, these results suggest that the Act, and/or more generally, the political climate around universities and their mission, including IPR management, have made universities more aggressive in reclaiming their share of IPRs over academic patents from companies, but have not changed their attitude much towards PROs. Possibly, the latter have also increased their pressure on companies to share the IPRs over the inventions produced by academics (most likely, with the participation of PROs' personnel and/or in university-based, PRO-staffed laboratories). It is important to stress, however, that the number of patents exclusively assigned to universities is still limited. In order to increase their control over academic patents, universities have mainly obtained to share the property of such patents, especially with companies, which, as a result, are now less likely to be the exclusive assignees. ${ }^{53}$

When examining the effect of TTO, we find that the estimated effect for the TTO dummy is significant (and positive) for the probability of university ownership (last two columns of Table 5.2 ), but it is not significant (albeit negative, as expected) for the probability of PRO and company ownership (first four columns of Table 4.8).

\footnotetext{
${ }^{53}$ Given the limited number of academic patents co-applied for by universities and companies (34 out of 1744 patent applications in the whole sample), we were unable to test such a statement empirically. However, in the university-company academic patent subsample, only 13 (38.2\%) were applied for between 1994 and 1998, whereas $56 \%$ of all academic patents were applied for during the same years.
} 
Table 4.8: Results of the Multinomial Logistic regressions

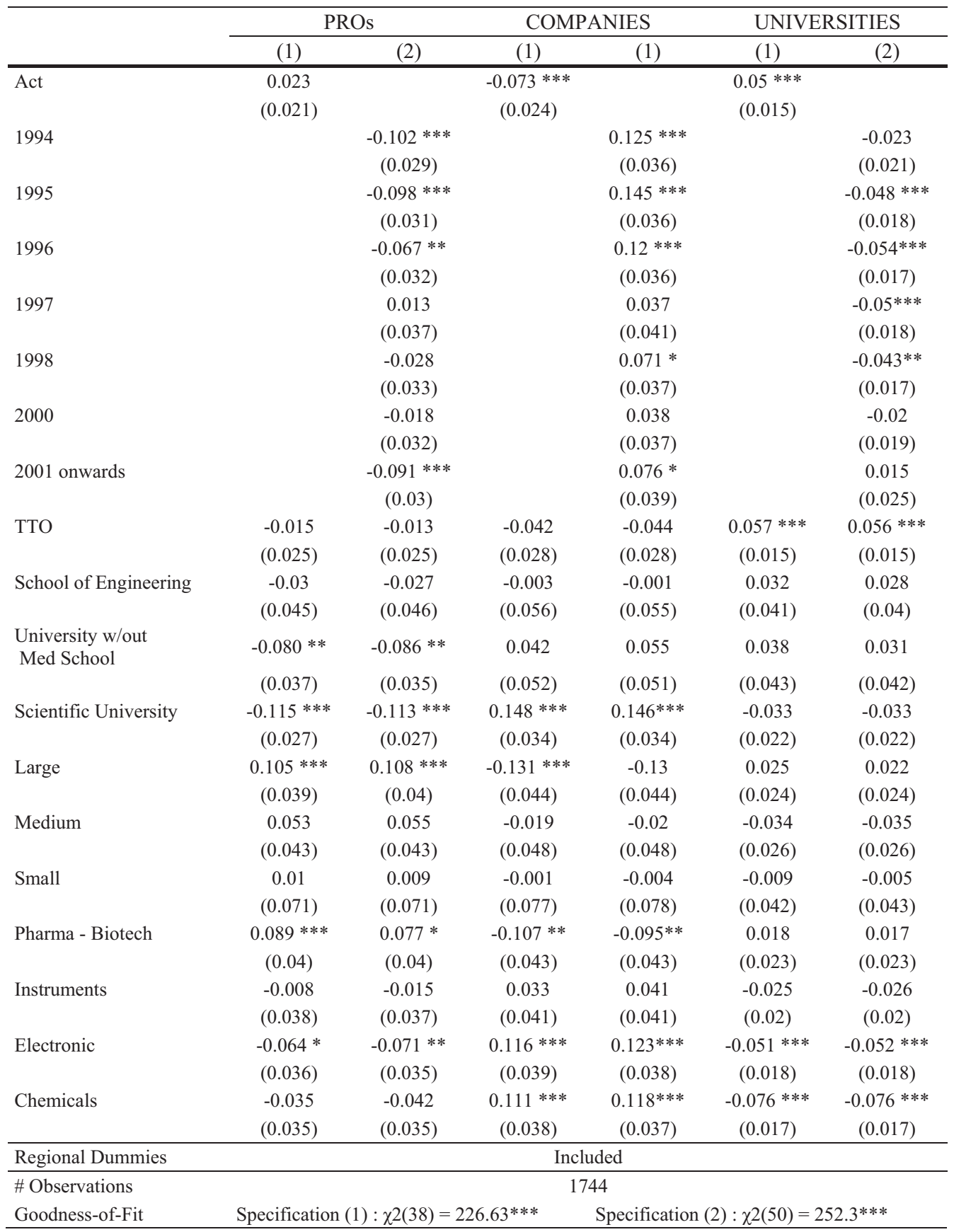

NOTE: $*=10 \%$ significance, $* *=5 \%$ significance, $* * *=1 \%$ significance. Standard errors are reported in parentheses below coefficient.

Results are reported as marginal effects calculated as changes from 0 to 1 of dummy variables. 
We explain the result as follows: the impact of TTOs on university ownership is significant per se, but it comes at the expense both of ownership by PROs and of ownership by companies; taken separately, these two negative effects are too small to be statistically significant (that is, when splitting the TTO effect on university ownership into two parts, neither part is significant, although exclusive ownership by companies seems to decline the most).

The regression results in Table 4.8 also provide interesting information on the relationship between PROs, companies, and universities of different type and size. From the first and second columns, we note that the probability for an academic patent to be assigned to a PRO, and not to the inventor's university or a company, is around 8\% lower for Universities without Medical Schools (compared to those with one), and around 11\% lower for Scientific Universities (while Schools of Engineering do not differ much from Universities with Medical Schools). This is possibly because Universities with Medical Schools and Schools of Engineering host a comparatively larger number of UMRs, so that CNRS and other large PROs have more bargaining power when it comes to IPR matters. At the same time, we note that academic patents from large universities are more likely to be retained by PROs than those from the largest ones (reference case) and small and medium ones.

Companies appear to be more likely to obtain exclusive ownership of academic patents when the latter come from Scientific Universities (the marginal effect is around $14.8 \%$ in the third column, very much the same in the fourth), which is the category of universities most engaged in contract research (see Bach and Llerena, 2010). As with the logistic regression, university type does not affect the probability of university ownership. The estimated marginal effects for technology dummies associated confirm the results and interpretation we described in section 5.1. Academic patents in Electronics and Chemicals are less likely to be reclaimed by universities (negative and significant marginal effects in fifth and sixth columns), and, at the same time, more likely to be assigned exclusively to companies (positive and significant marginal effects in third and fourth columns). PROs are also (weakly) less likely to reclaim property away from universities in these fields (first and second columns).

When it comes to Pharma-Biotech patents, however, PROs are more likely to reclaim property (exclusive or joint with companies), and companies less likely to obtain exclusive property. Note that the multinomial logistic exercise does not reproduce exactly the result we got from the logistic one, since we now find the probability of universities to retain or share the property of patents in this field is positive, but not significant. We also do not find significant differences in ownership patterns for patents over Instruments. ${ }^{54}$

\subsection{Conclusions}

In this chapter, we have dealt with French academic researchers' contribution to inventive activity between 1994 and 2002, as measured by patent applications at the EPO. In particular, we

\footnotetext{
${ }^{54}$ We performed the Hausmann-McFadden (1984) and the Small-Hsiao (1985) tests to test for the Irrelevance of independent alternatives (IIA) assumption. Both tests support the IIA assumption.
} 
have assessed the impact of a major institutional change (the Innovation Act of 1999) over the ownership distribution of academic inventions. In addition, we have explored the concurrent effects of an important organizational change such as the diffusion of technology transfer offices, over the same years. As for the distribution of academic patent ownership, we have confirmed what was found by other studies, such as Azagra-Caro et al. (2006) for the specific case of the University of Strasbourg, and Lissoni et al. (2008) for several European countries, namely, that universities own (or, more often, co-own) only a minor share of their scientists' patented inventions (around $11 \%$ over the whole period we considered). When we consider ownership or co-ownership by PROs, the share of academic patents in public hands over the period examined rises to around $33 \%$, still much less than those controlled exclusively by business companies. This ownership distribution is due to institutional factors, and not to any peculiarity in the technological distribution of French academic patents; the latter, in fact, does not differ much from what was found by Mowery et al. (2001) for the USA, in an altogether different institutional setting.

The econometric exercise has shown that changes in the institutional and organizational settings, however, may have some noticeable impact, even in a complex academic system such as the French one. However, understanding these effects requires taking into account such complexity, which in France has mainly to do with the relationship between universities and PROs, and with the stratification of universities themselves, by type and size. We have shown that the Innovation Act, which indicates technology transfer via commercialization as a mission for French universities and provides both incentives and recommendation to this end, has increased the probability that universities will reclaim (their share of) property rights over their scientists' inventions. The Act and its effects, however, fit into a more general trend of universities' involvement in IPR management of their scientists' inventions. In particular, we found that many universities' decision to open a technology transfer office pre-dates the Act and has exerted an even bigger effect than the latter. These results are in line with what Baldini et al. (2006) found for Italy, where universities increased the total number of patents applied for in their names after the adoption of internal IPR regulations, as required by a change in national legislation (such an adoption was contextual to the creation of a TTO).

Whether this more aggressive stance of French universities has been (or will be) beneficial in terms of technology transfer and societal welfare remains to be seen, our data being too limited in time and scope to provide information on this issue. Our findings suggest that any increase in universities' patenting rate may be due, at least in part, to a redistribution of ownership rights, rather than an increase in inventive activity. This interpretation is in line with the descriptive evidence provided in section 3. Although the number of academic patents has increased over time, the rate of growth has not exceeded the overall national growth rate, so the academic's share of total patents has not increased in a steady way. In order to check the robustness of this interpretation, we plan to repeat our assessment of academic patenting activity in the near future, based upon archival information on scientists active in more recent years, so to have a more reliable time series. It may also be that by reclaiming their share of IPRs from companies, French 
universities will achieve little in terms of financial returns, or strategic control of the knowledge their inventors produce, at the cost of creating tensions with their industrial partners (and possibly their own faculty). Again, this is an important direction for future research.

One limitation of our exercise concerns the possibility of endogeneity in our estimates. In particular, it may be that the Innovation Act was anticipated by French universities, so that the effects of ownership redistribution we observe took place as a result of a strategic change, rather than as the mere results of the implementation of a legislative change. Similarly, it may be that the Act was meant more as a way of extending to some "conservative" universities the technology transfer practices already in place in more "entrepreneurial" ones. At most, however, these limitations may challenge the exact value of the marginal effects we estimated in our logistic and multinomial logistic regressions. They cannot detract from the general findings, which point to a change in the French policy climate during the 1990s, and to the resulting efforts of universities to control more tightly the IPRs over their faculty's inventions. 



\section{Corporate Science in the Patent System: An Analysis of the Semiconductor Technology*}

\subsection{Introduction}

Innovation can be quintessential for achieving a competitive advantage vis-à-vis competitors and for long-term profitability. The extent to which firms profit from innovation hinges upon their ability to appropriate innovation rents. Traditionally, the effectiveness of appropriation strategies has been evaluated with regard to their success in excluding third parties from using the innovation, e.g. by attaching intellectual property rights to the inventio or by keeping the invention secret (Cohen et al., 2000). A more general view establishes that effective appropriation mechanisms should guarantee the inventor the freedom to operate her technology in the first place (Merges, 2004). The exclusion of third parties is only one way to achieve this. This broader view explains why companies submit technical information about inventions into the public domain at their own costs. When technical information is in the public domain, it increases the pool of prior art and therewith the novelty threshold for related patent applications. This strategy, referred to as defensive or preemptive publishing, precludes rivals from patenting, but not from using the published technology (Adams and Henson-Apollonio, 2002, Buxbaum, 2001, Colson, 2001, Maurer, 2002, Merges, 2004, Parchomocsky, 2000). ${ }^{55}$

The scholarly interest in the defensive use of publications has emerged in the last decade. The seminal article on the topic by Parchmovski (2000) made use of patent race models to analyze defensive publishing. Patent race models typically consider two inventors that compete for being first to complete and patent a specific invention. The time after which the invention occurs is ex-ante unknown and depends largely on the inventors' investment in research and development. In these models, the loser typically receives no or little return to her investment, while the winner takes all (e.g. Reinganum, 1982). Defensive publishing is introduced into these models by allowing for the option to disclose knowledge outside the patent system. The disclosure of relevant knowledge outside the patent system expands the state of the art and, therewith, increases the patentability requirements for the rivals; it hence generates a "legal externality", viz. a negative externality on the patentability requirements of competing

* This chapter is joint work with Katrin Hussinger (Maastricht University) and has circulated as ZEW working paper 098/10

${ }^{55}$ Merges (2004) and Maurer (2002) discuss defensive publishing in the context of genomics (see also Eisenberg, 2000a). Examples of firms being highly active in publishing technical advances are IBM, Philips, Hitachi, ICI, Ciba, Siemens, Sandoz, Roche, Hoechst and Toshiba (Hicks, 1995). In the technology field of computer science, IBM and AT\&T each published more than Stanford and MIT together in the period 1991-2001. In material sciences, IBM is ranked number two after Tohoku University (Science Watch, 2001). 
innovations. Parchomovski concludes that defensive publishing is mostly an option for laggard firms which can still earn profits once the invention is in the public domain, as the leader would never forgo the monopoly profits of the patented invention (e.g. Eisenberg (2000a) for the case of genomics). Alternatively, the laggard might also forestall the current race and set back the competitors for a new race where she can earn the monopoly profits (Bar, 2006). Therefore, defensive publishing and patenting are substitute strategies for laggards.

The sole interpretation of the "legal externality" in patent races has raised criticisms on both legal and strategic grounds (Eisenberg, 2000b). With regard to the U.S. patent legislation, Eisenberg argues that the first-to-invent rule ${ }^{56}$ and the statutory bars of the U.S. patent doctrine ${ }^{57}$, which define prior art as of one year prior to the application date, limit the effectiveness of defensive publications. Moreover, the disclosure of relevant technical knowledge could also affect the novelty of the inventor's own patent applications. According to Lichtman et al. (2000), in this institutional setting it is only the leader that has incentives to disclose relevant knowledge in order to reduce the rival's expected payoff and hence drive her out of the race. Furthermore, the inventor can also create strategic prior art for to justify her own subsequent inventions (Baker and Mezzetti, 2005). Yet, leaders only publish knowledge which would not narrow the breath of future patents (Baker and Mezzetti, 2005; Ponce, 2011). ${ }^{58}$

From a strategic point of view, Eisenberg (2000b) criticizes that the disclosure of relevant information outside the patent system might not be beneficial for firms in a patent race since it can speed up the completion of the rival's invention by means of knowledge spillovers (De Fraja, 1993; Ponce, 2011). Ponce (2011) shows that, indeed, companies disclose outside the patent system only when the magnitude of the knowledge spillover is limited as compared to the legal externality, suggesting that companies reveal freely information on minor technologies that, if patented by somebody else, could create holdup problems. Disclosure outside the patent system, thus, is used complementarily with patents by technological leaders.

This latter view is also consistent with a growing literature in the fields of law and management science, which explicitly suggests defensive publishing to be used complementarily to patenting. (Buxbaum, 2001; Colson, 2001; Henkel and Pangerl, 2008; Rinner, 2003). The general conclusion from these studies is that strategic disclosure should be used for minor improvements on existing core technologies which are already well protected.

${ }^{56}$ The first-to-invent rule allows the patent applicant to prove the invention was completed earlier than the conflicting prior art (U.S. patent doctrine, section 102(a)). This practice is referred as "swearing behind the reference" or "Rule 131 affidavit" (Eisenberg, 2000b: 2360)

${ }^{57}$ See U.S. patent doctrine, section 102(b).

${ }^{58}$ Baker and Mezzetti (BM) and Ponce (P) do not directly demonstrate this point. However, in both models, they introduce an exogenous parameter for the likelihood of obtaining a patent on inventions which are also disclosed in papers $(\beta$ in BM and $s$ in $\mathrm{P})$. The authors show that when the likelihood to obtain a patent decreases, companies disclose less not to jeopardize future profits from patents. Intuitively, firms do not publish information that would significantly reduce their chances of obtaining a patent. This interpretation is consistent with Rinner (2003) and Johnson (2004), who suggest that companies publish minor technical advancements on core technologies. 
The previous literature has highlighted two main facts on the use of publications for defensive purposes. Firstly, the disclosure of relevant technical knowledge in the public domain generates a negative externality on the patentability requirements of future patent applications (legal externality). Legal externalities impose a cost in terms of forgone monopoly profits to competitors. Secondly, the magnitude of the legal externality (the extent of relevant information disclosed in the public domain) depends on the technological leadership of the firm that generates it: technological leaders balance it with traditional forms of intellectual property exclusion to preserve a large part of future profits, and hence disclose only partial information through the public domain. Technological laggards, on the opposite, have less to lose from disclosing through the public domain and are expected to use defensive disclosure as a substitute strategy to patenting.

This article provides the first systematic empirical evidence on the existence of legal externalities and on their functioning in the patent system. Prior empirical evidence on the effectiveness of defensive publishing is limited to case illustrations (Eisenberg, 2000a, Maurer, 2002, Merges, 2004, Baker and Mezzetti, 2005) and interviews with IP experts in the private sector (Henkel and Pangerl, 2008). The research questions that guide our study are the following: i) Which are the real effects of the legal externalities generated by open disclosure? As a matter of fact, it is unclear whether the proposed mechanism of corporate publications as a means to preempt patents on related technologies actually works. In other words, do corporate publications block the grant of patent applications? ii) How do firms make use of open disclosure as defensive strategy? Do corporate publications hinder patent grant decisions as standalone documents - as in the case of technological laggards, or when combined with other IP strategies like patenting, as in the case of technological leaders.

We provide an empirical analysis for these research questions based on a sample of patent applications at the European Patent Office (EPO). We answer the first research question by investigating the impact of corporate scientific publications cited in patent applications on the patent examination outcome. ${ }^{59}$ We employ detailed information regarding the legal relevance of specific references for patent applications, which is available from the EPO (Webb et al., 2005). We can distinguish between prior art cited as non-infringing state of the art and documents that

${ }^{59}$ We focus on scientific publications for several reasons. First, from a legal point of view, scientific articles constitute a reliable source of prior art: scientific publications have technical relevance as evaluated by scientific peers, their technical advances should be replicable according to the ethical standards of science which substitutes for the requirement of enablement (35 U.S.C. 112(1)). Second, the majority of non-patent references cited in patents over all technologies refer to scientific journals (Callaert et al., 2006). Furthermore, scientific publications are largely available in standardized databanks containing information about journal outlets and institutional affiliations of the authors. Lastly, scientific publications have been rated as the second most used means for defensive publishing (Henkel and Pangerl, 2008). Disclosure platforms like "IP.com" are the first most preferred channel for strategic reasons. Practitioners elucidate the advantages of this channel as it allows for full control on timing and content of the disclosure. Unfortunately, not all companies that make use of such disclosure platforms unveil their identity (e.g. Xerox as reported in Baker and Mezzetti, 2005) so that information about the users and disclosed technologies is often not available, a feature that disclosure platforms share with other means to disclose technical inventions like presentations at trade fairs, for instance. For this reason, we can only focus on scientific publications. 
threaten the novelty of the patent application in question. To address the second question we distinguish between references in patent applications that are novelty threatening if taken alone, and those that are blocking if combined with other pieces of prior art, like for instance with a patent. This latter peculiarity of the evaluation process will shed light on the actual use that companies make of publications for defensive purposes.

Besides the access to detailed information about the patent examination procedure at the EPO, the institutional features of the European patent system prevent that the Eisenberg's (2000b) legal critique against the effectiveness of corporate science as an IP protection strategy apply. The EPO has a first-to-file rule in place rather than a first-to-invent regulation, so that all inventions being known before the first date of filing are considered prior art. The first-to-file rule means that there is less uncertainty for the inventor. In combination with the fact that all documents before the first date of filing count as prior art, the institutional set-up for patenting at the EPO is closer to the theoretical discussion reported above.

Our analysis focuses on the semiconductor technology in the period 1995-2000. At least two characteristics make this technology attractive for our analysis. First, it is characterized by a strong reliance upon scientific discoveries (Breschi and Catalini, 2010). Second, the semiconductor technology is a complex technology where a single product relies on several patents. Firms in complex technologies own fragmented patent portfolios and pursue "portfolio maximizing" IP protection strategies in order to avoid being held up by other firms (Hall and Ziedonis, 2001). Semiconductor firms, accordingly, engage in patent portfolio races rather than in traditional patent races (Ziedonis, 2004). In this context, the dissemination of scientific results by firms can represent an effective means (e.g. to patenting) for securing their freedom to operate technologies.

This study makes two contributions to the literature on corporate disclosure. Firstly, we provide the first systematic large-scale analysis on the existence of legal externalities in technological competitions. We show that corporate publications can effectively secure the freedom to operate a technology by blocking the granting of related patent applications as pieces of prior art. This shows that basic mechanism underlying the strategy of defensive publishing, i.e. the dissemination of technical information in the public domain contributes to increase the novelty requirements for future patents, actually works. Secondly, we show that corporate open disclosure is especially effective against patent grant decisions in combination with other pieces of prior art rather than as standalone documents. This indicates that corporate publications are used by companies as a complementary part of a firm's overall IP protection strategy, indirectly pointing to technological leaders as disclosers.

The remainder of the paper is organized as follows: section 2 describes the patentability criteria at the EPO and details how patent examiners consider prior art when they evaluate patent applications. Section 3 describes the construction of the data set and presents some descriptive evidence. The fourth section details our estimation strategy and shows the empirical results. Section 5 concludes. 


\subsection{The European Patent System ${ }^{60}$}

The European Patent Office (EPO) entered into force in 1977 after the ratification of the European Patent Convention (EPC) in 1973. Its main task is to examine patent applications and grant legal protection of inventions on behalf of all contracting states on a basis of a centralized procedure. ${ }^{61}$ Organizations and individuals seeking legal protection for their inventions in several or all EPC member states can file a single patent application and go through a single patent grant procedure. Legal protection is eventually granted or refused in accordance with the provisions of the EPC. ${ }^{62}{ }^{63}$ According to article 52(1) of the EPC, a patent application has to fulfill three criteria to be granted: a) novelty, b) inventive step and c) industrial applicability. Article 54(1) of the EPC defines novelty as not being part of the state of the art. The state of the art is defined as "everything made available to the public by means of a written or oral description, by use, or in any other way, before the date of filing of the European patent application." (EPC, article 54(2)). The inventive step requires that the invention "having regards to the state of the art, [it] is not obvious to a person skilled in the art" (EPC, article 56). ${ }^{64}$

Once a patent application is filed, the search divisions of the EPO carry out a patentability search. The aim of these searches is to collect technical information which defines the state of the art relevant to judge the appropriateness of the scope of the legal protection as requested in the application document. ${ }^{65}$ Examiners base their searches on the exact wording of the claims. The result of their search is documented in the so-called search report which lists all references to previous technical documentations in order to determine the novelty and the inventive step of the patent application at the time of the filing. The search of relevant prior art follows the Guidelines for Examination in the European Patent Office ${ }^{66}$ in order to guarantee homogeneous quality standards as wells as equal treatment of all EPO patent applications.

For this study, at least two features of the EPO search report deserve attention. Firstly, the examination guidelines explicitly require examiners to be objective and selective when defining the documents referred to as prior art. In most of the cases one to two documents are sufficient to

${ }^{60}$ For an exhaustive overview of the functioning of the EPO, see Guellec and van Pottelsberg (2007).

61 The member countries of the EPC are Austria, Belgium, Bulgaria, Switzerland, Cyprus, Czech Republic, Germany, Denmark, Estonia, Spain, Finland, France, the United Kingdom, Greece, Hungary, Ireland, Iceland, Italia, Latvia, Liechtenstein, Lithuania, Luxemburg, Monaco, the Netherlands, Poland, Portugal, Romania, Sweden, Slovenia, Slovakia, and Turkey.

${ }^{62}$ Note that once granted the patent is de facto a bundle of national patent rights that has to be validated, put in force and renewed on a country-by-country basis (EPC, article 65). The cost of the average patent is around $30.000 €$, which is almost three times as much as a national application (Guellec and van Pottelsberg, 2007).

${ }^{63}$ For an exhaustive overview of the functioning of the EPO see Guellec and van Pottelsberg (2007).

${ }^{64}$ The evaluation of the third criterion of industrial applicability usually does not imply further assessment based on prior art (Michel and Bettels, 2001).

${ }^{65}$ At the United States Patents and Trademarks Office (USPTO), in contrast, patent applicants are subject to the "duty of candor". This means that they have to submit a list of all relevant prior art along with the patent application. Non-compliance can result in a rejection of the patent application. Given that the duty of compliance the applicants, patent applicants at USPTO provide a disproportionate high number of references (Silverman, 2003).

${ }^{66} \mathrm{See}$ http://www.epo.org/patents/law/legal-texts/guidelines.html. 
determine the scope of the patent application in question (Michel and Bettels, 2001). This parsimonious and objective approach ensures that the references are a relevant subsample of the actual state of the art rather than an overview on the subject-matter of the invention (Harhoff et al., 2005).

A second feature of the EPO search reports is the classification of references according to their relevance in terms of the three criteria of patentability (Harhoff et al., 2005). Two types of citations challenge the patentability of patent applications (citation types $\mathrm{X}$ and $\mathrm{Y}$ ). X-type citations are documents showing essential features of the invention under investigation or at least questioning the novelty and the inventive step of these features if taken alone. Y-type citations question the inventive step claimed in the invention being examined, when combined with other pieces of prior art. The Guidelines for Examination in the European Patent Office give two examples for the occurrence of Y-type citations. In a first instance, the combination of patents and scientific documents receives Y-type citations if it challenges the novelty of the patent application in question. Secondly, patent families threatening novelty are cited as Y-type references (see Chapter X, paragraph 9.1.2). The first example describes the relevant case for our analysis. $^{67}$

The minimalistic approach to prior art searches and the categorization of the references according to the patentability criteria enable us to assess the impact of scientific contributions in the process of patent granting. The principle of parsimony regarding the references allows us to identify the scientific "shoulders" on which new technical improvements stand. The categorization of references tells us to which extent the novelty and incentive step of patent applications is threatened by prior art and by corporate science, in particular.

\subsection{Data Collection and Descriptive Statistics}

\subsubsection{Patent Data Sources}

We analyze a cross-sectional database of EPO patent applications in the field of semiconductor from 1995-2000 that were granted or rejected by 2009. Our primary source of information is the EPO database, which includes information about all patent applications since its foundation in 1977. From this database we retrieve all patent applications assigned to the semiconductor technology in the years $1995-2000 .^{68}$ We define the technology field of semiconductor according to the Observatoire des Sciences et des Techniques (OST-INPI/FhG-ISI), also known as the Fraunhofer technology classification (Schmoch, 2008). This categorization aggregates the narrowly defined patent technology classes of the International Patent Classification (IPCs) to

${ }^{67}$ Guellec et al. (2009) show that X- and Y-type references to the patent literature significantly hinder positive patent grant decisions. For this reason, we also use the term "blocking citations" or "blocking references" in the following. X-and Y-type references have, further, been used in the prior empirical literature to identify weak patents when predicting the likelihood of patent opposition (Harhoff and Reitzig, 2004; Czarnitzki et al., 2009).

${ }^{68}$ Later patent applications are not considered because we are interested in the outcome of the patent application decision which can take place several years after the application date. Earlier patents could not be considered as we have only limited information on (cited) scientific publications issued before 1988 . 
technology fields. Semiconductor applications are identified by the 4-digit IPC code "H01L".69 We identified 8,385 different semiconductor patent applications in our time period of interest. For these patents we retrieved the application year, IPC classes, inventor and applicant information as well as the patent decision outcome as of 2009 (granted, rejected, pending, withdrawn).

Information about the references made by our patents was gathered from the "EPO/OECD patent citation database". This database covers all types of references to prior art including references to patents and references to the non-patent literature (NPL) (Webb et al., 2005). The 8,385 semiconductor patent applications cite 37,307 other patents and make 9,925 references to the non-patent literature. We also extracted the classification of references from the search reports from this data source to be able to distinguish between blocking references (X- and Y-type of references) and such that describe the non-infringing state of the art in a particular field of semiconductor technology. ${ }^{70}$ Furthermore, we extracted information on patent priority claims from these files. A patent application may claim priority from a previously filed application at a different patent office in order to take advantage of the filing date of that earlier application. ${ }^{71}$ The pool of prior art is then restricted to documents that were published before that first filing date.

\subsubsection{Construction of the Sample}

While references to patent documents can be easily handled since they are identified by their patent application number this is not the case for the cited non-patent literature. NPLs are documented in form of text fields including the article title, author information, journal name and publication year. The format of these text fields differs across the records. This is partly explained by the fact that the NPL records are quite heterogeneous encompassing a range of documents such as scientific articles, books, abstract meetings and abstract services but also trade journals and presentations at trade fairs. Accordingly, not all NPLs represent a link to scientific work (Harhoff et al., 2003a). Across all technology fields, roughly about $65 \%$ of the NPL references are of scientific nature (Callaert et al., 2006). For our sample, we manually coded the NPL records in order to retrieve journal and author names. The result of this exercise was a list of all references to the patent and non-patent literature that are cited in our semiconductor patents.

${ }^{69}$ Using this definition of semiconductor patents has the advantage that our results are comparable to prior research that employs the same definition (e.g. Graham et al., 2003, Saragossi and van Pottelsberghe de la Potterie, 2003, Jerak and Wagner, 2006).

${ }^{70}$ Unfortunately, the data that is available to us does not allow identifying which of the cited documents belong together as novelty threatening if combined (Y-type of references). For researchers outside of the EPO, references to patent and the non-patent literature are available in different spreadsheets. These can be linked via the patent application numbers to the patent documents, but the link between different pieces of prior art that are blocking together is lost.

${ }^{71}$ Note that in Europe not all patent applications go through the EPO. There is also the possibility to apply for patent protection at national patent offices. Hence, our sample does not cover the whole population of semiconductor patents taken out in Europe, but the more valuable ones for which the inventor seeks protection for a larger geographical region at relatively high patent application costs (Deng, 2007). 
In the next step, we linked the list of NPL references to the SCI-Expanded (Science Citation Index Expanded) file of the Web of Science publication database in order to identify NPLs that correspond to scientific journal publications. The SCI-Expanded database provides access to articles published in the most important 8,130 journals across different disciplines. In total, $80 \%$ of all scientific journals are covered by this database (Van Vianen et al., 1990). NPLs were matched with the publication file based on author names, journal names and publication years. A computer-supported search algorithm was used to facilitate the link. Each potential match proposed by the algorithm was checked manually. The link allows us to distinguish references to scientific journals from other NPLs. We recovered 2,124 scientific contributions being cited 2,375 times in 893 patent applications in our sample. ${ }^{72}$ Furthermore, we extracted the author affiliations from the publication files in order to be able to distinguish corporate publications from scientific advances published by the public sector. ${ }^{73}$ The top publishing companies in our sample with more than 20 articles cited in the patent literature are AT\&T, IBM, NTT, Hitachi, NEC, Phillips, Siemens/Infineon, Motorola, Matsushita, Toshiba, Texas Instruments and Fujitsu. $^{74}$

The final sample is subject to some restrictions: First, we only kept granted and rejected patent applications. Pending patent applications were excluded since we have to observe the final decision on a patent application to be able to evaluate the impact of corporate scientific publications on the patent examination outcome. Withdrawn patent applications were excluded as well since withdrawals present a patent application outcome which is outside the control of the patent office. In total, 1,812 pending or withdrawn patent applications were dropped. Second, we restrict our analysis to corporate patent applications as there is some evidence that patent applications from scientific institutions or academic inventors are significantly different regarding the nature of the protected invention (Trajtenberg et al., 1997, Czarnitzki et al., 2009). In this step, 347 patent applications without any firm participation were excluded. In total, our final sample consists of 6,226 rejected or granted corporate patent applications in the field of semiconductor technology.

We created a unique identifier for patent applicants in our sample to account for unobserved effects on the level of the patent applicant in the empirical analysis. As before, a textbased search algorithm was used. Each potential "group" of patent applicants referring to the

72 These numbers are in line with a previous systematic exploration of the nature of NPLs in the semiconductor technology by Breschi and Catalini (2010). Examining the whole set of patent applications in Semiconductors - among other technology fields - between 1990 and 2003, the authors find that 20.5\% of NPL citations are from scientific articles retrievable from the SCI-Expandex database. Our figure is 23.9\% (2375/9925). The authors find that $13.5 \%$ of patent applications cite at least one scientific article; in our sample it is $14.3 \%$ (893/6226). Finally, the authors show that patent applications on average cite 0.25 scientific articles, whereas in our sample the number is 0.26 (see table 4 in section 3.4).

${ }^{73}$ We use that term "public sector" in the broadest sense in this paper. Publications from the public sector include all non-corporate publications such as scientific publications taken out by universities, public research institutions, governmental institutions, private persons etc.

${ }^{74}$ The majority of NPLs that did not represent links to scientific journals are references to specialized disclosure platforms, like IP.com, and company bulletins, like the IBM bulletin. 
same corporation proposed by the algorithm was manually checked. ${ }^{75}$ The top patenting firms in our sample are Infineon/Siemens, STMicroelectronics, NEC, Applied Materials Inc., Sumitomo, Texas Instruments, Philips, Canon, Matsushita, and IBM with more than 100 granted or rejected patent applications.

A limitation of the data gathering process was that the SCI-Expanded database is only available to us from 1988 onwards. Hence, we could not classify NPLs that were published earlier as being scientific or not. Further, we were not able to identify some references in the SCIExpanded database due to incomplete or ambiguous information in the patent reference list. We account for both in the empirical analysis by including a first dummy variable indicating that a patent application cites NPLs published before 1988 and a second dummy variable indicating citations to NPLs with unidentified nature in our regression model. In total, there are only $4 \%$ of the all NPLs for which we could not retrieve all necessary information.

\subsubsection{Some Descriptive Statistics on the Cited Scientific Publications}

Before exploring the blocking potential of corporate scientific publications in the patent examination process we look into potential systematic differences between corporate publications and publications from the public sector. There is mounting evidence on differences between science produced in the private and public sector (e.g. Dasgupta and David, 1994, Stokes, 1997). In brief, it is argued that the curiosity-driven public scientist strives for intellectual challenges which might not be of any industrial interest. In the public research sector, science has priority over commercialization and the incentives for innovators are significantly determined by peer recognition and career awards such as tenure rather than by monetary rewards (Merton, 1973). The corporate scientist, in contrast, is hired for the explicit purpose of generating knowledge with a commercialization potential for the firm (Cohen and Levinthal, 1990). These different conditions and motivations for corporate and public science cause that science in the private sector is typically more applied than research conducted in the public sector (Dasgupta and David, 1994). This is reflected in different degrees of appliedness of patents taken out under both regimes (Trajtenberg et al., 1997, Czarnitzki et al., 2009). If such differences between both sectors were reflected in the nature of scientific publications (cited by our semiconductor patents) the more applied character of the corporate publications might account for their suspected higher blocking power. In this section, we therefore investigate whether there is evidence for corporate publications being more applied than science published by the public sector.

\footnotetext{
${ }^{75}$ Multiple patent applicants on patent applications were treated as research consortia and, hence, received their own id as a group. The reason is that these such patents might be taken out by temporary joint ventures between firms or that they might be the outcome of a specific collaborative project between multiple firms. Such collaborative efforts can deviate from the firms' core research in semiconductor and are likely to have their own budgets. For this reason, we prefer to treat research consortia as separate entities.
} 
Table 5.1: Tests for different distributions of reference categories

\begin{tabular}{lcccc}
\hline Level of Aggregation & Categories & Companies & Public & Total \\
\hline Aggregated & Others & 463 & 683 & 1146 \\
& X or Y & 499 & 730 & 1229 \\
& Total & 962 & 1413 & 2375 \\
\hline \multirow{2}{*}{ Disaggregated } & & Pearson-X $^{2}$ & $(1)=0.0099-\mathrm{Pr}=0.921$ & \\
& Others & 464 & 683 & 1147 \\
& $\mathrm{Xs}$ & 324 & 515 & 839 \\
& Ys & 174 & 215 & 389 \\
& Total & 962 & 1413 & 2375 \\
\hline
\end{tabular}

Pearson- $\mathrm{X}^{2}(2)=4.1233-\mathrm{Pr}=0.127$

NOTE: We consider only articles which are exclusively authored by either corporate scientists or from public institutes. No coauthored articles are included. All citations to semiconductors patents applied in the period 1995-2000 are included.

As a first check we compare the distribution of citation categories (blocking versus noninfringing) assigned to scientific references taken out by the private and the public sector. We submit that if corporate publications reflect scientific advances which are closer to industrial applications they should be more likely to threaten the novelty of patent applications. Scientific publications from the public sector, in contrast, should be more likely to be cited as noninfringing state of the art if they reflected rather basic research. We conduct two different tests: first, we distinguish between patent citations to publications that are quoted as blocking (X- and Y-types) and other types of citations and check whether there is a systematic difference, and, second, we use a more disaggregated level of categories distinguishing between X-type, Y-type and the residual group of non-infringing citations and repeat the test. The residual group of citations refers to prior art representing the non-infringing state of art in a technology domain (Webb et al., 2005, Harhoff et al., 2005). Pearson $\chi^{2}$-tests show that the distribution of publications from the public sector across citation type categories is not significantly different from the citation type distribution of corporate publications.

Secondly, we compare the type of scientific journals in which the corporate and public articles that are cited in our patents are published. As previously advanced, we would expect that scientific articles authored by the private sector had been published in more theoretical journals if they addressed puzzles with a higher scientific relevance. Table 5.2 presents a list of the journals in which the majority of our articles cited in patents are published. There are no systematic differences regarding the distribution of corporate and public sector publications across journals. A Mann-Whitney-Wilcoxon rank-sum test on the rankings of publication frequencies across journals are equal at their medians ( $p$-value $=0.66$ ). The test was repeated for the subsample of articles cited as blocking document (X and $\mathrm{Y}$ ) leading to the same conclusion. 
Table 5.2: List of top 25 Journals

\begin{tabular}{|c|c|c|c|c|c|c|c|c|c|}
\hline \multirow{2}{*}{ Journals } & \multicolumn{3}{|c|}{ Total sample } & \multicolumn{4}{|c|}{ Corporate } & \multicolumn{2}{|c|}{ Non-profit } \\
\hline & Articles & Share & Rank & Articles & Share & Rank & Articles & Share & Rank \\
\hline $\begin{array}{l}\text { APPLIED PHYSICS } \\
\text { LETTERS }\end{array}$ & 354 & 0.166 & 1 & 113 & 0.155 & 1 & 200 & 0.17 & 1 \\
\hline $\begin{array}{l}\text { JAPANESE JOURNAL } \\
\text { OF APPLIED PHYSICS }\end{array}$ & 150 & 0.071 & 2 & 79 & 0.108 & 2 & 64 & 0.054 & 4 \\
\hline $\begin{array}{l}\text { JOURNAL OF APPLIED } \\
\text { PHYSICS }\end{array}$ & 132 & 0.062 & 3 & 35 & 0.048 & 5 & 72 & 0.061 & 2 \\
\hline $\begin{array}{l}\text { IEEE TRANSACTIONS } \\
\text { ON ELECTRON } \\
\text { DEVICES }\end{array}$ & 103 & 0.048 & 4 & 60 & 0.082 & 3 & 33 & 0.028 & 8 \\
\hline THIN SOLID FILMS & 95 & 0.045 & 5 & 21 & 0.029 & 11 & 65 & 0.055 & 3 \\
\hline $\begin{array}{l}\text { IEEE ELECTRON } \\
\text { DEVICE LETTERS } \\
\text { JOURNAL OF THE }\end{array}$ & 80 & 0.038 & 6 & 32 & 0.044 & 6 & 33 & 0.028 & 8 \\
\hline $\begin{array}{l}\text { ELECTROCHEMICAL } \\
\text { SOCIETY } \\
\text { JOURNAL OF VACUUM }\end{array}$ & 75 & 0.035 & 7 & 38 & 0.052 & 4 & 30 & 0.025 & 11 \\
\hline $\begin{array}{l}\text { SCIENCE \& } \\
\text { TECHNOLOGY A }\end{array}$ & 74 & 0.035 & 8 & 28 & 0.038 & 7 & 35 & 0.03 & 7 \\
\hline $\begin{array}{l}\text { JOURNAL OF CRYSTAL } \\
\text { GROWTH }\end{array}$ & 73 & 0.034 & 9 & 22 & 0.030 & 10 & 42 & 0.036 & 5 \\
\hline $\begin{array}{l}\text { ELECTRONICS } \\
\text { LETTERS }\end{array}$ & 68 & 0.032 & 10 & 23 & 0.032 & 9 & 38 & 0.032 & 6 \\
\hline $\begin{array}{l}\text { MATERIALS SCIENCE } \\
\& \text { ENGINEERING } \\
\text { IEEE PHOTONICS }\end{array}$ & 40 & 0.019 & 11 & 5 & 0.007 & 23 & 33 & 0.028 & 8 \\
\hline $\begin{array}{l}\text { TECHNOLOGY } \\
\text { LETTERS }\end{array}$ & 37 & 0.017 & 12 & 15 & 0.021 & 12 & 19 & 0.016 & 15 \\
\hline $\begin{array}{l}\text { SOLID STATE } \\
\text { TECHNOLOGY }\end{array}$ & 34 & 0.016 & 13 & 26 & 0.036 & 8 & 5 & 0.004 & 33 \\
\hline $\begin{array}{l}\text { MICROELECTRONIC } \\
\text { ENGINEERING } \\
\text { SOLAR ENERGY }\end{array}$ & 34 & 0.016 & 13 & 15 & 0.021 & 12 & 17 & 0.014 & 16 \\
\hline $\begin{array}{l}\text { MATERIALS AND } \\
\text { SOLAR CELLS }\end{array}$ & 28 & 0.013 & 15 & 7 & 0.001 & 17 & 21 & 0.018 & 12 \\
\hline $\begin{array}{l}\text { SOLID-STATE } \\
\text { ELECTRONICS }\end{array}$ & 26 & 0.012 & 16 & 5 & 0.007 & 23 & 20 & 0.017 & 14 \\
\hline $\begin{array}{l}\text { SENSORS AND } \\
\text { ACTUATORS A }\end{array}$ & 24 & 0.011 & 17 & 5 & 0.007 & 23 & 17 & 0.014 & 16 \\
\hline $\begin{array}{l}\text { SEMICONDUCTOR } \\
\text { SCIENCE AND } \\
\text { TECHNOLOGY }\end{array}$ & 23 & 0.011 & 18 & 7 & 0.001 & 17 & 14 & 0.012 & 19 \\
\hline PHYSICA C & 23 & 0.011 & 18 & 2 & 0.003 & 38 & 21 & 0.018 & 12 \\
\hline NATURE & 22 & 0.010 & 20 & 6 & 0.008 & 19 & 11 & 0.009 & 22 \\
\hline SCIENCE & 21 & 0.001 & 21 & 5 & 0.007 & 23 & 13 & 0.011 & 20 \\
\hline $\begin{array}{l}\text { ADVANCED } \\
\text { MATERIALS }\end{array}$ & 18 & 0.009 & 22 & 2 & 0.003 & 38 & 16 & 0.014 & 18 \\
\hline $\begin{array}{l}\text { IEICE TRANSACTIONS } \\
\text { ON ELECTRONICS }\end{array}$ & 17 & 0.008 & 23 & 15 & 0.021 & 12 & 2 & 0.002 & 66 \\
\hline $\begin{array}{l}\text { IEEE JOURNAL OF } \\
\text { SOLID STATE CIRCUITS } \\
\text { NUCLEAR }\end{array}$ & 17 & 0.008 & 23 & 10 & 0.014 & 16 & 6 & 0.005 & 31 \\
\hline $\begin{array}{l}\text { INSTRUMENTS \& } \\
\text { METHODS IN PHYSICS } \\
\text { RESEARCH }\end{array}$ & 17 & 0.008 & 23 & 6 & 0.008 & 19 & 11 & 0.0093 & 22 \\
\hline
\end{tabular}


Table 5.3: Tests for different citation lags (in years)

\begin{tabular}{lcccc}
\hline Full Sample & Observations & Mean & Std. Err. & t-Test \\
\hline Public & 1116 & 3.675 & 0.079 & \\
Companies & 921 & 3.975 & 0.092 & \\
Mean difference & & -0.299 & 0.121 & $\mathrm{t}=-2.466$ \\
\hline XY cited publications only & Observations & Mean & Std. Err. & t-Test \\
\hline Public & 485 & 3.688 & 0.1124 & \\
Companies & 386 & 4.2315 & 0.146 & \\
Mean difference & & -0.541 & 0.1849 & $\mathrm{t}=-2.944$ \\
\hline
\end{tabular}

NOTE: Results of the t-Tests with unequal sample size and unequal variance. I consider only articles which are exclusively authored by either corporate scientists or from public institutes. No co-authored articles are included. First citations to all patent application documents at EPO are included.

Lastly, we ran the test for the first 20, 30 and 50 journals in the total sample only and find the result that there is no difference in the journal distribution pattern for corporate publications and those taken out by the private sector confirmed.

Finally, we pay attention to the time lag with which scientific articles are cited in patent documents. Previous literature has established that university patents are cited later than corporate patents (Sampat et al., 2003). It is argued that university patents cover more basic technologies and are, hence, more difficult to be understood and adapted by other inventors. By applying the same rationale to scientific publications we compare the citation lags of publications (cited in our patents) taken out by the private and public sector. Citation lags are defined as the time lags from the publication year of the scientific articles and the year in which they receive the first citation in a patent application at the EPO. ${ }^{76}$ Table 5.3 shows that company publications are cited, on average, six months later than those taken out by scientific institutions. A t-test rejects the null-hypothesis that there is no difference between the average citation lags for corporate publications and publications taken out by the non-profit sector at the $1 \%$ level of statistical significance. The lower part of Table 3 repeats the test for infringing (XY) citations only. The results point into the same direction. This suggests that conditional on being cited in our sample of patents, public science is cited earlier than corporate science in the patent literature. If we applied the standard interpretation to the citation lag measure this would mean that corporate science cited in patents is more basic and complex than public science cited in patents since it takes longer until the corporate results are picked up in follow-up inventions.

To summarize our first explorative results, we do not find evidence that corporate publications differ from public sector publications in terms of their basicness conditional on being cited in the patent literature: corporate publications are not more often cited as infringing prior art than

${ }^{76}$ The OECD database provides unique identifiers for $96 \%$ of the cited scientific articles that we identified. This information allows us to trace the number of citations per scientific article. 
scientific articles from the public domain, they are published in the same journals and they are not cited later in the patent literature.

\subsubsection{Descriptive Statistics}

Table 5.4 presents descriptive statistics for the variables used in the later multivariate regression models for the patent application outcome. The descriptive statistics show that granted patent applications differ from rejected ones in several ways. Granted patents, for instance, make more references to prior art $(R E F)$. The number of backward citations has been given different interpretations in the previous literature. Some scholars argue that patents with many backward citations are of a more incremental nature and that they target more crowded technology fields in the U.S. context (Lanjouw and Schankerman, 2001). Others claim that patents with many backward citations protect an invention with a large scope that invites the patent examiner at the EPO to delineate the patent claims by inserting more references to relevant prior art (Harhoff et al., 2003a). As a measure for the scope of patents backwards citations are an important variable in our empirical analysis since novelty challenging (X-and $\mathrm{Y}$-type) citations are given by the examiner to limit the scope of patent applications. In the empirical specification, we use the logarithm of the total references to account for the skewness of this variable's distribution. As a second measure for the scope of a patent application the number of 4-digit IPC classes is used (Lerner, 1994). ${ }^{77}$ Due to the skewness of this variable's distribution the logarithm of $(R E F+1)$ is used. If this variable is larger than zero the patent application is attributed to other technology fields than semiconductor. The correlation between both patent scope proxies is low with $20 \%$ (Table 5.5).

Granted patent applications receive fewer novelty-threatening references $(X Y R E F)$ than rejected ones. Note that a patent application can still be granted if it receives many references classified as $\mathrm{X}$ or $\mathrm{Y}$. This can be the case for patent applications with many claims or with a broad scope. X- and Y-type references may pertain to single claims and the remaining claims can be strong enough to get a (modified) application granted. Since the number of total references as a proxy for the scope of the patent application and the number of blocking references are correlated by definition, we normalize the number of blocking references by the number of total references $(X Y R E F / R E F)$ for the specification of the empirical model.

Rejected patent applications make significantly more references to the non-patent literature. Rejected patent applications make significantly more reference to the scientific literature (JOUR) as a subgroup of citations to the non-patent literature as well. The average patent application in semiconductor cites .26 scientific sources. This underlines the science-basicness of semiconductor technologies. The fact that the number of scientific NPLs is higher among rejected patent applications than among granted ones suggests that, in the field of semiconductor, science does not only represent prior art that lays a foundation for technology development, but that scientific publications also challenge the novelty of patent applications.

\footnotetext{
77 The number of claims is unfortunately not available to us.
} 
Table 5.4: Descriptive statistics

\begin{tabular}{lcccccccc}
\hline & \multicolumn{3}{c}{ All Patent Applications } & \multicolumn{2}{c}{ Granted } & \multicolumn{2}{c}{ Rejected } & T-test \\
\hline Variables & Mean & Std. Dev. & Mean & Std. Dev. & Mean & Std. Dev. & $\begin{array}{c}\text { Mean } \\
\text { diff }\end{array}$ \\
\hline REF & 4.44 & 2.98 & 4.51 & 2.92 & 4.34 & 3.05 & $0.17 \mathrm{~b}$ \\
Log(REF) & 1.60 & 0.60 & 1.63 & 0.54 & 1.56 & 0.66 & $0.07 \mathrm{c}$ \\
XY REF & 1.39 & 1.91 & 1.22 & 1.78 & 1.61 & 2.04 & $-0.40 \mathrm{c}$ \\
XY REF/REF & 0.24 & 0.30 & 0.22 & 0.28 & 0.27 & 0.32 & $-0.05 \mathrm{c}$ \\
NPL & 0.46 & 1.46 & 0.43 & 1.47 & 0.51 & 1.45 & $-0.08 \mathrm{~b}$ \\
JOUR & 0.26 & 0.86 & 0.23 & 0.82 & 0.28 & 0.83 & $-0.05 \mathrm{~b}$ \\
XY JOUR REF / XY REF & 0.05 & 0.19 & 0.04 & 0.18 & 0.06 & 0.21 & $-0.02 \mathrm{c}$ \\
X JOUR REF / XY REF & 0.03 & 0.14 & 0.02 & 0.13 & 0.03 & 0.15 & $-0.01 \mathrm{c}$ \\
Y JOUR REF / XY REF & 0.02 & 0.13 & 0.02 & 0.12 & 0.03 & 0.14 & $-0.01 \mathrm{c}$ \\
XY comp JOUR REF/XY JOUR REF & 0.04 & 0.17 & 0.03 & 0.15 & 0.05 & 0.20 & $-0.02 \mathrm{c}$ \\
X comp JOUR REF/XY JOUR REF & 0.02 & 0.15 & 0.02 & 0.13 & 0.03 & 0.17 & $-0.02 \mathrm{c}$ \\
Y comp JOUR REF/XY JOUR REF & 0.01 & 0.11 & 0.01 & 0.10 & 0.02 & 0.14 & $-0.02 \mathrm{c}$ \\
IPCs & 2.53 & 1.56 & 2.57 & 1.56 & 2.48 & 1.57 & $0.09 \mathrm{~b}$ \\
TIME & 4.98 & 2.33 & 5.26 & 2.20 & 4.59 & 2.43 & $0.67 \mathrm{c}$ \\
INV & 2.72 & 1.77 & 2.78 & 1.82 & 2.65 & 1.68 & $0.13 \mathrm{c}$ \\
PUBLIC & 0.01 & 0.12 & 0.02 & 0.13 & 0.01 & 0.11 & 0.01 \\
NPLs before 1988 & 0.03 & 0.17 & 0.03 & 0.17 & 0.03 & 0.17 & -0.00 \\
Unidentified NPLs & 0.07 & 0.25 & 0.06 & 0.24 & 0.07 & 0.26 & $-0.01 \mathrm{~b}$ \\
\hline \# Obs & 6,226 & & 3,559 & & 2,667 & & \\
\hline
\end{tabular}

NOTE: a, b, c indicate respectively significance at $10 \%, 5 \%$ and $1 \%$ statistical level.

The variable $X Y$ JOUR REF/XY REF presents the average share of scientific references among the blocking type of references the patent applications receive. An average of $5 \%$ of the blocking references per patent application stem from scientific publications. Again, the share is significantly higher among rejected patent applications.

Distinguishing between X-and Y-type of references among journal references shows that $3 \%$ of the blocking type references per patent application refer to scientific publications that are blocking as standalone documents ( $X J O U R$ REF/XY REF) while another $2 \%$ refer to Y-type citations to science that is blocking in combination with other pieces of prior art ( $Y J O U R$ $R E F / X Y R E F)$.

Regarding the origin of the novelty threatening scientific publications, an average of $4 \%$ of the blocking references to science per patent refers to corporate publications (XY comp JOUR $R E F / X Y$ JOUR REF). On average, $4 \%$ of these refer to X-type citations to corporate scientific publications (X comp JOUR REF/XY JOUR REF) and 2\% refer to Y-type references to science taken out by the private sector ( $Y$ comp REF/XY JOUR REF). 
Table 5.5: Bivariate Correlations

\begin{tabular}{|c|c|c|c|c|c|c|c|c|c|c|c|c|c|}
\hline & Variables & 1. & 2. & 3. & 4. & 5. & 6. & 7. & 8. & 9. & 10. & 11. & 12. \\
\hline 1. & Granted & 1.00 & & & & & & & & & & & \\
\hline 2. & $\log (\mathrm{REF})$ & 0.06 & 1.00 & & & & & & & & & & \\
\hline 3. & XY REF/REF & -0.10 & 0.16 & 1.00 & & & & & & & & & \\
\hline 4. & XY JOUR REF/XY REF & -0.05 & 0.11 & -0.11 & 1.00 & & & & & & & & \\
\hline 5. & X JOUR REF/XY REF & -0.04 & 0.07 & -0.07 & 0.76 & 1.00 & & & & & & & \\
\hline 6. & Y JOUR REF/XY REF & -0.03 & 0.08 & -0.10 & 0.69 & 0.06 & 1.00 & & & & & & \\
\hline 7. & $\begin{array}{l}\text { XY comp JOUR } \\
\text { REF/XY JOUR REF }\end{array}$ & -0.06 & 0.12 & -0.01 & 0.63 & 0.50 & 0.42 & 1.00 & & & & & \\
\hline 8. & $\begin{array}{l}\text { X comp JOUR REF XY } \\
\text { JOUR REF }\end{array}$ & -0.04 & 0.10 & 0.00 & 0.49 & 0.61 & 0.08 & 0.77 & 1.00 & & & & \\
\hline 9. & $\begin{array}{l}\text { Y comp JOUR REF/ XY } \\
\text { JOUR REF }\end{array}$ & -0.05 & 0.09 & -0.04 & 0.46 & 0.07 & 0.63 & 0.62 & 0.15 & 1.00 & & & \\
\hline 10. & Log(IPCs) & 0.04 & 0.20 & -0.01 & 0.04 & 0.03 & 0.03 & 0.04 & 0.03 & 0.02 & 1.00 & & \\
\hline 11. & Log(TIME) & 0.17 & 0.01 & -0.03 & 0.06 & 0.05 & 0.03 & 0.03 & 0.03 & 0.02 & 0.03 & 1.00 & \\
\hline 12. & $\log (\mathrm{INV})$ & 0.04 & 0.04 & -0.01 & 0.04 & 0.05 & 0.00 & 0.03 & 0.04 & 0.01 & 0.07 & 0.04 & 1.00 \\
\hline 13. & PUBLIC & 0.01 & 0.03 & -0.03 & 0.04 & 0.03 & 0.03 & 0.01 & 0.02 & -0.01 & -0.02 & -0.01 & 0.06 \\
\hline
\end{tabular}

In addition to our main variables of interest and the control variables for patent scope, we have a number of additional control variables. We control for the time that passed between the patent application at EPO and the final grant decision. More complex technologies presumably need more time to be evaluated (Sampat et al., 2003). The logarithm of this variable as measured in years (plus one) is used to account for the skewness of its distribution. Further, the (log of the) number of inventors is used as a proxy for the size of the innovation project. The major share of investments into innovation projects typically represents the wages of the R\&D personnel. The number of inventors can, hence, be seen as a proxy for the investment made for a patent application. Further, we control for the priority of the patent applications in our sample. A patent examiner might use the priority application of the EPO patent application as a reference when searching for prior art.

The bivariate correlations for the main regressors are very low. High values appear only for variables that are correlated by definition, like XY JOUR REF/ XY REF and X JOUR REF/ XY REF or Y JOUR REF/ XY REF, where the former variable is the sum of the latter two. Note that these variables are not used in the same regression model. We use four dummies to control for priority at different patent offices, namely the USPTO (2,220 patent applications), the Japanese 
Patent Office $(2,271)$, the EPO (473) and national European patent offices (1,561). Patents with priority at other patent offices worldwide are used as the benchmark (257). ${ }^{78}$

Moreover, a dummy variable is used to indicate if a patent application has co-applicants from the public sector $(P U B L I C)$. In total, 91 granted and rejected patent applications in our sample are applied for by private-public research co-operations. This variable accounts for the possibility that patents co-developed with a public research institution might be more basic than purely corporate patent applications. Further, a set of application year dummies is used to control for time trends because patent pending at the EPO increased sharply since the later 1980s (Harhoff and Wagner, 2009). In order to control for technology subclasses within semiconductor eight subfield dummies are used. ${ }^{79}$

Lastly, we use two dummy variables to account for weaknesses of our database. First, a dummy variable controls for patent applications with NPLs published before 1988 as we could not retrieve information about the authors and author affiliation of these publications from the Web of Science. A second dummy variable indicates references to NPLs that could not be classified as being scientific or not due to incomplete or ambiguous information on their citations records. In total, for $8 \%$ of the patents we have incomplete information.

\subsection{Empirical Results}

In this section, we estimate probit models to analyze the effect of scientific publications on the patent grant decision. We model the patent grant decision $d_{i}$ as a function of the different types of prior art cited in the search report for the focal patent application $i . d_{i}$ takes the value one if patent application $i$ gets granted and zero if the examination at EPO leads to a rejection. Due to the high correlation of the different types of references to prior art (i.e. an average patent application with many references typically has also many references in the particular categories that we want to distinguish) we use a cascade specification (Hall et al., 2005), i.e. we orthogonalize each patent reference variable by the next more general group of references:

$$
d_{i}=\beta_{1} \log \left(R E F_{i}\right)+\beta_{2} \frac{X Y R E F_{i}}{R E F_{i}}+\beta_{3} \frac{X Y J O U R R E F_{i}}{X Y R E F_{i}}+\beta_{4} \frac{X Y \operatorname{compJOURREF_{i}}}{X Y J O U R R E F_{i}}+\beta_{5} X_{i}+u_{i}
$$

The interpretation of the coefficients of this specification is that each ratio presents a premium (or a discount) on the former one (Hall et al., 2005). For instance, if the total number of references $(R E F)$ would have a positive impact on the patent grant decision and the share of novelty challenging cites among them $(X Y R E F / R E F)$ would have a negative impact, the estimated coefficient for the latter variable would reflect a discount on the positive effect of the total number of references. This logic applies to all variables in the cascade. The share of scientific publications among the references with a blocking potential is depicted by XY JOUR

\footnotetext{
${ }^{78}$ We do not include applicant countries in our empirical specification since they are highly correlated with the priority dummies. Most applicants get priority at the patent office of the country in which they are located.

${ }^{79}$ See table 6 in the working paper version of this chapter for a definition of the eight subfield dummies.
} 
$R E F / X Y R E F$ and indicates whether scientific prior art among the blocking references is more (or less) relevant for the patent grant decision than the average novelty challenging. The last variable of central interest ( $X Y$ comp JOUR REF/ XY JOUR REF) presents the share of company publications among the challenging scientific references. This variable shows whether corporate science is more (or less) challenging for the novelty of patent applications than the average blocking reference to science. A negative estimated coefficient would show that corporate scientific publications are more effective when challenging patent applications than the average $\mathrm{XY}$ scientific reference. This answers the research question whether corporate publications are an effective means to preempt patent applications by expanding the patentability threshold. Finally, $X_{i}$ presents the vector of control variables as described in the previous section.

We replace the homoscedastic variance $\sigma$ by $\sigma_{i}=\exp \left(\omega_{i}^{\prime} \alpha\right)$ where $\omega_{i}$ represents the regressors determining the variance function and $\alpha$ the additional coefficients to be estimated. ${ }^{80}$ $\omega_{i}$ includes five application year dummies, eight technology field dummies and the (log of) the time until a decision about a patent application is reached. ${ }^{81}$ We tested for the presence of heteroscedasticity in our probit models by means of LM tests (see Greene, 2003). We tested for the presence of heteroscedasticity in our probit models by means of LM tests (see Greene, 2003). The test statistics presented at the bottom of Table 5 show that homoscedasticity is rejected in all cases. Hence, the coefficients of standard probit models would be misleading. In addition, we use clustered standard errors on the level of the applicant to account for the fact that the error terms of the empirical model might be correlated for patent applications by the same applicant.

The estimation results summarized in Table 5.6 show several interesting findings. Concerning the baseline specification (model 1), which includes only the control variables, we find, for instance, that patents citing more prior art are more likely to become granted. This result does not support the interpretation that patents with many backward citations are of more incremental nature (Lanjouw and Schankerman, 2001). It is rather in line with previous research about patenting the EPO arguing that backward citations reflect the scope of the patented technology (Harhoff et al., 2003a). The finding that patents with references to many different technology classes is more likely to become granted points in the same direction. Patents associated with many different technologies presumably have a greater patent scope, which has been shown to correlate with the importance of patents (Lerner, 1994) and renders a positive granting decision more likely.

The next control variable captures the effect of time since application. The longer the patent examination takes the more likely is a grant. This suggests that patent applications which require a longer examination time are more complex (Sampat et al., 2003) and potentially more novel.

${ }^{80}$ Note that robust standard errors do not help if heteroscedasticity is found in nonlinear models.

${ }^{81}$ Greene (2003, p.317) suggests that if groupwise heteroscedasticity (in our case in form of application year and technology field dummies) is taken into account the inclusion of additional continuous variables does not necessarily improve the result. The log of the time until a decision about a patent was reached was, however, highly significant so that we included this continuous variable as well. Our findings are robust with regards to different specifications of the heteroscedasticity term. 
Table 5.6: Heteroscedastic Probit model for the patent grant decision

\begin{tabular}{|c|c|c|c|c|c|}
\hline & \multicolumn{5}{|c|}{ Specifications } \\
\hline & (1) & (2) & (3) & (4) & $(5)$ \\
\hline \multirow[t]{2}{*}{$\log (\mathrm{REF})$} & $0.37 * *$ & $0.42 * *$ & $0.50 * *$ & $0.52 * *$ & $0.52 * *$ \\
\hline & $(0.18)$ & $(0.19)$ & $(0.22)$ & $(0.22)$ & $(0.22)$ \\
\hline \multirow[t]{3}{*}{ XY REF/REF } & & $-1.16 * * *$ & $-1.29 * * *$ & $-1.29 * * *$ & $-1.28 * * *$ \\
\hline & & $(0.32)$ & $(0.35)$ & $(0.35)$ & $(0.35)$ \\
\hline & & & $-1.41 * * *$ & -0.91 & \\
\hline \multirow[t]{2}{*}{ XY JOUR REF/ XY REF } & & & $(0.52)$ & $(0.56)$ & \\
\hline & & & & & -0.94 \\
\hline \multirow[t]{2}{*}{ X JOUR REF/ XY REF } & & & & & $(0.65)$ \\
\hline & & & & & -0.77 \\
\hline \multirow[t]{2}{*}{ Y JOUR REF/ XY REF } & & & & & $(0.75)$ \\
\hline & & & & $-0.97 * *$ & \\
\hline \multirow[t]{2}{*}{ XY comp JOUR REF/ XY JOUR REF } & & & & $(0.48)$ & \\
\hline & & & & & -0.61 \\
\hline \multirow[t]{2}{*}{ X comp JOUR REF/ XY JOUR REF } & & & & & $(0.56)$ \\
\hline & & & & & $-1.49 * *$ \\
\hline Y comp JOUR REF/ XY JOUR REF & & & & & $(0.62)$ \\
\hline \multirow[t]{2}{*}{$\log (\mathrm{IPCs})$} & $0.46^{* * *}$ & $0.39 * * *$ & $0.39 * * *$ & $0.40 * * *$ & $0.40 * * *$ \\
\hline & $(0.14)$ & $(0.13)$ & $(0.13)$ & $(0.13)$ & $(0.13)$ \\
\hline \multirow[t]{2}{*}{$\log (\mathrm{TIME})$} & $1.92 * * *$ & $1.75 * * *$ & $1.80 * * *$ & $1.85 * * *$ & $1.84 * * *$ \\
\hline & $(0.51)$ & $(0.45)$ & $(0.47)$ & $(0.49)$ & $(0.50)$ \\
\hline \multirow[t]{2}{*}{$\log (\mathrm{INV})$} & $0.30^{*}$ & $0.26^{*}$ & $0.27^{*}$ & $0.28^{*}$ & $0.28 *$ \\
\hline & $(0.16)$ & $(0.15)$ & $(0.16)$ & $(0.16)$ & $(0.16)$ \\
\hline \multirow[t]{2}{*}{ Public } & -0.02 & -0.10 & -0.05 & -0.06 & -0.06 \\
\hline & $(0.48)$ & $(0.46)$ & $(0.47)$ & $(0.49)$ & $(0.48)$ \\
\hline \multirow[t]{2}{*}{ Constant } & $-3.02 * * *$ & $-2.65 * * *$ & $-2.71 * * *$ & $-2.87 * * *$ & $-2.85 * * *$ \\
\hline & $(0.99)$ & $(0.89)$ & $(0.92)$ & $(0.98)$ & $(0.99)$ \\
\hline \multicolumn{6}{|l|}{ LR-tests: } \\
\hline Appl. Years & $78.65 * * *$ & $78.64 * * *$ & $70.07 * * *$ & $74.58 * * *$ & $75.04 * * *$ \\
\hline Priority dummies & $248.22 * * *$ & $243.59 * * *$ & $244.44 * * *$ & $252.54 * * *$ & $252.46 * * *$ \\
\hline Tech. classes & $34.33 * * *$ & $36.14 * * *$ & $36.80 * * *$ & $35.35 * * *$ & $34.97 * * *$ \\
\hline Wald test for heteroscedasticity & $90.83 * * *$ & $84.58 * * *$ & $82.48 * * *$ & $85.38 * * *$ & $85.36^{* * *}$ \\
\hline LogLikelihood & $-3,889.26$ & $-3,865.17$ & $-3,851.24$ & $-3,847.42$ & $-3,846.40$ \\
\hline
\end{tabular}

NOTE: ***,**** indicate statistical significance at the 1\%-, 5\%-, 10\%-level. Standard errors are clustered for the individual applicants.

6,226 observations.

Estimated coefficients for a dummy for the share of NPLs that could not be identified (model 3, 4 and 5) and a dummy for NPLs issued before 1988 (model 4 and 5). All regressions include five application year dummies, eight technology class dummies and four priority dummies.

The number of inventors as a proxy for the size of the innovation project has a positive, but weakly significant effect. There is no difference between purely private patents and patents taken out in alliance with the public sector regarding the likelihood of a positive grant decision. 
Application year dummies, priority dummies and technology class dummies are jointly significant as LR-tests at the bottom of Table 5 show. In particular, the priority dummies are highly significant, which is mainly driven by the fact that patents with a U.S. priority are significantly less likely to become granted at the EPO. The estimated effects of the control variables are robust across the different specifications presented in Table 5.6. In model 2, we add the share of all references (patents and scientific and non-scientific NPLs) which are classified as prior art that threatens the novelty of patent applications $(X Y R E F / R E F)$ as an additional regressor to our specification. These references are made to limit the scope of patent applications by evaluating their claims with regard to prior inventions. As expected, the estimated coefficient clearly indicates that these references that patent examiner includes to delineate the patent claims make a positive grant decision less likely (Guellec et al., 2009). The marginal effect equals -0.14 at the means of all other variables indicating that the likelihood of a positive grant decision decreases by $14 \%$ in response to a unit change of the share of blocking references, i.e. if a patent application without any blocking reference would suddenly have only blocking references. ${ }^{82}$ The fact that additional blocking references do not inhibit the grant decision shows that patent applications that receive many blocking references can well be granted if claims are removed or modified and the scope of the patent application is narrowed. Documents cited as blocking can, hence, cause that patent protection is not granted for important claims. Model 3 adds the share of scientific publications that are classified as novelty threatening ( $X Y J O U R R E F / X Y R E F$ ) to the specification.

The results show that novelty threatening journal publications increase the probability of getting a patent application rejected significantly. Accordingly, in the field of semiconductor, scientific NPLs do not only reflect scientific results that lead to technology development. In this science-based technology field, scientific publications have the power to threaten the novelty of patent applications beyond the power of an average blocking reference. The regression results suggest that scientific articles even have an extra blocking effect on top of the average blocking citation which is captured by the variable $(X Y R E F / R E F)$. The marginal effect equals -0.17 at the means of all other variables indicating that the likelihood of a positive grant decision decreases by $17 \%$ in response to a unit change of the share of scientific blocking references among all blocking references. ${ }^{83}$

${ }^{82}$ The marginal effect is calculated as the derivative with regard to the variable of interest. In this case: $\frac{\partial P(d=1)}{\partial\left(\frac{X Y R E F}{R E F}\right)}=\frac{\partial \Phi\left(\beta_{1} \log (R E F)+\beta_{2} \frac{X Y R E F}{R E F}+\beta_{5} X\right)}{\partial\left(\frac{X Y R E F}{R E F}\right)}$.

${ }^{83}$ Marginal effects are calculated as the derivative with regard to the variable of interest. In this case: $\frac{\partial P(d=1)}{\partial\left(\frac{X Y \text { JUUREF }}{X Y R E F}\right)}=\frac{\partial \Phi\left(\beta_{1} \log (\text { REF })+\beta_{2} \frac{\text { XYREF }}{\text { REF }}+\beta_{3} \frac{\text { XYJOURREF }}{X Y R E F}+\beta_{5} X\right)}{\partial\left(\frac{X Y \text { OURREF }}{X Y R E F}\right)}$. 
Table 5.7: Heteroscedastic Probit model for the patent grant decision for the subsample of firms with less than 200 patent applications

\begin{tabular}{|c|c|c|c|c|c|}
\hline & \multicolumn{5}{|c|}{ Specifications } \\
\hline & $(1)$ & (2) & $(3)$ & (4) & $(5)$ \\
\hline \multirow[t]{2}{*}{$\log (\mathrm{REF})$} & 0.28 & 0.31 & $0.37^{*}$ & $0.37^{*}$ & $0.37 *$ \\
\hline & $(0.20)$ & $(0.20)$ & $(0.22)$ & $(0.22)$ & $(0.22)$ \\
\hline \multirow[t]{3}{*}{ XY REF/REF } & & $-0.85 * * *$ & $-0.94 * * *$ & $-0.94 * * *$ & $-0.93 * * *$ \\
\hline & & $(0.27)$ & $(0.28)$ & $(0.28)$ & $(0.28)$ \\
\hline & & & $-1.05^{* *}$ & -0.48 & \\
\hline \multirow[t]{2}{*}{ XY JOUR REF/ XY REF } & & & $(0.48)$ & $(0.50)$ & \\
\hline & & & & & -0.75 \\
\hline \multirow[t]{2}{*}{ X JOUR REF/ XY REF } & & & & & $(0.63)$ \\
\hline & & & & & -0.18 \\
\hline \multirow[t]{2}{*}{ Y JOUR REF/ XY REF } & & & & & $(0.63)$ \\
\hline & & & & $-1.18 * *$ & \\
\hline \multirow[t]{2}{*}{ XY comp JOUR REF/ XY JOUR REF } & & & & $(0.55)$ & \\
\hline & & & & & -0.74 \\
\hline \multirow[t]{2}{*}{ X comp JOUR REF/ XY JOUR REF } & & & & & $(0.53)$ \\
\hline & & & & & $-1.65 * *$ \\
\hline Y comp JOUR REF/ XY JOUR REF & & & & & $(0.76)$ \\
\hline \multirow[t]{2}{*}{$\log (\mathrm{IPCs})$} & $0.43 * * *$ & $0.37 * * *$ & $0.38 * * *$ & $0.39 * * *$ & $0.39 * * *$ \\
\hline & $(0.15)$ & $(0.14)$ & $(0.14)$ & $(0.15)$ & $(0.15)$ \\
\hline \multirow[t]{2}{*}{ Log(TIME) } & $2.01 * * *$ & $1.87 * * *$ & $1.93 * * *$ & $1.99 * * *$ & $1.95 * * *$ \\
\hline & $(0.51)$ & $(0.47)$ & $(0.48)$ & $(0.50)$ & $(0.49)$ \\
\hline \multirow[t]{2}{*}{$\log (\mathrm{INV})$} & $0.24^{*}$ & 0.21 & 0.22 & 0.22 & 0.22 \\
\hline & $(0.14)$ & $(0.13)$ & $(0.14)$ & $(0.14)$ & $(0.14)$ \\
\hline \multirow[t]{2}{*}{ Public } & -0.07 & -0.11 & -0.08 & -0.11 & -0.11 \\
\hline & $(0.47)$ & $(0.46)$ & $(0.47)$ & $(0.50)$ & $(0.49)$ \\
\hline \multirow[t]{2}{*}{ Constant } & $-2.74 * * *$ & $-2.46 * * *$ & $-2.52 * * *$ & $-2.70 * * *$ & $-2.63 * * *$ \\
\hline & $(0.97)$ & $(0.90)$ & $(0.91)$ & $(0.97)$ & $(0.95)$ \\
\hline \multicolumn{6}{|l|}{ LR-tests: } \\
\hline Appl. Years & $37.54 * * *$ & $39.62 * * *$ & $34.22 * * *$ & $33.54 * * *$ & $24.92 * * *$ \\
\hline Priority dummies & $120.50 * * *$ & $116.75 * * *$ & $117.99^{* * *}$ & $116.68 * * *$ & $107.15^{* * *}$ \\
\hline Tech. classes & $28.62 * * *$ & $29.59 * * *$ & $28.67 * * *$ & $28.32 * * *$ & $19.38 * * *$ \\
\hline Wald test for heteroscedasticity & $78.57 * * *$ & $72.89 * * *$ & $71.12 * * *$ & $71.65 * * *$ & $71.16^{* * *}$ \\
\hline LogLikelihood & $-3,188.83$ & $-3,176.99$ & $-3,169.98$ & $-3,165.88$ & $-3,165.22$ \\
\hline
\end{tabular}

NOTE: $* * *, * * *$ indicate statistical significance at the $1 \%-, 5 \%-, 10 \%$-level. Standard errors are clustered for the individual applicants.

5,095 observations.

Estimated coefficients for a dummy for the share of NPLs that could not be identified (model 3, 4 and 5) and a dummy for NPLs issued before 1988 (model 4 and 5). All regressions include five application year dummies, eight technology class dummies and four priority dummies.

Model 4 investigates whether corporate scientific publications (XY comp JOUR REF/XY $J O U R R E F$ ) are responsible for this extra blocking effect of scientific NPLs. The results show that the extra blocking effect of science in the patent system stems from company publications. 
When company publications are considered on top of the overall effect of blocking scientific NPLs, the latter variable becomes insignificant. This suggests that only corporate publications have a blocking effect on patent applications. Scientific publications from the public sector are to the same extent blocking as the average piece of prior art classified as X or Y. This result confirms the existence of negative externalities on the likelihood of obtaining a patent generated by corporate disclosures in to the public domain: corporate science has the power to challenge patent applications. The finding of superior blocking power of corporate science is, further, in line with the presumption that there is a strategic consideration behind company publications. The marginal effect of the blocking company citations equals -0.11 at the means of all other variables suggesting that the likelihood of a positive grant decision decreases by $11 \%$ in response to a unit change of the share of company references among all blocking scientific references, i.e. if a patent application without any scientific blocking reference to company publications suddenly had only scientific blocking references to the private sector. The marginal effect might seem small. But one has to keep in mind that this is the effect that realizes in addition to the effect of the other blocking references. Model 5 distinguishes between $\mathrm{X}$ - and Y-type citations to corporate publications and to scientific references in general. With this distinction, we test whether corporate publications convey technical information relevant for the evaluation of a patent on their own (X-type) or whether they have to combined with another piece of prior art like a patent (Y-type). A very interesting result appears. Only the share of Y-type citations to the private sector has an additional blocking effect (on top of the average cited blocking document). This suggests that corporate publications are only effective if combined with other pieces of prior art and not as standalone documents (X-type citation). The marginal effect equals -0.16 at the means of all other variables suggesting that the likelihood of a positive grant decision decreases by $16 \%$ in response to a unit change of the share of Y-type company references among all blocking scientific references. ${ }^{84}$

The finding that company publications have a blocking power when combined with other pieces of prior art (and not as standalone documents) indicates that companies use publications defensively in combination with stronger IP protection means, like patents. ${ }^{85}$ This result, coupled with the list of top publishers presented in Section 5.3.2, is consistent with the view that defensive publishing is mostly employed by technological leaders.

One could hypothesize that the patent portfolios of the largest patent applicants are better known to the patent examiners since they have to evaluate many patents from these submitters.

\footnotetext{
${ }^{84}$ The estimated marginal effects for the other significant regressors did not decrease significantly in size if more variables are added. Hence, they are not reported again.

${ }^{85}$ At the bottom of Table 5 we present two goodness of fit measures, the McFadden $\mathrm{R}^{2}$ which is based on the loglikelhood ratio of the fitted model and a baseline model with only a constant as regressor and Efron's (1978) goodness of fit measure which is oriented towards the relationship between the fitted probabilities and the actual values. It becomes apparent that the measures do not change significantly over the different specification. There is a small increase when moving from the first to the second specification where we add the first blocking references variable. This is explained by the fact that the later specifications disentangle the blocking references variable rather than adding new information.
} 
This might impact the examination procedure of these applicants' patents. Table 5.7 shows that our results are robust when we delete the most active patent applicants with more than 200 patent applications each. Hence, we are confident that our results are not driven by potentially different examination procedures at the EPO for the submissions by the largest patent applicants. We further checked whether the journal publications that are cited as blocking prior art are citations to the companies' own scientific publications. If the fraction of the blocking citations to science taken out by the same applicant is added as a separate variable to model 4 the estimated effects do not change significantly and the effect of journal self-citations is not statistically significant. The finding that self-citation at the EPO are not different from other citations is not surprising. This is likely to be explained by the fact that within the European patent system about $90 \%$ of the citations are given by the examiner (Criscuolo and Verspagen, 2008) and that applicant-given citations need approval by the examiner. This stands in contrast to the U.S. patent system where applicants submit most citations themselves and where the share of self-citations is accordingly higher. $^{86}$

\subsection{Conclusions}

Open disclosure of technological knowledge by companies with the aim to preempt rivals' patents has attracted the attention of academic scholars in the field of law, economics and management science (e.g. Baker and Mezzetti, 2005; Colson, 2001; Merges, 2004). The publication of research results increases the pool of prior art and raises the novelty requirements for later patent applications. This generates a negative externality or a legal externality. The academic discussion has raised two main views on the use of defensive disclosure as mechanism to preserve the freedom to operate technologies. The first view claims that firms voluntarily generate legal externalities at the cost of forgoing the exclusivity afforded by patent rights. Relevant technological knowledge is disclosed exclusively through the public domain and open disclosure substitutes patenting (Bar, 2006; Parchomvski, 2000). This view is consistent with the assumption that only technological laggards (i.e. small or financially constrained companies, companies operating in a different market ) have incentive to pursue this strategy. A second view, instead, claims that companies complement the use of defensive disclosure strategies with traditional forms of intellectual property rights. This is the case of technological leaders, which

\footnotetext{
${ }^{86}$ In order to complete the analysis, we made an attempt to check whether there is evidence for cited scientific publications enabling patents (Eisenberg, 2000b). In order to do so we investigated whether applicant-given A-type (enabling) citations have a positive effect on the patent grant decision. The results did not show evidence in favor of this hypothesis. However, we believe that EPO patent data is not suited for the identification of the enabling effect of disclosure since the majority of references to patent applications are added by the patent examiner (and applicantgiven citations are examiner approved). Therefore, they do not represent a complete picture of the prior art that was essential for developing the invention in question. Inventor survey data uncovering the relevant prior art for an invention should be used to investigate this question. We further checked the correlation of applicant-given blocking citations and applicant-given enabling, citations (A citations) that each scientific publication receives by our sample patents. The correlation was negative suggesting that the cited publications are either cited as blocking or noninfringing state of the art in the patent literature.
} 
publish outside the patent system intermediate research results or minor improvements on core technologies (Baker and Mezzetti, 2005; Johnson, 2004; Henkel and Pangerls, 2008; Lichtmann et al., 2000; Rinner, 2003). Both views, however, share the assumption that legal externalities exist, that is corporate disclosures enter the pool of prior art which is relevant to evaluate the novelty of patent applications at the patent office and that they actually have the power to block or hinder patent applications.

This study provides for the first time systematic large-scale evidence on the existence of legal externalities, in the form of scientific publications, generated by companies to secure the freedom-to-operate their technologies. We focus on the field of semiconductor technology as an example of a science-based, complex technology. Our empirical analysis reveals several interesting findings. First, in line with previous studies on the nature of NPLs in patent documents, we show and confirm that the technology field of semiconductor is heavily based on scientific knowledge. An average patent application in semiconductor cites .26 scientific journal articles. Second, we show that science in semiconductor does not exclusively serve as a foundation for technology development, but that it also challenges the novelty of patent applications. In particular, company publications are effective in blocking related patent applications and, accordingly, are used as a device for securing the freedom to operate a technology. Hence, we show for the first time that the presumed negative externality on the novelty requirement of future patent applications actually works.

In a second step of the analysis, we use detailed information from the patent examination process at the EPO to show that companies use publications defensively in combination with other pieces of prior art like patents. ${ }^{87}$ In the Semiconductor technology, publications are used to secure the freedom to operate mostly by companies that have already a stable foothold in the technological market. This finding is intuitive for a complex industry like semiconductor where firms pursue "portfolio maximizing" IP protection strategies in order to avoid being held up by other firms (Ziedonis, 2004).

We can reject that corporate scientific publications are more relevant for the evaluation of the novelty of patent applications because they deal with scientific advances that are more applied and closer to commercial ends than scientific publications from the public sector. We rule out this alternative explanation based on a number of tests. The results show that there is no significant difference in the nature and significance of publications by corporation and by non-profit organizations in the technology domain. We can, further, reject that the effects are driven by the fact that a company's own patents are those that cite its corporate publications most often.

Let us clarify that our finding that corporate publications block patent applications does not exclude possible enabling effects of publications on technology developments in the sense that publications can trigger or speed up technology developments (Eisenberg, 2000b). Since the list of references that the examiner at EPO assembles does by no means represent a complete list of

\footnotetext{
${ }^{87}$ Although our data does not allow us to determine which documents are combined when threatening a patent application as a combination we can rely on the EPO patent examination guidelines. See Section 2.1.
} 
the relevant prior technologies that influenced the patent application at hand inventors should be surveyed in order to investigate the enabling power of scientific publications.

A limitation of this study is that we cannot provide evidence for the motivations behind corporate scientific publications. We acknowledge that there are several other reasons for companies to disclose their inventions (Penin, 2007). Companies can, for instance, disclose technical advances to allow upstream suppliers improving their products. Disclosure of technologies can increase the size of downstream markets or trigger feedback from users in downstream markets. Knowledge can also be disclosed with the intention to implement a technology as a standard or to achieve compatibility with interdependent products. Scientific publications can further be used as a means to increase firm reputation, to motivate researchers in the private sector and to attract the best employees (Penin, 2007). Nevertheless, we want to stress that these alternative motivations for corporate scientific publications do not impact our findings that corporate science generates legal externalities in the patent system and that this effect stems from the combination of corporate publications with other pieces of prior art.

As it is not possible to investigate the motivations behind corporate publications on a large scale our study has to be seen as a complement to case study evidence on this topic (e.g. Henkel and Pangerl, 2008). Interviews with industry expert could uncover how publishing and patenting is strategically used at the firm level. Information on the firms' technology portfolio and on the different IP protection tools that are used at the level of the individual innovation project (and their combinations) would be necessary which renders this research question impossible for large-scale empirical analyses. ${ }^{88}$ We also acknowledge that it is difficult for manager to ex ante assess whether a corporate publication will block future patent applications. Our study cannot inform manager how to determine the blocking potential of corporate publications. However, it

${ }^{88}$ An approach applied in prior studies to assign patents and publications to innovation projects is to define patent-publications pairs within a firms' patent and publication portfolio (Ducor, 2000; Murray and Stern, 2007; Lissoni and Montobbio, 2008). This approach relies either on the knowledge of a person skilled in the art who is able to define patent-publication pairs by studying their content (Ducor, 2000; Murray and Stern, 2007), hard to implement on a large scale database like ours, or it is based on co-word analyses of patent documents and scientific publications (Lissoni and Montobbio, 2008). In our eyes, it is not evident that the latter approach would yield valid matches in a complex, cumulative technology like semiconductor where one invention is based on many different building blocks that are likely to be relevant for more than one innovation projects. The fact that semiconductor has many big players holding large patent and publication portfolios would make the definition of individual innovation projects even less credible.

Similarly, cross-citations between patents and publications are not a perfect means for defining patentpublication pairs. The majority of references to prior art in EPO patent applications are added by the patent examiner. This means that publications cited in patents do not necessarily indicate that the cited publications refer to the same innovation project as the patent application. Further, the patent examination guidelines dictate that only the most important and earliest sources are to be cited. Hence, we would miss many citations to publications from the same project. Patent citations in publications might be a more promising venue for identifying patents and publications belonging to the same project. Again, there is no guarantee that all patents belonging to the same project are cited in publications. Further, patents belonging to different projects can be cites in publications. Hence, the question remains how reliable this approach is for a complex, cumulative technology with many agents with large publication and patent portfolios. 
points to strategic complementarities between the two appropriation strategies: patenting and publishing.

Furthermore, we only focus on scientific articles as a channel for corporate strategic disclosure. We are aware of the fact that there are alternative platforms for corporate disclosure as, for instance, specialized publication platforms like "Research Disclosure" and "IP.com". Interviews with IP experts in industry, however, underline the importance of scientific publications for defensive publishing (Henkel and Pangerl, 2008). They conclude that companies rate scientific publications as the second most effective mechanism to disclose strategically (after internet providers specialized in public disclosure). Notwithstanding, in the context of a sciencebased industry like semiconductor, scientific publications might well be an important conveyers of relevant technical information for companies.

Another limitation is that our results for the semiconductor technology cannot be considered as representative for other technology fields. Semiconductor is one of the most science-based technologies. Most likely, corporate publications are less effective for blocking patent applications in other technological areas. Semiconductor is, furthermore, a complex technology where firms engage in patent portfolio races rather than in traditional patent races (Hall and Ziedonis, 2004). It cannot be taken for granted that our result that publications block patent applications in combination with other pieces of prior art applies to other technology sectors as well. In particular, for discrete industries, more research should be needed.

Lastly, one should be careful to generalize our results for the EPO to other patent systems like the USPTO since both systems exhibit significant institutional differences (Guellec and van Pottelsberghe de la Potterie, 2007, Deng, 2007). The granting process at the EPO is, for instance, more rigorous than at the USPTO (Guellec and van Pottelsberghe de la Potterie, 2007, p.203, Lemley, 2001) and obtaining and maintaining a European patent is two to three times more expensive than in the U.S. (Lazaridis and van Pottelsberghe, 2006). Hence, European patent applications are a subsample of inventions with a higher economic potential. Further, due to the fact that most citations are examiner-given in Europe but applicant-given in the U.S. (due to the "duty of candor", see section 2) we observe significant differences in citation pattern, e.g. is the list of references to prior art for patents at the USPTO typically longer than for European patents (Bacchiocchi and Montobbio, 2010), U.S. patents cite disproportionally more domestic patent applications than other patents (Cotropia et al., 2010) and self-citations are likely to be more often observed in the U.S. since a missing reference to patent that was known to the applicant can forgo the patent grant. Such institutional differences make it difficult to generalize our findings to other patent regimes.

Concluding, this study has confidently provided a lower bound estimate of the magnitude of legal externalities. 



\section{Concluding remarks and directions for future research}

\subsection{Summary of main findings}

This dissertation has empirically investigated some challenges and opportunities that emerge from the interaction between the world of Science and the world of Technology. The point of departure is that Science, intended as the Episteme or what we know, increases the understanding of the natural principles governing Technology (Techné or how we apply), and, with it, the range of applications of the set of techniques comprising Technology. Scientific discoveries, hence, pave the way for continuing improvements in the production process, either as refinement of existing techniques or emergence of new technological trajectories.

This dissertation has first explored two channels that should facilitate the economic exploitation of scientific knowledge: scientific eminence and entrepreneurship. By taking a simplistic view to the relation between Science and Technology, where the advancements in the former represent a necessary condition for the developments of the latter, scientific eminence can be conceived as an input of the process that transforms knowledge in profits and economic growth, whereas entrepreneurship as a throughput of this process.

Scientific eminence is only achieved when scientists discover regularities in nature which are original in their contents, rigorous in their explorations and universal in their implications for Technology, as assessed by the academic community. It hence pertains to the inherent qualities of the improvements to the epistemic base from which techniques can be built upon or improved. Technologists, who before others can have access to these new and superior pieces of knowledge, should be able to refine their techniques and consequently improve the outputs of their innovative efforts. I argued that scientific knowledge, produced in academic laboratories (the most prominent producers of Science), mostly spills over through market transactions, such as the market for graduates and technological services. From this perspective, accessibility - co-location - is crucial, because knowledge, unlike information, not only requires unanimated media to be transferred across space, but also, and foremost, face-to-face contacts with the direct source (the scientist). The first study aimed at drawing regularities with regards to this hypothesis: technologists located in the neighbourhood of universities hosting eminent research groups (in hard-science disciplines) should produce more and better innovations than technologists located elsewhere. Empirical results for 86 European regions (NUTS 1 and NUTS 2) between 1997 and 2007 confirm the role that scientifically eminent universities have on the innovative capabilities of local technologists. Other sources of scientific knowledge (intended as epistemic, directed towards the understanding of natural phenomena) do not show any statistical relation with regional innovative outputs. Nevertheless, the very small real effect attributed to the scientific 
eminence of academic research casts some doubts on the effectiveness of knowledge transfer between scientists and technologists.

The second study moves forward from this conclusion to investigate under which peculiarities of the industrial structure academic knowledge is better exploited from an economic standpoint. Scientific discoveries can be both evolutionary and a revolutionary with regards to the way existing techniques are designed and assembled. Indeed, the process through which scientific advancements are assessed is, in its self, a tension between conformity to the state of the art and dissent from it. Evolutionary and revolutionary scientific advancements have tremendously different implications for economic performances. Whereas most of the measured productivity growth might come from evolutionary improvements in the knowledge base, revolutionary discoveries introduce new concepts that have the potential to generate new markets and through a mix of competitive and cooperative interactions, trigger follow-up innovations and growth in other firms. They are therefore critical building blocks of nations' creative destruction capacity and their long-term economic growth. While existing organizations do not have to incur in severe reorganizations of their production processes to incorporate evolutionary discoveries, they have harder times when new discoveries require the reformulation of the existing productive logics. Entrepreneurs are not constrained by the rigidities of existing productive architectures. Therefore, they can redesign production processes so as to embed revolutionary advancements. The second study, hence, investigates whether sustained market entry is conducive to a more efficient exploitation of scientific knowledge. The starting point is the academic system because it is the place where scientific activities are carried out systematically. Universities, however, not only pursue scientific research, but they also train students and, lately, have become involved directly in the commercialization of scientific discoveries in the form of technologies. The econometric exercise carried out for 99 Italian provinces (NUTS 3) between 1999 and 2006 indicates that none of the above mentioned outputs exerts a significant impact on the rate of economic growth, neither for the manufacturing sector nor for the whole economy. It is only when research activities occur where sustained entrepreneurial activities take place that economic growth is affected: the traditional mandate of scientific inquiry seems to provide new ventures with valuable commercial opportunities overseen by established companies. Despite the positive impact of new ventures in exploiting scientific knowledge from an economic standpoint, their magnitude is very limited.

The first two studies clearly indicate that there exists potential for economic growth in the pursuit of scientific endeavours. Yet, the limited real implications call for further understanding of the process with which scientific knowledge is embedded in technological innovation. An often abused justification to the little real impact of scientists is their intellectual distance from problems of immediate practical relevance. The norms of the community of Science push for original contributions which would question the existing understanding of reality. These contributions, however, are also expected to explain a wide range of phenomena (the criterion of universality). The common sense would suggest that the introduction of clear monetary incentives should induce scientists to develop industrial applications of their scientific findings. A 
simple statistics, the number of patent applications from universities, would reinforce this view. The third study has hence examined a set of policy tools to increase the awareness of Intellectual Property Rights at public research organizations. The French government embarked in a similar initiative in 1999, when it passed the Innovation Act. The Act had the explicit goal of losing the legal burdens to ease the management of IPRs at universities. The study uses a novel measure of academic inventive activity: patent applications whose inventors are scientists, irrespective of the ownership of the patent. The results show that scientists are involved in technological developments more than the common sense would suggest. Traditional statistics are misleading because scientists tend to leave the ownership of their inventions to corporate sponsors in more than two thirds of the cases. French universities own only $11 \%$ of all patent applications at EPO whose inventors are scientists between 1994 and 2001. The passage of the Act and the opening of technology transfer offices have increased the patenting rate at French universities; yet, any increase may be due, at least in part, to a redistribution of ownership rights, rather than an increase in inventive activity.

The final study of this dissertation has shifted the attention from science produced at universities to science produced in corporate environments. Companies are expected to have a comparative advantage in the production of new techniques. Investments in Science are a "necessary evil" to tap into knowledge external to the organization. However, companies increasingly pay attention to mechanisms that could secure their intellectual assets from rentseeking forms of technological brokerage (patent trolls, patent sharks, etc...). The tremendous increase in patenting activities worldwide reflects this tendency. Patents, however, are costly to apply, maintain and enforce. The output of Science can well serve this purpose (at a lower cost): companies disclose relevant information in the public domain to pre-empt competitors from gaining exclusive rights on the technologies disclosed. This strategic use of Science has raised a debate between economists and legal scholars. Economists argue for the perfect substitutability between patents and publications for defensive purposes. Legal scholars instead The last chapter has provided for the first time an investigation of the presumed mechanism behind this strategic use of Science. The results from the Semiconductor Technology indicate that, unlike publications from the public sector, corporate publications have the power to threaten the novelty and originality of claimed inventions. This effect is not driven by any systematic difference in the contents of the articles from both communities. Moreover, publications are effective only when they are combined with other pieces of prior art, confirming the view of legal scholars.

\subsection{Room for future research}

The underlying rationale of the first three studies is that scientific knowledge generated in academic communities has the potential to revolutionize the way products and processes are conceived. The emergence of science-based sectors like Biotechnology and Information and Communication Technology in the last thirty years points exactly to his. The limited magnitudes of the factors that supposedly should influence the generation and the diffusion of revolutionary 
scientific knowledge call for a deeper understanding of the role that Science actually plays in the generation of radical techniques and how they actually diffuse.

\subsubsection{The Scientific Backbone of Radical Innovations}

A first research area will be to detect the scientific background of radical innovations. The studies on the origins of radical innovations have since long be debating on whether radical innovations originate from completely new knowledge or from new combinations of already existing knowledge (Fleming, 2001; Puel, 2003; Rosenberg, 1982). Whereas the debate has mostly remained on a conceptual level, only recently the technical contents of radical innovations have been studied extensively (Ahuja and Lampert, 2001; Schoenmakers and Duysters, 2009). The authors report that combinations of emerging and mature technologies pave the way for radical innovations to emerge. Yet, little is known on the scientific contents of radical innovations. In this regard, some recent empirical evidence has shown that corporate scientific involvement is related to faster exploitation of knowledge (Fabrizio, 2007), but it barely translates directly in better than average inventions (Cassiman et al., 2008). The question arises which research topics, fields and types of codification (articles, presentations, patents) are important sources and conveyers of information to be transformed to innovations that carry 'radical' characteristics.

\subsubsection{Academic Entrepreneurship}

It has been argued in the literature that science may not only be a major driver of innovation, but that also commercialization of technologies through university scientists themselves may be a very important channel for radical innovations. Academic inventions are mainly at an early stage of development, general in purpose, characterized by high uncertainty about their actual applications, and demand further development efforts from the buyers and inventors to be commercialized (Colyvas et al., 2002; Jensen and Thursby, 2001; Jensen et al., 2003). The fact that these inventions are affected by higher uncertainty about possible uses than typical inventions, often require the inventor to be involved in the commercial development (Agarwal, 2006). For instance, the works by Zucker et al. (2002), Thursby and Thursby (2003), MachoStadler, Perez-Castrillo and Veugelers (2008) among others, suggest that not science itself, but the faculty involvement in the commercialization process is a critical factor for major industrial innovations. Entrepreneurial companies, indeed, are found to be most likely to introduce newer inventions from universities (Shane, 2001). A promising area of investigation is indeed to delve into the ability of academic spinoffs to commercialize academic innovations overseen by other companies.

\subsubsection{Market Structure and Radical Innovations}

A next research area relates to the institutional origins of radical innovations at large. The literature on the relationship between market structure and innovation has found inconclusive empirical findings in support of small firms being more innovative than large firms: small firms realize a greater number of innovations per research dollar, but large firms may still have an R\&D 
advantage in the sense that these firms can spread the costs of development over greater output where these firms have developed markets (Cohen and Klepper 1996). Industry-specific evidence and expert panels have found that young firms are the main candidates of break-through innovations (Henderson, 1993; Prusa and Schmitz, 1991). Young firms have been systematically found to be more radically innovative; the latter measured as the self-reported share of revenues from products new to the market (Schneider and Veugelers, 2010). Management studies have pointed out the difficulties for large firms in organizing both exploitation of mature technologies and the exploration of new technologies simultaneously. These activities require different mindsets and organizational routines (e.g. Christensen, 1997), with flexible, organic, organizational structures being preferable for exploration purposes, and efficiency-oriented, mechanistic organizational practices being better suited for performing exploitation activities (Abernathy, 1991). The question arises which type of company is most likely to introduce radical innovations: the young small entrepreneurial start-up, not concerned with safeguarding incumbent competences and profits, or large companies, using their scale and scope advantages.

\subsubsection{IPRs in Science in Europe}

The debate on the usefulness of IPRs in Academia to accelerate the flow of knowledge transfer from Science to Technology has been hot and inconclusive so far. IPRs might have led university managers to take off their shelves a good number of industrial applications of scientific discoveries otherwise unexploited. Critics instead point to two main facts: a) especially in Europe, academic scientists produce innovations irrespective of IPRs (academic patents) (chapter 4 in this dissertation), b) the innovations commercialized directly by universities (university patents) might be of inferior technical relevance in the short run, although potentially have a wider range of applications (Sampat et al., 2003). Empirical evidence for Europe highlights that academic patents have higher and more immediate technical relevance than university patents (Baciocchi and Montobbio, 2009), the inexperience of universities in the management of IPRs being one of the main reasons (Conti and Gaulé, 2011). A fertile area of investigation is the explorations of modes of commercialization of academic technologies and their implications for technology transfer. If European companies have extensively benefited from academic knowledge in the form of new technologies privately held, the question arises how these technologies are embedded in the innovative organizations of the industrial partners, which effects they have for companies' future innovative and financial performance and eventually for competitors.

\subsubsection{Corporate Open Disclosure}

Finally, this dissertation has proposed a novel approach to understand how the results of Science, and particularly their open format intended as the absence of residual claims on the benefits accrued by the exploitation of the information contained, can interact with the appropriation mechanisms in place in Technology. So far, the economic attention for open disclosure mechanisms has been constrained to one particular type of them: scientific publications. They 
were considered as a "necessary evil" to tap into knowledge external to the organization (Cohen and Levinthal, 1989) or fundamental ingredients for developing better technologies (Narin et al, 1997). The evidence and the magnitude of other forms of open disclosure (corporate journals, disclosure platforms, private sponsorship of public research, etc...) call for alternative explanations of the phenomenon. Indeed, as patent offices have become more lenient in their assessments of patentability criteria, markets for technologies have expanded and IP rights have become more fragmented. New forms of technological brokerage have emerged, often with hostile intentions (e.g. patent trolls). To protect their ability to use their own technologies, companies build portfolios of patents for strategic purposes that they eventually use as "hostages" in negotiations with competitors. Yet, patents are costly to apply, maintain and enforce in court. Hence, a new venue for research is to understand the conditions under which other, cheaper, alternatives - in this case open disclosure - can serve the same purpose, without undermining the primary goal of companies, capturing value from innovations. 


\section{References}

Acs Z., Audretsch D. and Feldman M. (1992) "Real effects of academic research: comment", American Economic Review, . 81, 363-367.

Acs, Z. J., Braunerhjelm, P., Audretsch, D. B., and Carlsson, B. (2009). "The Knowledge Spillover Theory of Entrepreneurship", Small Business Economics, 32(1): 15-30.

Adams J. and A. B. Jaffe, (1996) "Bounding the Effects of R\&D: An Investigation Using Matched EstablishmentFirm Data," RAND Journal of Economics, . 27, 700-721.

Adams, J. D. (1990). "Fundamental Stocks of Knowledge and Productivity Growth", Journal of Political Economy, 98(4): 673-702.

Adams, S., and V. Henson-Apollonio (2002). "Defensive publishing: a strategy for maintaining intellectual property as public goods", International Service for National Agriculture Research, 53, 1-8.

Agarwal, R., Echambadi, R. , Franco, A.. and Sarkar, M. B. (2004), "Knowledge Transfer through Inheritance: Spinout Generation, Growth and Survival", Academy of Management Journal, 47(4): 501-522.

Agrawal, A. and R. Henderson (2002) "Putting Patents in Context: Exploring Knowledge Transfer from MIT". Management Science, . 48, 44-60.

Andersson R., Quigley J., Wilhelmson M. (2009) "Urbanization, Productivity and Innovation: Evidence from Investment in Higher Education", Journal of Urban Economics, 66, 1, 2-15.

Anselin L, Varga A. and Acs Z. (1997) "Local Geographic Spillovers between University Research and High Technology Innovations," Journal of Urban Economics, . 42, 422-448.

Anselin, L. (1988). Spatial Econometrics: Methods and Models, Dordrecht: Kluwer.

Arora A. and Gambardella A. (2008) "Ideas For Rent: An Overview Of Markets For Technology", mimeo.

Arora, A., and Gambardella, A. (1994). "The Changing Technology of Technological Change: General and Abstract Knowledge and the Division of Innovative Labour", Research Policy, 23: 523-532.

Arrow, K. (1962). "Economic Welfare and the Allocation of Resources for Innovation", in R. R. Nelson (editor), The Rate and Direction of Inventive Activity, Cambridge (MA): NBER Books, 609-626.

Arundel A., G. van de Paal and L. Soete (1995). "Innovation strategies of Europe's largest industrial firms. PACE Report", MERIT, Maastricht, The Netherlands.

Audretsch D. and Feldman M. (1996) "R\&D spillovers and the geography of innovation and production", American Economic Review 86, 630-640.

Audretsch D. and Stephan P. (1996) "Company-Scientist Locational Links: The case of Biotechnology", American Economic Review, . 86, 641-652.

Audretsch, D. B. (1995). Innovation and Industry Evolution, Cambridge (MA): MIT Press.

Audretsch, D. B. (2007). "Entrepreneurship Capital and Economic Growth", Oxford Review of Economic Policy, 93(1): 63-78.

Audretsch, D. B., and Keilbach, M. (2008). "Resolving the Knowledge Paradox: Knowledge-spillover Entrepreneurship and Economic Growth”, Research Policy, 37(10): 1697-1705.

Autant-Bernard, C. (2001)."Science and knowledge flows : Evidence from the French case.”, Research Policy., 30, 7 , 1069-1078.

AUTM (2004) AUTM U.S. Licensing Survey: FY 2004, Association of University Technology Managers, Deerfield IL

Azagra-Caro J., Carayol N., Llerena P. (2006) "Patent Production at a European Research University: Exploring Evidence at the Laboratory Level", Journal of Technology Transfer 31(3): 257-268.

Azoulay P., W. Ding and T. Stuart (2007) "The determinants of faculty patenting behaviour: demographics or opportunities?", Journal of Economic Behavior and Organization, 63, 4, 599-623.

Azoulay, P., Ding, W., and Stuart, T. (2009). "The Effect of Academic Patenting on the Rate, Quality, and Direction of (Public) Research Output", Journal of Industrial Economics, 57(4): 637-676.

Bacchiocchi , E. and F. Montobbio (2010). "International Knowledge Diffusion and Home-Bias Effect: Do USPTO and EPO Citations Tell the Same Story", Scandinavian Journal of Economics, 112(3), 441-470.

Bach L., Llerena P. (2010), Les activités de recherche contractuelle et de transfert de technologie dans les établissements français d'enseignement supérieur: Enquête 2006-2007 - Rapport final, BETA-University of Strasbourg: Strasbourg 
Baker, S., and C. Mezzetti (2005). "Disclosure as a strategy in the patent race", Journal of Law and Economics, 48, 173-194.

Baldini N., Grimaldi R., Sobrero M. (2006) "Institutional changes and the commercialization of academic knowledge: A study of Italian universities' patenting activities between 1965 and 2002", Research Policy 35(4): 518-532.

Bania, N., Eberts, R. W., and Fogarty, M. S. (1993). "Universities and the Startup of New Companies: Can We Generalize from Route 128 and Silicon Valley?", The Review of Economics and Statistics, 75(4): 761-66.

Bar, T. (2006). "Defensive publications in an R\&D race", Journal of Economics and Management Strategy, 15, 229254.

Bar-Gill, O., and Parchomovsky, G (2003). "The value of giving away secrets", Virginia Law Review, 89, 18571895.

Barrett, B. (2002). "Defensive use of publications in an intellectual property strategy", Nature Biotechnology, 20, 191-193.

Barrio-Castro T., Garcia-Quevedo J. (2005) "Effects of university research on the geography of innovation", Regional Studies, 39, 9 1217-1229.

Barro, R. J. (1991). "Economic Growth in a Cross Section of Countries", Quarterly Journal of Economics, 106(2): 407-443.

Baumol, W. J., Panzar, J. C., and Willig, R. D. (1988). Contestable Markets and the Theory of Industry Structure, San Diego: Harcourt Brace Jovanovic.

Becker, G. (1964). Human Capital: A Theoretical and Empirical Analysis, with Special Reference to Education, New York: Columbia University Press.

Beeson P. and E. Montgomery (1992) "The Effects of Colleges and Universities on Local Labor Market", Review of Economics and Statistics, . 75, 753-761.

Berghoff S., U. Brandenburg D. J. Carr, C. Hachmeister and D. Müller-Böling (2008) "Identifying the Best: The CHE Ranking of Excellent European Graduate Programmes in the Natural Sciences and Mathematics", CHE working paper 99,

Blind K., K. Cremers and E. Muller (2009) "The influence of strategic patenting on companies' patent portfolios", Research Policy, 38, 428-436

Borchardt, J. (2007, May 31). "The Role of Defensive Publications in Intellectual Property Protection", Called on November $24^{\text {th }}, 2009$, from Lab Manager: http://www.labmanager.com/articles_pf.asp?ID=62

Braunerhjelm, P., Acs, Z. J., Audretsch, D. B., and Carlsson, B. (2010). "The Missing Link: The Knowledge Filter and Entrepreneurship in Endogenous Growth", Small Business Economics, 34(2): 105-125.

Breschi S. and C. Catalini (2008). "Tracing the linkages between science and technology: an exploratory analysis of the research networks among scientists and inventors", Research Policy, 39(1), 14-26.

Breschi S. and Lissoni F. (2001). "Knowledge Spillovers and Local Innovation Systems: A Critical Survey," Industrial and Corporate Change, . 10, 975-1005

Breschi S., Lissoni F. and F. Montobbio (2005), "From Publishing To Patenting: Do Productive Scientists Turn Into Academic Inventors?" Revue d'Economie Industrielle, 110, 2eme trimestre.

Buensdorf, G., and Klepper, S. (2009). "Heritage and Agglomeration: The Akron Tyre Cluster Revisited", Economic Journal, 119(537): 705-733.

Bun, M.J.G., and Carree, M.A. (2005). "Bias-corrected estimation in dynamic panel data models", Journal of Business and Economic Statistics 23, 200-210.

Burhop, C. (2010) “The transfer of patents in Imperial Germany", Journal of Economic History, 70, 921-939.

Bush, V. (1945) Science the Endless Frontier, United States Government Printing Office, Washington, retrieved from http://www.nsf.gov/about/history/vbush1945.htm.

Buxbaum P. (2001). "Publish or perish", The Bridge, Fall 2001, 2-8.

Callaert J., B. Van Looy, A. Verbeek, K. Debackere and B. Thijs (2006). "Traces of prior art: an analysis of nonpatent references found in patent documents", Scientometrics, 69(1), 3-20.

Callon, M. (1994) “Is Science a Public Good?", Science, Technology and Human Values, 19, 4, 395-424.

Caloghirou, Y., Tsakanikas, A., Vonortas, N.S., (2001). "University-industry cooperationin the context of the European framework programmes", Journal of TechnologyTransfer, 26, 1-2, 153-161.

Carayol N. (2006) "La production de brevets par les chercheurs et enseignants-chercheurs", Economie and prévision 4(175-176): 117-134. 
Ceccagnoli, M. (2009). “Appropriability, preemption, and firm performance”, Strategic Management Journal, 30, 8198.

Chandler, A.DJ. (1990) Scale and Scope, The Belknap Press of Harvard University Press, Cambridge, MA.

Chesnais F. (1993) "The French National System of Innovation”, in Nelson, R., ed. National Innovation Systems, Oxford University Press, New York.

Christensen, C. M. (1997). The Innovator's Dilemma: When New Technologies Cause Great Firms to Fail, Boston: Harvard Business School Press.

Clarke M. (1985) "British technology Group - UK technology transfer grows", Nature 316(6027), p. 385

Cohen W. and D. Levinthal. (1990). "Absorptive capacity: a new perspective on learning and innovation", Administrative Science Quarterly, 35,128-152.

Cohen W. M., Nelson R. R. and Walsh J. P. (2000) Protecting Their Intellectual Assets: Appropriability Conditions and Why U.S. Manufacturing Firms Patent (Or Not). NBER working papers 7552.

Cohen W. M., Nelson R. R. And Walsh J. P. (2002) Links and impacts: the influence of public research on industrial R\&D, Management Science, . 48, 1-23.

Cohen, W. M and Levinthal D. A, (1989). "Innovation and Learning: The Two Faces of R\&D," Economic Journal, . 99, 569-96.

Cohen, W. M. and D.A. Levinthal (1990) "Absorptive Capacity: A New Perspective on Learning and Innovation", Administrative Science Quarterly, . 35, 128-152.

Colson, T.J. (2001). "Leveraging the power and value of intellectual property rights", Ivey Business Review, July/August, 28-33.

Colyvas, J., M., Crow, A., Gelijns, R., Mazzoleni, R., Nelson, R. R., Rosenberg, N., and Sampat, B. N. (2002). "How Do University Inventions Get Into Practice?", Management Science, 48(1): 61-72.

Coriat B., and Orsi F. (2002) "Establishing a new intellectual property rights regime in the United States. Origins, content and problems", Research Policy, 31, 1491-1507

Cotropia, C.A., M.A. Lemley and B.N. Sampat (2010). "Do applicant patent citations matter? Implications for the presumption of validity", Stanford Law and Economics Olin Working Paper No. 401.

Criscuolo, P. and Verspagen B.(2008). "Does it matter where patent citations come from? Inventor vs. examiner citations in European patents". Research Policy, 37, 1892-1908.

Cusumano, M. and A. Gawer (2002). "Platform leadership. How Microsoft, Intel and Cisco drive industry innovation", Harvard: Harvard Business School Press.

Czarnitzki, D., Hussinger, K., and Schneider, C. (forthcoming). "The Nexus Between Science and Industry: Evidence From Faculty Inventions", Journal of Technology Transfer.

Czarnitzki, D., K. Hussinger and C. Schneider (2009). "Why challenge the ivory tower? New evidence on the basicness of academic patents", Kyklos 62, 488-499.

Dasgupta P. and David P. A. (1994) "Toward a new economics of science," Research Policy, . 23, 487-521.

De Fraja, G. (1993). "Strategic spillovers in patent races", International Journal of Industrial Organization, 11, 139146.

Della Malva A., Breschi S., Lissoni F. and Montobbio F. (2007) "L'Attività Brevettuale dei Docenti Universitari: l'Italia in un Confronto Internazionale", Economia e Politica Industriale, 34(2): 43-70.

Deng, Y. (2007). "The Effects of Patent Regime Changes: A Case Study of the European Patent Office." International Journal of Industrial Organization, 25, 121-138.

Di Gregorio, D., and Shane, S. (2003) "Why do some universities generate more start-ups than others?" Research Policy, . 32, 209-227.

Ducor, P. (2000). "Coauthorship and Coinventorship", Science, 289, 873-875.

Efron, B. (1978). "Regression and ANOVA with Zero-One Data: Measures of Residual Variation", Journal of the American Statistical Association 73, pp. 113-212.

Eisenberg, R. (2000a). "The promise and perils of strategic publication to create prior art: a response to Professor Parchomovky", Michigan Law Review, 98, 2358-2370.

Elhorst, P. J. (2003). "Specification and Estimation of Spatial Panel Data Models", International Regional Science Review, 26(3): 244-268.

Europe Innova (2010), Priority Sector Report: Creative and Cultural Industries, Deliverable D9-1, Brussels: European Commission.

Feldman M and Florida R. (1994) "The geographic sources of innovation: technological infrastructure and product innovation in the United States", Annals of the Association of American Geographers, . 84, 210-229. 
Feldman, M. P., and Desrochers, P. (2003). "Research Universities and Local Economic Development: Lessons from the History of Johns Hopkins University", Industry and Innovation, 10(1): 5-24.

Feller I. (1990) "Universities as engines of R\&D-based economic growth: they think they can", Research Policy 19, 335-348.

Felsenstein, D. (1996) "The university in the metropolitan arena: Impacts and public policy implications", Urban Studies, 33, 1565-1580.

Fini, R., Grimaldi, R., and Sobrero, M. (2009). "Factors Fostering Academics to Start Up New Ventures: An Assessment of Italian Founders' Incentives", Journal of Technology Transfer, 34(4): 380-402.

Fleming, L. and O. Sorensen (2004). "Science as a Map in Technological Search", Strategic Management Journal, 25, 909-928.

Franzoni, C. (2009). "Do Scientists get Fundamental Research Ideas by Solving Practical Poblems?", Industrial and Corporate Change, 18(4): 671-699.

Fritsch M. and Slavtchek V. (2007), "Universities and innovation in space", Industry and Innovation, 14, 2, 201-218.

Fritsch, M., and Mueller, P. (2008). "The Effect of New Business Formation on Regional Development Over Time: The Case of Germany", Small Business Economics, 30(1): 15-29.

Furman J, M. MacGarvie (2007) "Academic Science and the Birth of Industrial Research in the U.S. Pharmaceutical Industry," Journal of Economic Behavior and Organization, 63, 4, 573-576.

Gallochat A. (2003) "French Technology Transfer and IP Policies", in: OECD (2003) Turning Science into Business. Patenting and Licensing at Public Research Organizations, Organisation for Economic Co-operation and Development, Paris.

Gering T., Schmoch U. (2003) "Management of Intellectual Assets by German Public Research Organisations", in: OECD (2003) Turning Science into Business. Patenting and Licensing at Public Research Organizations, Organisation for Economic Co-operation and Development, Paris.

Geroski P., and Jacquemin, A. (1984). "Dominant Firms and their Alleged Decline", International Journal of Industrial Organization, 2(1): 1-27.

Geuna A., Nesta L.J (2006) "University patenting and its effects on academic research: the emerging European evidence", Research Policy 35: 790-807.

Geuna, A. (2001) "The changing rationale for European university research funding: Are there negative unintended consequences", Journal of Economic Issues 35: 607-32.

Gibbons M., Limoges C., Nowotony H., Schwartzman S., Scott P. and Trow M., (1994) "The New Production of Knowledge", Sage, London.

Glaeser, E. L., and Kerr, W. R. (2009). "Local Industrial Conditiond and Entrepreneurship: How Much of the Spatial Distribution Can We Explain?", Journal of Economics and Management Strategy, 18(3): 623-663.

Graham, S.J.H., B.H. Hall, D. Harhoff and D.C. Mowery (2002). "Post-Issue patent "Quality Control": A Comparative Study of U.S. patent Re-examinations and European Patent Oppositions". NBER Working Paper 8807.

Greene, W.H. (2003), "Econometric Analysis" (5th ed.), New York.

Grimpe, C. and K. Hussinger (2008a). "Preempting technology competition through firm acquisitions", Economics Letters, 100, 189-191.

Grimpe, C. and K. Hussinger (2008b). "Building and blocking: the two faces of technology acquisition", ZEW Discussion Papers 08-042, Mannheim.

Grossman G and E. Helpman (1994) "Endogenous innovation in the theory of economic growth". Journal of Economic Perspectives, . 8, 23-44.

Guellec D. and B. van Pottelsberghe de la Potterie (2007). "The Economics of the European Patent System", Oxford University Press: New York.

Guellec D., C. Martinez and M.P. Zuniga (2009). "Preemptive patenting: securing market exclusion and freedom of operation", OECD Science, Technology and Industry Working Paper No. 2009/08, Paris.

Gurmu S., P. G. Black and P. Stephan (2010) "The knowledge production function for university patenting", Economic Enquiry, 48, 1, 192-213.

Hall B.H., A.B. Jaffe and M. Trajtenberg (2005). "Market value and patent citations", RAND Journal of Economics, $36,16-38$.

Hall, B.H. and R.H. Ziedonis (2001). "The determinants of patenting in the U.S. semiconductor industry, 19801994”, RAND Journal of Economics, 32, 101-128. 
Harhoff D., Narin F., F. M. Scherer and K. Vopel (1999) "Citation Frequency and The Value Of Patented Inventions," The Review of Economics and Statistics, . 81, 511-515.

Harhoff, D. (1996). "Strategic spillovers and incentives for R\&D”, Management Science 42, 907-925.

Harhoff, D. and M. Reitzig (2004). "Determinants of opposition against EPO patent grants - the case of biotechnology and pharmaceuticals", International Journal of Industrial Organization , 22, 443-480.

Harhoff, D. and S. Wagner (2009). "The Duration of Patent Examination at the European Patent Office", Management Science, 55(12), 1969-1984.

Harhoff, D., F. M. Scherer and K. Vopel (2003). "Citations, Family Size, Opposition and the Value of Patent Rights Evidence from Germany”, Research Policy, 32, 1343-1363.

Harhoff, D., Hoisl, K., and C. Webb (2005). "European patent citations. How to count and how to interpret them", LMU Discussion Papers. Munich.

Harhoff, D., J. Henkel and E. von Hippel (2003). "Profiting from voluntary information spillovers: how users benefit by freely revealing their innovation”, Research Policy 32, 1753-1769.

Hausman J., McFadden D. (1984) "Specification tests for the Multinomial Logit Model”, Econometrica 52: 1219-40

Henderson R., Jaffe A.B., Trajtenberg M. (1998) "Universities as a source of commercial technology: A detailed analysis of university patenting 1965-88", Review of Economics and Statistics 80: 119-132.

Henderson, R. and I. Cockburn (1994). "Measuring competence? Exploring firm effect in pharmaceutical research", Strategic Management Journal, 15, 63-84.

Henderson, R., Jaffe, A. B., and Trajtenberg, M. (1998). "Universities as a Source of Commercial Technology: A Detailed Analysis of University Patenting 1965-88", The Review of Economics and Statistics, 80(1): 119-132.

Henkel, J., and S. Pangerl (2008). "Defensive publishing - an empirical study”, DRUID Working Paper No. 08-04.

Hicks, D. (1995). "Published papers, tacit competencies and corporate management of the public/private character of knowledge", Industrial and Corporate Change, 4(2), 363-400.

Hill, C. W. L., and Rothaermel, F. T. (2003). "The Performance of Incumbent Firms in the Face of Radical Technological Innovation”, Academy of Management Review, 28 (2): 257-274.

ISTAT (2009). Conti Economici Trimestrali, retrive http://www.istat.it/salastampa/comunicati/in_calendario/contitri/20091210_00/testointegrale20091210.pf

Jacobs J. (1969) The Economics of Cities, New York: Vintage.

Jaffe A. (1989) "Real Effects of Academic Research", American Economic Review . 79, 957-970.

Jaffe A.B. (2000) "The U.S.patent system in transition: policy innovation and the innovation process", Research Policy, 29, 531-557

Jensen R. A., J. G. Thursby and M. C. Thursby (2003) "Disclosure and licensing of university inventions: 'the best we can do with the $\mathrm{S}^{* * * \mathrm{~T}}$ we get to work with?", International Journal of Industrial Organization, 21, 12711333.

Jensen R., Thursby M.C. (2001) "Proofs and Prototypes for sale: the tale of university licensing", American Economic Review 91: 240-259.

Jerak, A., and S. Wagner (2006). "Modeling probabilities of patent oppositions in a Bayesian semiparametric regression framework". Empirical Economics, 31(2), 513-533.

Johnson, J.P. (2004). "Defensive publishing by a leading firm" Available at SSRN: http://papers.ssrn.com/sol3/papers.cfm?abstract_id=606781

Klepper, S., and Sleeper, S. (2005). "Entry by Spinoffs", Management Science, 51(8): 1291-1306.

Kortum S., Lerner J. (1999) "What is behind the recent surge in patenting?", Research Policy 28: 1-22

Krugman P. (1991) "Increasing returns and economic geography”, Journal of Political Economy, 99, 3, 483-499.

Lamoreaux N. R. and K. L. Sokoloff (2001) "Market Trade in Patents and the Rise of a Class of Specialized Inventors in the Nineteenth-Century United States," American Economic Review, Papers and Proceedings, 91, pp. 39-44

Lanjouw, J. and M. Schankerman (2001). "Characteristics of patent litigation: a window on competition", RAND Journal of Economics, 32, 129-151.

Larédo P., Mustar P. (eds) (2001) Research and Innovation Policies in the New Global Economy, Edward Elgar, Cheltenham.

Lazardis, G. and B. van Pottelsberghe de la Potterie (2007). "The rigor of EPO's patentability criteria: an insight into the "induced withdrawals"”, World Patent Information, 29(4), 317-326.

Le Feuvre N., Metso M. (2005) "Disciplinary Barriers between the Social Sciences and Humanities - National Report on France”, Université de Toulouse-Le Mirail, mimeo 
Lecuyer, C. (1998) "Academic Science and Technology in the Service of Industry: MIT creates a permeable engineering school", American Economics Association Papers and Proceedings,88, 2, 28-33.

Lemley, M.A. (2001). "Rational Ignorance at the Patent Office", Northwestern University Law Review, 95, 14951532.

Lenoir T. (1998) "Revolution from Above: The Role of the State in Creating the German Research System, 18101910," American Economics Association Papers and Proceedings,88, 2, 22-27

Lerner J. (1994). "The importance of patent scope: An empirical analysis", RAND Journal of Economics, 25, 319333.

Levin R.C., A.K. Klevorik, R.R. Nelson, S.G. Winter (1987). "Appropriating the returns from industrial R\&D", Brooking Papers on Economic Activity, 75, 783-820.

Lichtman, D., S. Baker, S., and K. Kraus (2000). "Strategic disclosure in the patent system", Vanderbilt Law Review, 53, 2175-2217.

Lissoni F., Franzoni C. (2009) “Academic entrepreneurs: critical issues and lessons for Europe”, in: Varga A. (ed.), Universities, Knowledge Transfer and Regional Development: Geography, Entrepreneurship and Policy, Edward Elgar, Aldershot.

Lissoni F., Llerena P., Mckelvey M. and Sanditov B. (2008) “Academic patenting in Europe: new evidence from the KEINS database", Research Evaluation, . 17, 87-102.

Lissoni F., Lotz P., Schovsbo J., Treccani A. (2009) "Academic Patenting and the Professor's Privilege: Evidence on Denmark from the KEINS database", Science and Public Policy 36: 595-607.

Lissoni F., Sanditov B., Tarasconi G. (2006) "The Keins Database on Academic Inventors: Methodology and Contents", CESPRI working paper 181, Università “L.Bocconi”, Milan.

Lissoni, F. and F. Montobbio (2008). "Inventorship and authorship in patent-publication Pairs: An enquiry in the economics of scientific credit", CESPRI Working Paper 224, Milan.

Loi $\mathrm{n}^{\circ}$ 82-610 du 15 juillet 1982 pour la recherche et le développement technologique de la France. (http://www.senat.fr/dossierleg/s81820242.html; last visited: November 2009).

Loi $\mathrm{n}^{\circ}$ 84-52 du 26 janvier 1984 sur l'enseignement supérieur (http://www.admi.net/jo/loi84-52.html; last visited: November 2009).

Loi $\mathrm{n}^{\circ}$ 99-587 du 12 juillet 1999 sur l'innovation et la recherche (http://www.recherche.gouv.fr/technologie/mesur/loi/inovloi.htm; last visited: November 2009).

Los B. and B. Verspagen, (2000). "R\&D spillovers and productivity: Evidence from U.S. manufacturing microdata," Empirical Economics, . 25, 127-148.

Lucas R. (1988) "On the mechanism of economic development", Journal of Monetary Economics, . 22, 3-42.

Lundvall B. (1992) "National Systems of Innovation. Towards a Theory of Innovation and Interactive Learning ", Pinter Publishers, London.

Mansfield, E. and Lee, J.Y., (1996) "The modern university: contributor to industrial innovation and recipient of industrial R\&D support", Research Policy, . 25, 1047-1058.

Maurer, S.M. (2002). "Promoting and disseminating knowledge: The public/private interface", Paper Prepared for the U.S. National Research Council's Symposium on the Role of Scientific and Technical Data and Information in the Public Domain, Washington, D.C., September 5-6, 2002. Information Services and Use, 22(4), 183-189.

McMillan, G.S. and R.D. Hamilton (2000). "Corporations need to publish or perish", Research Technology Management, 43, 8-10.

Merges, R. (2004). “A new dynamism in the public domain”, University of Chicago Law Review, 71, 183-203.

Merton, R. K. (1973). "The Sociology of Science: Theoretical and Empirical Investigation”, Edited by N. W. Storer. Chicago: University of Chicago Press.

Michel, J., and B. Bettels (2001). "Patent citation analysis", Scientometrics, 51, 185-201.

Mokyr, J. (2002) The Gifts of Athena: Historical Origins of the Knowledge Economy. Princeton: Princeton University Press,

Moran, P. A. P. (1950). "Notes on Continuous Stochastic Phenomena", Biometrika, 37(1), 17-33

Mowery D.C., Nelson R.R, Sampat B.N., Ziedonis A.A. (2001) "The growth of patenting and licensing by US universities: an assessment of the effects of the Bayh-Dole act of 1980", Research Policy 30(2): 99-119.

Mowery D.C., Nelson R.R., Sampat B., A Ziedonis A. (2004), Ivory tower and industrial innovation: universityindustry technology transfer before and after the Bayh-Dole Act in the United States, Stanford Business Books: Palo Alto CA 
Mowery D.C., Sampat B.N., (2005) "The Bayh-Dole Act of 1980 and University-Industry Technology Transfer: A Model for Other OECD Governments", Journal of Technology Transfer 30: 115-127.

Mowery, D. (1984) "Firm Structure, Government Policy, and the Organization of Industrial Research: Great Britain and the United States, 1900-1950", Business History Review, 58, 4, 504-531.

Murmann, J. P. (2003). Knowledge and Competitive Advantage: The Coevolution of Firms, Technology and National Institutions, Boston: Cambridge University Press.

Murray F. (2002). "Innovation as co-evolution of scientific and technological networks: exploring tissue engineering", Research Policy, 31, 1389-1403.

Murray, F. and S. Stern (2007). "Do formal intellectual property rights hinder the free flow of scientific knowledge? An empirical test of the anti-commons hypothesis", Journal of Economic Behavior and Organization 63(4), 648687.

National Scientific Foundation (NSF) (2006) Science and Engineering Indicators 2006, (http://www.nsf.gov/statistics/seind06/pdfstart.htm)

Neave G. (1993) "Séparation de Corps. The Training of Advanced Students and the Organization of Research in France", in: Clark B.R. (ed.), The Research Foundations of Graduate Education: Germany, Britain, France, United States, Japan, University of California Press: Berkeley CA.

Nelson, R. (1959) "The Simple Economics of Basic Scientific Research”, Journal of Political Economy, . 67, 297.

Nelson, R. (1987) "Understanding Technical Change as an Evolutionary Process" NorthHolland, Amsterdam.

Nelson, R. (1993) "National Innovation Systems", Oxford University Press, New York.

Nelson, R., and Wright, G. (1992). "The Rise and Fall of American Technological Leadership: The Postwar Era in Historical Perspective", Journal of Economic Literature, 30(4): 1931-1964.

Nelson, R., and Phelps, E., (1966). "Investment in humans, technological diffusion, and economic growth". American Economic Review: Papers and Proceedings, 51, 2, 69-75.

Nelson, R. (2001) "Observations on the Post-Bayh-Dole rise of patenting at American universities", Journal of Technology Transfer, . 26, 13-19.

Nightingale P. (1998). "A cognitive model of innovation", Research Policy, 27, 689-709.

Orsenigo L. (2001) "The (Failed) Development of a Biotechnology Cluster: The Case of Lombardy," Small Business Economics, . 17, 77-92.

OST (2004) Indicateurs de Sciences et de Technologies - Rapport 2004, Observatoire de Sciences et de Technologies, Paris (http://www.obs-ost.fr/services/rapport_ost/)

Owen-Smith J., Powell W.W. (2001) "To patent or not: Faculty decisions and institutional success at technology transfer", Journal of Technology Transfer 26: 99-114.

Parchomovsky, G. (2000). "Publish or perish", Michigan Law Review, 98, 926-951.

Patel, P., Arundel, A., and Hopkins, M. (2008). Sectoral Innovation Systems in Europe: Monitoring, Analysing Trends and Identifying Challenges in Biotechnology, Brussels: Europe Innova, Sector Report.

Penin J. (2007). "Open knowledge disclosure: An overview of the evidence and economic motivations", Journal of Economic Surveys , 21, 326-348.

Perkmann M, King Z, Pavelin S, (2011)"Engaging excellence? Effects of faculty quality on industry engagement across disciplines, Research Policy, 40, 539-552

Piergiovanni, R., and Santarelli, E. (2001). "Patents and the Geographic Localization of R\&D Spillovers in French Manufacturing", Regional Studies, 35(8): 697-702.

Piergiovanni, R., Carree, M. A., and Santarelli, E. (2011). "Creative Industries, New Business Formation, and Regional Economic Growth", Small Business Economics, forthcoming.

Pisano, G. (2006). Science Business: The Promise, the Reality and the Future of Biotech, Boston: Harvard Business School Press.

Polanyi, M (1962) “The Republic of Science: Its Political and Economic Theory”, Minerva, 1, 54-74.

Polanyi, M. (1967) “Tacit Dimension”, New York: Anchor Books.

Popp D., T. Juhl, and D. Johnson. (2004). "Time in Purgatory: Examining the Grant Lag for U.S. Patent Application", Topics in Economic Analysis and Policy, 4:art.29

Prusa, T. J., and Schmitz, J. A. (1991). "Are New Firms an Important Source of Innovation? Evidence from the PC Software Industry”, Economic Letters, 35(3), 339-342.

Quatraro, F. (2009). "Innovation, Structural Change and Productivity Growth: Evidence from Italian Regions, 19802003", Cambridge Journal of Economics, 33(5):1001-1022. 
Rai A.K., Eisenberg R. (2003) "Bayh-Dole Reform and the Progress of Biomedicine", Law and Contemporary Problems 66: 289-314.

Reinganum J.F. (1982). "A dynamic game of R\&D: patent protection and competitive behavior”, Econometrica, 50, 671-688.

Reitzig, M. (2004). "Improving patent valuations for management purposes - validating new indicators by analyzing application rationales", Research Policy, 33, 939-957.

Rinner, T.E. (2003). "Protecting minor improvements on core patents: complementing traditional patent protection with strategic disclosure", The John Marshall Review of Intellectual Property Law, 2, 398-422.

Romer P. (1990) "Endogenous technological change", Journal of Political Economy 98.

Romer, P. (1986). "Increasing Returns and Long-run Growth", Journal of Political Economy, 94(5): 1002-37.

Rosenberg N. (1974) "Karl Marx on the Economic Role of Science", Journal of Political Economy, 82, 4, 713-728.

Rosenberg N. (1982) Inside the Black Box, Cambridge, Cambridge University Press.

Rosenberg N. and Nelson R. R. (1994) "American universities and technical advance in industry", Research Policy $23,323-348$.

Sampat, B.N., D. Mowery and A. Ziedonis (2003). "Changes in university patent quality after Bayh-Dole: A reexamination", International Journal of Industrial Organization, 21, 1371-1390.

Santarelli, E., Carree, M. A., and Verheul, I. (2009). "Unemployment and Firm Entry and Exit: An Update on a Controversial Relationship”, Regional Studies, 43(8): 1061-1073.

Saragossi, S. and B. van Pottelsberghe de la Potterie (2003). "What patent data reveal about universities: the case of Belgium". Journal of Technology Transfer, 28, 47-51.

Saxenian, A. (1994). Regional Advantage: Culture and Competition in Silicon Valley and Route 128, Boston: Harvard University Press.

Saxenian, A., J.Y. Hsu. (2001). "The Silicon Valley-Hsinchu Connection: Technical Communities and Industrial Upgrading." Industrial and Corporate Change, 10, 893-920

Schmoch, U. (2008). "Concept of a technology classification for country comparison." Final report to the World Intellectual Property Organization (WIPO), Fraunhofer Institute for Systems and Innovation Research, Karlsruhe.

Schumpeter, J A. (1934). The Theory of Economic Development, New Brunswick (NJ): Transaction Publishers. First published in German, 1911.

Schumpeter, J. A. (1942) Capitalism, Socialism, and Democracy. New York: Harper and Brothers.

Schumpeter, J. A. (2005) “Development”, Journal of Economic Literature, 43, 1, 108-120.

Science Watch (2001). "World institutional rankings in select fields, by yotal citations, 1991-2001", July/August 2001, http://archive.sciencewatch.com/july-aug2001/sw_july-aug2001_page2.htm

Shane, S. (2004). Academic Entrepreneurship: University Spinoffs and Wealth Creation, Aldershot: Edward Elgar.

Silverman A.B. (2003). "Duty to disclose prior art to the United States Patents and Trademarks Office", JOM Journal of the Minerals Metals and Materials Society, 55(10), 64-64.

Small, K.A., Hsiao, C. (1985) "Multinomial Logit Specification Tests" International Economic Review 26: 619-627.

Smith J.K.j. (1990) "The Scientific Tradition in American Industrial Research”, Technology and Culture, 31, 1, 121131.

Spencer, J.W. (2003). "Firm's knowledge-sharing strategies in the global innovation system: empirical evidence from the flat panel display industry”, Strategic Management Journal, 24(3), 217-233.

Spulber, D. F. (2010). “Competition Among Entrepreneurs”, Industrial and Corporate Change, 19(1): 25-50.

Stephan P. (1996) "The Economics of Science" Journal of Economic Literature 34, 1199-1235.

Stephan P., Sumell A. J., Black G. and Adams J (2004) "Doctoral Education and Economic Development: The Flow of New PhDs to Industry" Economic Development Quarterly, . 18, 151-167.

Sterlacchini, A. (2008). "R\&D, Higher Education and Regional Growth: Uneven Linkages among European Regions", Research Policy, 37(6-7): 1096-1107.

Stokes, D.E. (1997). "Pasteur's quadrant: Basic science and technological innovation", Brookings Institute, Wasgington D.C.

Thurik, A. R., and Carree, M. A. (2003). "The Impact of Entrepreneurship on Economic Growth", in Z. Acs and D. Audretsch (eds) Handbook of Entrepreneurship Research, Dordrecht: Kluwer Academic Publishers, . 1, 437471.

Thursby J., Fuller A.W., Thursby M. (2009) "US faculty patenting: Inside and outside the university", Research Policy 38(1): 14-25. 
Trajtenberg M, A. Jaffe and R. Henderson (1997). "University versus corporate patents: A window on the basicness of invention", Economics of Innovation and New Technology, 5, 19-50.

Trajtenberg M., (1990) "A Penny for Your Quotes: Patent Citations and the Value of Innovations," RAND Journal of Economics, . 21, 172-187.

Van Vianen B., H. Moed and A. Van Raan (1990). "An exploration of the science base of recent technology", Research Policy, 19, 61-81.

Varga A. (2000). "Local Academic Knowledge Transfers and the Concentration of Economic Activity", Journal of Regional Science, . 40, 289-309.

Vavakova B. (2006) "Reconceptualizing innovation policy. The case of France", Technovation 26: 444-462

Verspagen B. (2006) "University Research, Intellectual Property Rights and European Innovation Systems", Journal of Economic Surveys 20(4): 607-632.

von Hippel, E. (1988) “The Sources of Innovation”, Oxford University Press, New York

Webb, C., D. Harhoff, and K. Hoisl (2005). "Analyzing European and international patent citations: a set of EPO database building blocks". OECD Science, Technology and Industry Working Paper no. 2005/9, Paris

Winter, S. (2006). "The logic of appropriability: from Schumpeter to Arrow to Teece." Research Policy, 35, 11001106.

Ziedonis R. H. (2004). "Don't fence me in: fragmented markets for technology and the patent acquisition strategies of firms." Management Science, 50, 804-820

Zucker, L. G., Darby, M. R., and Armstrong, J. (1998b). "Geographically Localized Knowledge: Spillovers or Markets?", Economic Inquiry, 36(1): 65-86.

Zucker, L. G., Darby, M. R., and Brewer, M. B. (1998a). "Intellectual Human Capital and the Birth of U.S. Biotechnology Enterprises", American Economic Review, 88(1): 290-306. 



\section{Acknowledgements}

Almost 5 years ago - it was sometimes at the end of August - I landed at the airport of Eindhoven. The sky was gloomy, the day windy and the temperature around 18 degrees. God, it was so cold for me, coming in shorts and t-shirt from Milan, where in that time of the year it is still warm and humid - not to say that where I am actually from you can swim until the end of September. Anyhow, I came to the Netherlands with great curiosity: how is a PhD like?

Now I can tell you: it is a morbid feeling with some strong elements of martyrdom. In that respect, it draws heavily from Catullo's interpretation of relationships: Hate and Love. Hate it, because you just can't stand it, as simple as that. It's a big and continuous frustration, any given day, with no breaks. Your days are painted with the colours of nullity, futility; impotence. Love it, because you cannot live without it. The very rare shocks of adrenaline which come from peer recognition at conferences, meetings, drafts are like flashes of light in the dark. And you keep fooling yourself that one day the darkness will be over, the light will prevail. To the point that, once it is over, you just got used to the darkness and proved yourself that you manage to handle that shit. You cynically realize that there is little else for you out there and you are now locked in the Plato's cavern, and you enjoy it.

To survive "in hac lacrimarum valle", a guide, a Virgil, is necessary. I made it through because I had the chance to come across two good guides: Martin and Anita. A perfect combination. Martin, you forced me to go on my own; watched me fall and waited till I stood up again. Anita, you instead reached me out and lifted me when I was all the way down. THANK YOU.

The further you go through this process, the deeper you feel, but actually the stronger you are getting. To my co-authors Enrico, Katrin, Francesco, who challenged me and supported me through this maturity: THANK YOU.

In Maastricht I soon realized that I was not alone in this fight for intellectual survival. I was not a special case - and made me think ever further on the perverted pleasure of self-inflicting pain a PhD is all about: Anant, Daniela, David, Omar, Andrea, Sebastian, Jo-jo Dick, Myrthe, Charlotte, Julio, Anka, Giorgio, Ruud. We were all on the same sinking boat - some sort of elitist and metaphorical Costa Concordia.

Anyhow, let's move on, that was not only this, there was something else. There was Football, captained by the only Doctor of the crew: Prof. Dr. Steiger Felix Höppe, and made special by the Bengal Tiger. There were never ending discussions in front of countless glasses of spirit and filled ashtrays, with the Tiger who neither drank nor smoked. Kitchen filled with exotic aromas: hardcore Spaghetti alla Carbonara, Curry Potatoes and some spicy stuff I cannot yet digest. Saturdays spent in front of the TV to discuss a midfielder's pass or a defendant's move. Coffee breaks arguing about the logistics of the German Army during WWII and the effectiveness of Italian tanks. We are now sparse, but there is still friendship, one built on solid ground. THANK YOU. 



\section{About the Author}

Antonio Della Malva (1982) is a nice guy. He left his home town Vieste, in the sunny and warm Puglia, on September 11 $1^{\text {th }}, 2001$ to study Business Economics at Universita' Commerciale "Luigi Bocconi" in the cloudy and industrious Milan. After having completed a Bachelor and a Master of Science with a major in Innovation and International Markets, he went all the way to France, at the University of Strasbourg, where he earned a second Master in Industrial Organization and Knowledge Economics. Fascinated by the profession, after a couple of months of research assistantship, he thought he could earn a living by doing that. (Altum Silentium). There he is now, finally presenting the results of the last four years as $\mathrm{PhD}$ student at the Department of Organization and Strategy at the University of Maastricht.

By the way, as of October 2011, Antonio has started a slow and long journey to get closer to his home country as he moved to Leuven, Belgium, where he joined the Managerial Economics, Strategy and Innovation Department at KU Leuven as Research Associate - soon a Marie Curie Fellow. 